\title{
EFECTOS COMUNITARIOS DE LOS REGÍMENES AGROALIMENTARIOS
}

\author{
ELUCIDACIÓN DE UN MODELO SUBYACENTE A THE STRUGGLE FOR MAIZE
}

Diego Méndez

\begin{abstract}
RESUMEN
En el presente trabajo se reconstruye el modelo de transformaciones agrosocioeconómicas que subyace en The Struggle for Maize de Elizabeth Fitting, obra que interpreta un conjunto de datos etnográficos e históricos de una comunidad del sur del valle de Tehuacán, México, en relación con dinámicas mundiales o continentales de la producción y distribución alimentaria. La autora apela a la teoría de los regímenes agroalimentarios de Philip McMichael y otros autores para dar cuenta de un desarrollo agrosocioeconómico local. La labor de acople que realiza The Struggle for Maize implica un modelo de la articulación entre lo mundial y lo local; un modelo que podría generalizarse para dar cuenta de dinámicas en otros escenarios. Sin embargo, hay que extraerlo pues The Struggle for Maize no lo presenta a modo de un esquema conciso y explícito. A ese fin se orienta el presente artículo: con base en la teoría de categorías, aquí se reconstruye el modelo mencionado como un diagrama de la categoría de los conjuntos. La intención principal es explorar las posibilidades expresivas del aparato en cuestión, así como desarrollar un modo de presentación didáctico que le permita al lector entender cabalmente la propuesta de Fitting y comprender el instrumento reconstructor empleado. El presente texto ilustra una manera de reconstruir arquitecturas conceptuales usando como ejemplo una monografía académica con importante impacto social, pues incide en la discusión actual sobre la soberanía alimentaria.
\end{abstract}

PALABRAS CLAVE: modelo - teoría de categorías - régimen agroalimentario - milpa - unidad doméstica - valle de Tehuacán

\section{RESUMO}

O presente trabalho reconstrói o modelo de transformações agrosocioeconômicas subjacentes a The Struggle for Maize de Elizabeth Fitting, um trabalho que interpreta um conjunto de dados etnográficos e históricos de uma comunidade do sul do Vale de Tehuacán, México, em relação à dinâmica global ou continental de produção e distribuição de alimentos. O autor recorre à teoria dos regimes agroalimentares de Philip McMichael e outros para dar conta do desenvolvimento agrosocial local. O trabalho de acoplamento de The Struggle for Maize implica um modelo de articulação entre o global e o local; um modelo que poderia ser generalizado para levar em conta dinâmicas em outros cenários. No entanto, ele deve ser extraído, pois The Struggle for Maize não o apresenta como um esquema conciso e explícito. Este é o propósito deste artigo: com base na teoria das categorias, aqui reconstruímos o modelo mencionado como um diagrama da categoria dos conjuntos. A intenção principal é explorar as possibilidades expressivas do aparelho em questão, bem como desenvolver um modo de apresentação didático que permita ao leitor compreender plenamente a proposta de Fitting e compreender o instrumento reconstrutivo utilizado. O presente texto ilustra uma forma de reconstruir arquiteturas conceituais usando como exemplo uma monografia acadêmica com importante impacto social, na medida em que afeta a discussão atual sobre soberania alimentar.

PALAVRAS-CHAVE: modelo - teoria de categorias - regime agroalimentar - milharal - unidade doméstica - vale de Tehuacán

\footnotetext{
¥Universidad Autónoma Metropolitana.mendezgranados@gmail.com. Perspectivas - Revista do Programa de Pós-Graduação em Filosofia da UFT - n. 2 - 2018
} 


\section{Introducción}

En el presente trabajo se reconstruye el modelo soterrado en la monografía titulada The Struggle for Maize, de Elizabeth Fitting (2011), la cual discute los cambios de subsistencia que han sufrido familias campesinas de una región de México, a lo largo del siglo Xx y principios del XXI, pero con mayor énfasis en el periodo en que posturas neoliberales han dominado la política agraria mexicana. El aparato empleado para semejante tarea está inspirado en la teoría de categorías, pues la intención del texto a continuación es mostrar las bondades de este instrumental, sin dejar de mencionar las complicaciones que puede tener su implementación.

Por lo general, la reconstrucción de una teoría o elemento teórico debe hacerse a partir de fuentes canónicas que exponen dicha teoría; los libros de texto son el material idóneo para ello. Puesto que están escritos para el entrenamiento y formación de futuros cuadros científicos, la exposición del contenido es clara y explícita, y no está sujeta a las ambigüedades y vaguedades propias de un trabajo donde apenas se está formulando una concepción original. Si bien muchas monografías académicas cumplen este papel, es decir, su cometido es explicar la teoría que sus autores han elaborado -El origen de las especies de Carlos Darwin es un ejemplo que viene a colación-, los cometidos de muchas otras son más modestos. Realizan exploraciones iniciales de un nuevo dominio de conocimiento, proponen una técnica experimental innovadora, critican una concepción vigente, sugieren nuevas aplicaciones intencionales de una teoría ya establecida o bien desarrollan un modelo incipiente para dar cuenta de tal o cual fenómeno que solo recientemente ha sido objeto de investigación científica. Aquí se defiende la idea de que las estructuras conceptuales subyacentes a todas estas posibilidades se pueden reconstruir con instrumentos formales $\mathrm{o}$ semiformales, aunque quizá los resultados obtenidos pongan de relieve lagunas en la reconstrucción (o remedos artificiosos de ella), surgidas de vaguedades o ambigüedades intrínsecas a la concepción que se pretendió reconstruir.

Ciertamente, si la labor reconstructiva tiene en miras contribuir a una metateoría de las teorías científicas - más aun una metateoría orientada a generar una taxonomía de teorías científicas-, centrar la investigación en los libros de texto o en monografías académicas que cumplen semejante papel facilita mucho las cosas. Tener por base material a los papers o monografías "no canónicas", por llamarlas de alguna manera, implica examinar un alud de textos en el que es fácil perderse. De cualquier manera, algunos de esos escritos describen de manera incipiente la estructura y/o dinámica de alguna parcela del mundo, la cual no 
había sido considerada anteriormente como objeto de investigación científica. En otras palabras, la reconstrucción de lo que una monografía así dice del mundo que describe es la reconstrucción de la estructura conceptual de un modelo. Quizá se trate de un modelo efímero que no tenga mayor trascendencia en el campo científico del cual se trate; sin embargo, brinda una instantánea de algún desarrollo conceptual en ese campo.

Si fuera menester resumir The Struggle for Maize en una sentencia corta, la siguiente cumple bien el cometido: es una monografía que describe el cambio de una comunidad campesina, corporativa y cerrada a una comunidad semiproletaria agrícola, corporativa pero en proceso de desincorporación- y transnacional. El texto abunda sobre las transformaciones que, a lo largo del siglo XX y principios del XXI, ha sufrido el modo de vida de pequeños agricultores de maíz y sus familias, de una comunidad llamada San José Miahuatlan, ubicada en el sur del valle de Tehuacán, en el estado mexicano de Puebla. El libro interpreta los datos históricos y etnográficos correspondientes a esta dinámica comunitaria con base en la teoría de los regímenes agroalimentarios, desarrollada por Philip McMichael, Harriet Friedmann y otros autores. Ahora bien, dicha teoría tiene por objeto de estudio la producción y distribución mundial de alimentos, en relación con los patrones de la acumulación sucesivos que han marcado el desarrollo del modo de producción capitalista desde 1870 hasta el presente. The Struggle for Maize opera un cambio de escala pues enfoca lo comunitario y microregional (el sur del valle de Tehuacán), en lugar de enfocar lo mundial. Parecería que el trabajo esencialmente es la aplicación novedosa de una teoría a un sistema de datos que no había sido contemplado antes por los usuarios de dicha teoría. Quizá sea una caracterización correcta, pero es menester destacar que The Struggle desarrolla un andamiaje conceptual intermedio que permita el acople entre los datos locales y la teoría de dinámicas alimentarias mundiales.

Ahora bien, Fitting no utiliza todo el aparato conceptual de la teoría en cuestión, solo emplea algunas partes. Privilegia lo que ella llama el régimen neoliberal del maíz (neoliberal corn regime), una variante norteamericana/mexicana de lo que McMichael (2014) llama el régimen agroalimentario corporativo (coorporate food regime). Según este último autor ha habido una sucesión de tres regímenes desde 1870 al presente (ver abajo): el corporativo es el último de la serie y abarca desde los años ochenta del siglo pasado hasta el día de hoy; le antecedió el denominado "régimen intensivo centrado en Estado Unidos", que perduró entre las décadas de los cuarenta y ochenta del siglo Xx. Fitting también alude a este segundo y pone de relieve que su instanciación mexicana se expresó mediante el reparto agrario y la 
tutela/coerción del Estado sobre el campesinado, pero curiosamente no le da un nombre a dicha instanciación (para fines del presente trabajo, se le designará "régimen de maíz posrevolucionario"). A pesar de que Struggle for Maíze es una aplicación de la teoría mencionada, el libro solo ocupa dos páginas (18 y 19) para dar una exposición general de ella; uno esperaría más. Salvo la continua aparición de la frase neoliberal corn regime a lo largo del texto, al lector bien se le podría pasar por alto que el texto tenga algo que ver con la teoría de los regímenes agroalimentarios.

De cualquier manera, la propuesta de Fitting parece ir encaminada a poner de relieve que los cambios que ha registrado la antropología, tocantes a los modos de subsistencia y de organización familiar y comunitaria de los pueblos agrarios de los últimos cien años, siguen la trayectoria de los regímenes agroalimentarios, pues estos últimos, a pesar de su envergadura mundial, tienen efectos locales. Es una concepción que complementa el aparato conceptual de la teoría mencionada, pero no es isomorfa a él. De cualquier manera, en The Struggle for Maize está implícito un modelo de esta articulación entre lo mundial -o lo continental-y lo local; un modelo (en las páginas que siguen se le denomina MdF, como abreviatura a "modelo de Fitting") que podría generalizarse para dar cuenta de dinámicas en otros escenarios, distintos al sur del valle de Tehuacán. Sin embargo, hay que extraerlo pues el texto no lo presenta a modo de un esquema conciso y explícito. ${ }^{2}$ Esto es lo que se pretende hacer aquí mediante diagramas inspirados en la teoría de categorías. ${ }^{3}$ Se pretende explorar las posibilidades expresivas del aparato reconstructor empleado, así como desarrollar un modo de presentación didáctico que le permita al lector entender dicho aparato y comprender cabalmente la concepción que se reconstruye. Es este aspecto uno de los móviles principales del presente escrito, dado los problemas de inteligibilidad que puede acarrear la exposición con base en diagramas. Usualmente son objetos que no cuentan con puntos precisos de inicio

\footnotetext{
${ }^{2}$ Lo que aquí se denomina "el modelo de Fitting" es una arquitectura conceptual abstracta, representada en la figura 8, que, una vez interpretada, da cuenta de la situación que Fitting describe para el sur del valle de Tehuacán. Pero dicha arquitectura no se limita a esta localidad: provista de interpretaciones adecuadas puede instanciarse en las situaciones de otras regiones de México y Centro América, y quizá de otras regiones del mundo. Desde una perspectiva tarskiana del concepto "modelo", las instanciaciones de la arquitectura antes mencionada, en tanto que realizan dicha estructura, son los modelos de ella. De este modo, la situación que describe Fitting respecto del sur del valle de Tehuacán es un modelo de la estructura representada en la figura 8.

${ }^{3}$ Badiou (2014), Goldblatt (2006), Lawvere y Schanuel (2002), y McLarty (1992) brindan exposiciones claras y accesibles de la teoría de categorías. Por su parte, Ibarra y Mormann (2006), Mormann (2010), Peruzzi (2006) y el reciente texto colectivo editado por Landry (2017) discuten la importancia de la teoría de categorías para la filosofía de la ciencia. En cuanto a modelizaciones en las ciencias especiales (ciencias cognitivas, neurociencias, biología y economía) con base en dicha teoría véase: Ehresmann y Vanbremeersch (2007), Gómez-Ramirez (2014), Rosen (1958) y Sallach (2015).
}

Perspectivas - Revista do Programa de Pós-Graduação em Filosofia da UFT - n. 2 - 2018 
y término de lectura, ni una dirección estándar por la cual deben ser leídos. Se deja a las intuiciones del usuario resolver tales asuntos, las cuales suelen ser suficientes si el esquema en cuestión es relativamente simple. Pero tratándose de un diagrama cuyo cometido es mostrar una concepción científica sofisticada, es menester desarrollar un método de presentación.

En lo que sigue se desarrollarán las siguientes secciones: i) un breve resumen de la teoría de los regímenes agroalimentarios (con especial énfasis en la que propone Philip McMichael), para contextuar el texto de Elizabeth Fitting; ii) un resumen del libro de dicha investigadora; iii) una explicación comprehensiva del aparato reconstructor empleado; iv) un preámbulo respecto de ciertos conceptos nodales de MdF; v) la reconstrucción del modelo subyacente a The Struggle for Maize, a modo de un diagrama de puntos y flechas, con las explicaciones de sus componentes; vi) la exposición de las rutas inferenciales más destacadas del modelo; y vii) las conclusiones.

\section{Los regímenes agroalimentarios}

La presente sección es un breve resumen del libro Food Regimes and Agrarian Questions (MCMICHAEL, 2014). ${ }^{4}$ Según McMichael, el concepto de régimen agroalimentario define un orden mundial capitalista gobernado por reglas que estructuran la producción, distribución y consumo de alimentos a escala mundial; vincula estos procesos e intercambios mundiales con formas de acumulación que, de manera general, distinguen periodos de transformación capitalista desde 1870 hasta el presente. Con este concepto se pretende dar cuenta de las relaciones históricas entre los siguientes procesos y ensambles: formación de estados nacionales, colonización de tierras fronterizas, circuitos de alimentos, agroindustrialización, patrones de consumo, estrategias corporativas transnacionales, contramovimientos agrarios y alimentarios, y otras cuestiones. Así, la noción de régimen agroalimentario adopta varias formas históricas concretas, de modo que cada una de ellas representa una coyuntura mundial particular en donde la normatividad imperante define relaciones internacionales de producción y distribución de comestibles, mediante la estabilización de precios mundiales de los mismos. Para McMichael este último aspecto es

\footnotetext{
${ }^{4}$ Puesto que The Struggle for Maize se publicó en 2011, no podría aludir al libro de McMicael que se menciona aquí, el cual se publicó por primera vez en 2013. No obstante, The Struggle mencionan otros trabajos de McMichael, así como estudios de otros autores destacados en el tema de los regímenes agroalimentarios (Freidman; Pechlaner y Otero). Para lo que sigue a continuación se ha privilegiado Food Regimes, pues es una expresión sucinta y más reciente de la teoría de tales regímenes, y cita los antecedentes mencionados en el libro de Fitting (McMichael también cita, muy favorablemente, The Struggle for Maize).

Perspectivas - Revista do Programa de Pós-Graduação em Filosofia da UFT - n. 2 - 2018
} 
crucial: la estabilización de precios mundiales de determinados cereales y cárnicos básicos es un fenómeno que surge a partir del último tercio del siglo XIX; por ende, el concepto de régimen agroalimentario no tiene aplicación en lo concerniente a la producción y comercio agropecuario (aun si se privilegia el contexto del modo de producción capitalista y una perspectiva internacional) antes de 1870.

El investigador canadiense identifica tres formas o regímenes particulares sucesivos: el régimen centrado en el Imperio Británico (1870 hasta la década de los treinta del siglo XX), el régimen intensivo centrado en Estados Unidos (circa 1934 a 1980) y el régimen agroalimentario corporativo (años ochenta del siglo XX hasta el presente). Cada uno de ellos desarrolla un complejo propio de circuitos mercantiles y procesos productivos - desde la tecnología de semillas y los sistemas de cultivo hasta el procesamiento y manufactura de víveres- que apoya el ejercicio de formas particulares de poder, dominancia ideológica y expansión comercial. El deterioro de un régimen particular coincide con la transición a una nueva dinámica de acumulación capitalista, la cual da pie a un nuevo marco de relaciones institucionales que organizan el aprovisionamiento social de alimentos, renovadas formas y ciclos productivos, y nuevos límites de expansión.

El régimen centrado en el Imperio Británico se caracterizó por combinar la importación a Europa de productos provenientes de colonias tropicales con la tercerización (outsourcing) de la producción de granos y carne a territorios con importantes núcleos de población originalmente británica (Australia, Canadá y Estados Unidos). Desde mediados del siglo XIX el dominio británico en la India desmanteló los sistemas autóctonos y locales de reservas de semillas, y transformó los granos producidos en el subcontinente en mercancías de exportación. A la vez, importantes inversiones británicas capitalizaron la producción ganadera en el oeste de Estados Unidos para satisfacer la demanda inglesa de carne. El sistema de libre comercio que operó Gran Bretaña estableció un precio mundial del trigo entre 1870 y 1913. El ocaso de esta hegemonía resultó de la rivalidad y conflicto entre estados europeos en vísperas y durante la Primera Guerra Mundial, las políticas nacionalistas y proteccionistas adoptadas por las naciones industrializadas durante el periodo entre guerras, la crisis de la agricultura norteamericana en la década de los treinta y los movimientos de liberación nacional en las colonias.

Al finalizar la Segunda Guerra Mundial se estabilizó el sector agropecuario en los Estados Unidos vía subsidios gubernamentales, lo cual consolidó un nuevo régimen agroalimentario, cuyos orígenes se remontan a la década de los treinta con el New Deal de 
Roosevelt. Entre las décadas de los cincuenta y setenta del siglo pasado, Estados Unidos recanalizó el excedente nacional de alimentos a países dependientes de su esfera de influencia; con ello la potencia subsidió salarios de los sectores manufactureros de dichas colonias informales (o semi-colonias), aseguró lealtades anti-comunistas en el contexto internacional de la Guerra Fría, y aseguró el control de mercados internacionales. Los estados en desarrollo internalizaron el modelo norteamericano de agroindustrialización, adoptaron tecnologías de la Revolución Verde y efectuaron reformas agrarias para mitigar el descontento campesino e introducir relaciones mercantiles en el campo. A la vez, las agroindustrias establecieron vínculos entre sectores agrícolas nacionales, sectores que fueron subdivididos en series de agriculturas especializadas, entreveradas por cadenas mundiales de insumos (por ejemplo el complejo de proteína animal que ligaba la producción y circulación comercial de forrajes con granjas industriales de pollos, cerdos y vacas (feeding lots)) La producción alimentaria en los Estados Unidos, después de la Segunda Guerra Mundial, se consolidó en derredor de una agricultura de capital intensivo, sustentada en la especialización de mercancías agropecuarias, con un régimen internacional de distribución de excedentes agrícolas. El contexto de la Guerra Fría, las independencias nacionales de colonias europeas en África y Asia, y las campañas contra el hambre de las Naciones Unidas permitieron a los Estados Unidos utilizar los alimentos como instrumento de poder.

A partir de la década de los ochenta del siglo XX ha surgido un tercer esquema, el cual coincide con la implementación mundial de políticas neoliberales y que McMichael bautiza "régimen agroalimentario corporativo". Bajo este sistema se han incorporado nuevas regiones en las cadenas productivas de proteína animal (Brasil y China), se ha expandido la red internacional de supermercados como distribuidores de comestibles, y la biotecnología, en la forma de cultivares genéticamente modificados, ha impactado profundamente la agricultura comercial. Los alimentos estandarizados y los estándares de calidad han sufrido divisiones orientadas a satisfacer dietas diferenciadas en términos clasistas (dietas para distintas clases sociales). Los excedentes de agriculturas subsidiadas del Norte Global han inundado los países del Sur Global, y con ello han sido desarraigados de sus parcelas miles de agricultores tradicionales, con la subsecuente expansión de favelas urbanas y periurbanas para la población desplazada. En contra tendencia, se ha desarrollado un movimiento campesino global que pugna por la defensa del pequeño agricultor y una producción sustentable y local de alimentos. Esta movilización contestataria ha puesto en evidencia la creciente crisis de la agricultura industrializada. El régimen corporativo encierra una 
contradicción entre un sistema agrícola globalizado y una demanda de soberanía alimentaria que hace hincapié en prácticas agroecológicas y en la diversidad de formas locales de cultivar la tierra.

Si bien McMichael plantea que el concepto de régimen agroalimentario se corresponde con un desarrollo del modo de producción capitalista de los últimos 150 años, y que dicho concepto presenta tres formas históricas, también pone de relieve que estas últimas tienen variantes regionales. Al respecto, su estudio privilegia tres grandes zonas: Asia oriental, América Latina y el Medio Oriente. El autor destaca que, visto en términos genéricos o de larga duración, el fenómeno correspondiente al régimen agroalimentario, con sus modalidades históricas y variantes regionales, ha ocasionado una crisis agroecológica de proporciones mayúsculas que ha minado y amenaza la reproducción de las condiciones de producción planetarias para alimentar a la población humana en su estado actual.

\section{Resumen de The Struggle for Maize}

El libro, The Struggle for Maize (FITTING, 2011) está dividido en dos partes: la primera, titulada "Debates", abarca los capítulos uno y dos, y abunda sobre las polémicas suscitadas en torno al maíz transgénico en México; la segunda, con el título de "Subsistencias" (Livelihoods), comprende los capítulos tres a seis, y está dedicada a describir la situación de los pequeños productores de maíz del sur del valle de Tehuacán (estado de Puebla, México), particularmente de San José Miahuatlán, desde principios del siglo XX hasta el presente. Así, la primera parte destaca un aspecto nodal del debate en torno al maíz transgénico, a saber: el papel que, según el movimiento en defensa del maíz nativo, debe jugar el pequeño productor rural en la formulación de políticas agropecuarias. La segunda parte del libro ofrece un estudio histórico y etnográfico de la situación en que viven pequeños agricultores reales de una región de México.

A lo largo del capítulo 1, Fitting ofrece una crónica detallada del movimiento en defensa del maíz nativo en México, durante la década del dos mil. Aborda las distintas posturas en torno al debate sobre los cultivos transgénicos en México, no sólo en lo concerniente a riesgos de contaminación génica, sino también en relación con la productividad agrícola versus la preservación de valores y prácticas culturales; así como el conocimiento técnico, experto, versus el conocimiento tradicional del cultivador. En el capítulo 2, la investigadora hace una historia de la política agraria en México, desde la Colonia hasta el presente. Desarrolla el concepto de campesino como identidad política del 
México posrevolucionario y abunda sobre el agrarismo, el reparto agrario y la revolución verde. Aquí pone de realce el vínculo entre el desarrollo del régimen agroalimentario intensivo centrado en Estados Unidos y las políticas agropecuarias del estado mexicano entre los años cuarenta a ochenta del siglo pasado. También menciona discusiones académicas sobre el devenir del campesinado. Finalmente, pormenoriza aspectos destacados de la política agraria neoliberal mexicana y pone de relieve que, al seno del movimiento en defensa del maíz, se está formulando una propuesta de soberanía alimentaria que implica el surgimiento de otro régimen agroalimentario.

A partir del capítulo 3, Fitting reduce el enfoque del contexto nacional al contexto local y empieza a desarrollar el caso de San José Miahuatlán, una comunidad nahua cercana a la ciudad de Tehuacán, Puebla. Describe la comunidad y hace una historia de las luchas intestinas sobre el control del agua. El relato se centra sobre todo en el siglo XX, aunque se mencionan aspectos que se remontan más atrás. Lo importante a destacar aquí es, por una parte, que la comunidad ha desarrollado una infraestructura hidráulica propia, mediante la explotación de manantiales y la construcción de galerías filtrantes. De cualquier manera, el acceso al agua no ha sido siempre igualitario: antes de la Revolución una parte importante de los recursos hídricos la controlaban las haciendas; después del conflicto armado, se realizaron los esfuerzos por instrumentar un sistema de distribución equitativa, pero también surgieron asociaciones privadas, si bien locales e indígenas, que funcionaron (y aún funcionan) como sociedades de acciones, de modo que el acceso a líquido para fines de irrigación depende de las acciones que se tiene en las asociaciones que construyen galerías filtrantes y otras obras hidráulicas. Fitting pone de relieve la formación de agrupaciones locales, antagónicas entre sí, cuyas disputas han llegado a la violencia.

El capítulo cuatro está dedicado al proceso agrícola en sí y a otras fuentes de ingresos de las unidades domésticas de San José Miahuatlán, en particular el trabajo en las maquiladoras de ropa en Tehuacán y la migración a Estados Unidos. Está muy bien desarrollado el efecto que tiene la migración en la dinámica familiar y en la descomposición de la llamada comunidad tradicional. La autora recurre al análisis de casos para destacar que estos efectos se resienten de manera diferente en distintos hogares. Una idea muy interesante que se propone en este capítulo es el hecho de que la comunidad y sus unidades domésticas se están "trasnacionalizando", en tanto que una parte variable de sus integrantes reside intermitentemente fuera de Miahuatlán, pero mantiene vínculos afectivos y financieros con 
quienes se quedan, y con ellos también comparten responsabilidades familiares y comunitarias.

El quinto capítulo discute el devenir del campesinado sanjoselpeño, las dinámicas de proletarización y de acumulación que genera el fenómeno migratorio, así como los cambios ideológicos y de valores que suscita, a saber: la transformación de los roles de género al interior de la unidad doméstica y el deterioro de la cultura milpera entre las generaciones más jóvenes. ${ }^{5}$ Finalmente, el capítulo seis se corresponde con las conclusiones: aquí Fitting vuelve a destacar los motivos que le llevaron hacer su investigación y, además, discute algunas cuestiones sobre la metodología que siguió. La autora hace énfasis en no suscribirse a un modelo general de comunidad campesina indígena; en lugar de ello conviene destacar el desarrollo histórico de la comunidad que se estudia.

La sinopsis recién hecha brinda un panorama demasiado general, por lo cual a continuación se pormenorizan los contenidos más específicos y sustanciales del libro (sobre todo de la segunda parte, pues de ella se reconstruye el modelo que se discute más adelante), y, entre paréntesis, se anotan las páginas en las cuales se discuten estas cuestiones.

Desde la década de los ochenta a la fecha, impera en América del Norte un modo particular en que está organizada la producción, distribución y consumo del maíz. La autora lo denomina régimen de maíz neoliberal (RMN), y afirma que ha contribuido a diversificar los estilos de vida de la población rural (cfr. FITTING, 2011, pp. 5, 24). Un acontecimiento clave en la consolidación del RMN fue la firma y entrada en vigor del Tratado de Libre Comercio de América del Norte (TLCAN): el precio del maíz cayó de manera drástica, pero el consumidor no se vio beneficiado pues también se eliminó el subsidio a la tortilla. Con el libre comercio y el desmantelamiento de la CONASUPO (empresa estatal de provisión de alimentos sectores populares), unas cuantas empresas multinacionales comenzaron a dominar el mercado del maíz y la tortilla en México, las cuales, en lugar de comprar la gramínea producido en el país, optaron por importar grano barato de Estados Unidos, donde el cultivo está subvencionado por el Estado (cfr. FITTING, 2011, pp. 102, 107). Debido al influjo de maíz foráneo barato y la presencia de semillas transgénicas, los primeros casos de maíz nativo contaminado con transgenes se empezaron a reportar en la década del dos mil, sobre todo en el estado de Oaxaca. Desde entonces dicha entidad federativa ha sido uno de los bastiones más firmes del movimiento en defensa del maíz nativo. También se ha

\footnotetext{
${ }^{5}$ En México la milpa es el policultivo tradicional de maíz (Zea mays), frijol (Phaseolus spp.) y calabaza (Cucurbita spp.).

Perspectivas - Revista do Programa de Pós-Graduação em Filosofia da UFT - n. 2 - 2018
} 
detectado evidencia de contaminación por transgenes en razas del valle de Tehuacán; sin embargo, Fitting señala (cfr. 2011, pp. 37, 119) que la controversia en torno al maíz transgénico en México no figuraba en las preocupaciones de sus informantes.

El RNM hace hincapié en la importación de alimentos en lugar de la autosuficiencia alimentaria; promueve el desarrollo rural mediante la agricultura comercial, las variedades mejoradas, el libre comercio y el desplazamiento de productores ineficientes. Si bien las políticas vinculadas con este régimen han presentado variaciones sexenales y regionales, en conjunto han empeorado la condición de los pequeños agricultores. Una diferencia notoria respecto de políticas agrarias del pasado es que el régimen neoliberal del maíz pone el acento en la libre mano del mercado, en lugar de la intervención estatal, en la asignación de recursos al campo (cfr. FITTING, 2011, pp. 103, 107).

Bajo la férula del RMN se están re-haciendo los modos de vida de los campesinos del sur del valle de Tehuacán, en relación a cinco tendencias, a saber: 1) al interior de la unidad doméstica, la combinación del trabajo en la milpa con la emigración y/o el trabajo en maquiladoras para así obtener ingresos (estrategia intergeneracional); 2) La distribución desigual, entre las unidades domésticas, de las remesas que envían los migrantes; 3) La monetarización del trabajo agrícola y el efecto mercantilizador respecto del trabajo no remunerado (los integrantes de las unidades domésticas calculan cuánto ganarían en una fábrica por el tiempo de trabajo invertido en las labores hogareñas que cumplen y que no son pagadas); 4) El trabajo en la milpa se está convirtiendo en un dominio de adultos mayores, ya que los jóvenes migran o se emplean en fábricas de ropa y están perdiendo el conocimiento agrícola tradicional; 5) La milpa está perdiendo su característica de policultivo y, además, se están dejando de sembrar algunas variedades locales de maíz, a la vez que aumenta la siembra de maíz comercial que se vende a las rosticerías de elote en la ciudad de Tehuacán (cfr. FITTING, 2011, pp. 158-159, 176, 188-189, 194). 


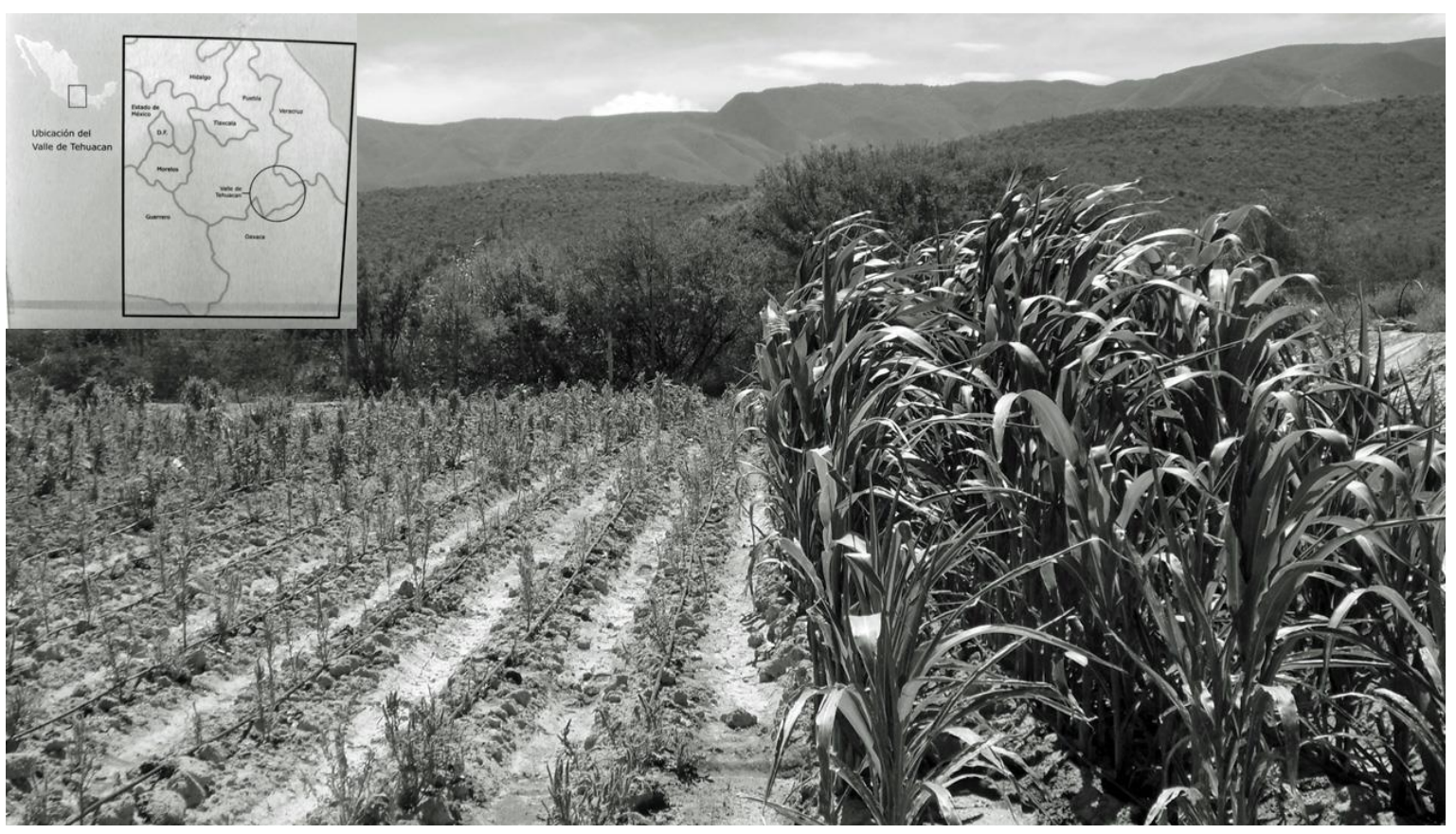

Figura 1. Ubicación del valle de Tehuacán y cultivo de maíz y amaranto en Chilac, comunidad vecina de San José Miahuatlán. Fotografías y montaje propios.

Dado el clima árido del valle de Tehuacán (ver figura 1), buena parte de la agricultura en la zona depende del agua de riego. Hasta mediados del siglo XX se distribuía el agua de manantial por barrios, en San José Miahuatlán y otras comunidades vecinas. En años posteriores comenzaron a cobrar importancia los sistemas de irrigación basados en la explotación del manto freático, a saber: galerías filtrantes y pozos profundos con bombas eléctricas. Estos desarrollos fueron independientes de instancias del Estado, tanto en lo que se refiere a la experticia técnica como al financiamiento. Fueron iniciativas locales, con base en asociaciones comunitarias denominadas "sociedades explotadoras de aguas", cuyos miembros administraban las galerías y canales (cfr. FITTING, 2011, pp. 123-124). Las asociaciones de agua son colectivas y administradas localmente; son organizaciones orientadas a la ganancia y la acumulación, si bien algunas están estructuradas bajo los lineamientos de otras instituciones indígenas -con una estructura democrática, rotación anual de dirigentes y un santo patrón. En San José, por lo general, los miembros son hombres, aunque existe una minoría de mujeres, usualmente viudas que heredaron las acciones de sus maridos (cfr. FITTING, 2011, p. 130). Quienes no son miembros de una sociedad de agua $\mathrm{y}$, a la vez, tienen poco acceso al flujo del sistema comunal por barrios, se hacen del recurso hídrico vinculándose con un socio de alguna sociedad de aguas. Pueden rentarle una acción o bien pueden ser aparceros en terrenos irrigados. El acceso al agua ha sido uno de los factores que han contribuido a la diferenciación social en Miahuatlan, a partir de la década Perspectivas - Revista do Programa de Pós-Graduação em Filosofia da UFT - n. 2 - 2018 
de los cincuenta del siglo pasado. Las dos formas de acceso al agua -la distribución comunal por barrio y la de una asociación privada- existen el día de hoy, pero de manera muy distorsionada. Desde mediados del siglo XX, la mayoría de los agricultores reciben agua de las asociaciones privadas, aunque existen remanentes del sistema barrial, pero con poco flujo hídrico (cfr. FITTING, 2011, p. 134). La crisis económica de 1982 coincidió con el conflicto violento por control del agua en Miahuatlan, y la producción agrícola del municipio bajó de manera dramática. Estos factores jugaron un papel muy importante para que un número creciente de sanjosepeños decidieran migrar a Estados Unidos y otras partes de México en búsqueda de trabajo (cfr. FITTING, 2011, p. 157).

La emigración a Estados Unidos, en lo que concierne a San José, cobra realce a partir de la década de los ochenta del siglo pasado. En un inicio, los campos agrícolas de California fueron la meta preferida, pero dada la saturación del mercado laboral en ese estado, las sucesivas olas de sanjosepeños comenzaron a desplazarse a Oregón y a Nevada. Y ahora, más que realizar labores de campo van a trabajar en restaurantes, plantas procesadoras de alimentos y casinos en Las Vegas (cfr. FITTING, 2011, pp. 157, 181). Durante los noventa, además de intensificarse la emigración a Estados Unidos, se asentaron maquiladoras de ropa en el valle de Tehuacán. En San José se siguió sembrando maíz, pero las unidades domesticas comenzaron a combinar esta actividad con la emigración y/o el trabajo en maquiladoras, en una estrategia intergeneracional para la obtención de ingresos, donde los jóvenes migran o trabajan en maquiladoras mientras que los adultos mayores siembran y atienden la milpa (cfr. FITTING, 2011, pp. 157-158). Otra diferencia entre la migración previa y posterior a los años ochenta es que antes la ausencia del pueblo era de 8 o 9 meses, y ahora llega a ser de dos, tres o hasta de cinco años (cfr. FITTING, 2011, p. 181). Algunos migrantes envían el dinero ahorrado para poner un pequeño negocio en su comunidad, pero la mayoría de las remesas van al fondo de consumo familiar. Así, las remesas no necesariamente generan alternativas de empleo en San José (cfr. FITTING, 2011, p. 184). Los migrantes y empleadas en maquiladoras desarrollan una concepción distinta de su relación con la tierra, su identidad étnica y su identidad de género: cuestionan los valores tradicionales de sus padres y abuelos, y perciben el modo de vida de las generaciones anteriores como una vida opresiva (cfr. FITTING, 2011, p. 200).

La emigración en San José es una práctica generalizada: los migrantes dependen de rutas que han establecido ellos mismos y de redes de familiares y amigos, al norte de la frontera o en ambos lados de ella, para asegurar alojamiento y/o para encontrar empleo. A 
pesar de que la emigración sea una práctica generalizada, las diferencias socioeconómicas al interior de San José no se han borrado, como algunos estudiosos de la migración sugieren que sucede cuando el fenómeno es generalizado (cfr. FITTING, 2011, p. 183). Cabría considerar a los migrantes que tiene entre treinta y cuarenta años como semiproletarios, dado su trajinar entre el trabajo agrícola de la unidad doméstica y el trabajo como migrante en Estados Unidos. Por su parte, cabría pensar a los migrantes y los trabajadores de maquiladoras más jóvenes que los treinta años como completamente proletarizados, pero flexibles. Son trabajadores informales y sustituibles, cuya experiencia y preferencia laboral está fuera de la milpa y depende del mercado de trabajo (cfr. FITTING, 2011, p. 175). Cuando regresan a San José, los migrantes jóvenes actuales (adolescentes o en sus años veinte) trabajan en las industrias del valle de Tehuacán o simplemente pasan el tiempo hasta que se les acaba el dinero y vuelven a migrar. Estos jóvenes no tienen experiencia en el trabajo de milpa. Es más probable que los migrantes mayores de treinta años trabajen en la agricultura o la construcción, cuando regresan a San José (cfr. FITTING, 2011, p. 181).

Tradicionalmente, cultivar maíz es una lección que los niños aprenden para hacerse hombres, y el procesamiento de los granos en tortillas es parte del entrenamiento tradicional de las niñas. El trabajo en la milpa es un dominio masculino, aunque en ocasiones las mujeres pueden trabajar como destapadoras, removiendo el suelo excesivo que cubre a las tiernas plantas, luego del primer deshierbe con arado. Ahora bien, en la tarea de seleccionar semillas para el siguiente ciclo agrícola participan ambos, hombres y mujeres. Viudas o mujeres de migrantes ausentes pueden poseer una milpa, pero contratan jornaleros varones para trabajarla. De cualquier manera, la obtención de ingresos vía la migración y el trabajo asalariado en empresas locales está cambiando los patrones de actividades por género, al interior de la unidad doméstica (cfr. FITTING, 2011, pp. 164-166, 188).

Si bien la producción milpera vincula hogares en relaciones de reciprocidad, obligación e intercambio, hay una creciente tensión generacional en lo referente a realizar dicha actividad, pues las generaciones más jóvenes la consideran poco redituable y la están abandonando (cfr. FITTING, 2011, p. 119). Los informantes de Fitting señalan que una familia no puede vivir solo de la milpa: a lo mucho, lo que se obtiene de una cosecha alcanza para cinco meses de subsistencia. Informantes de mayor edad pusieron de relieve que el único empleo disponible para ellos es el trabajo de milpa: los mantiene activos y les permite hacer aportaciones efectivas al fondo familiar. A falta de pensiones, seguros de desempleo $\mathrm{u}$ otra red de seguridad del Estado, y ante las amenazas de posibles desabastos y 
fluctuaciones del mercado, sembrar maíz brinda cierta seguridad a las unidades domésticas rurales (cfr. FITTING, 2011, pp. 170-173, 175). Hay un efecto etario en la apreciación del trabajo en la milpa: mientras que los residentes mayores a los 35 años estiman el cultivo de maíz como un seguro familiar, los migrantes y trabajadores en maquiladoras que están en la adolescencia o en sus años veinte no sienten que esta actividad agrícola sea importante (cfr. FITTING, 2011, p. 175). Ahora bien, el conocimiento local sobre el maíz no está repartido de manera uniforme entre los habitantes del sur del Valle de Tehuacán: está diferenciado por generación y por género (cfr. FITTING, 2011, pp. 204-206).

En San José hay familias que ya no cultivan la tierra y dependen de ingresos monetarios para comprar los granos con los cuales hacer tortillas. También hay sanjosepeños que ahora viven en la ciudad de Tehuacán y viajan a Miahuatlán (un recorrido de hora y media en autobús) a cultivar milpa (cfr. FITTING, 2011, p. 164). Por otra parte, está cambiando el patrón de uso del suelo en la comunidad: conforme han venido llegando remesas, ha ido expandiéndose el área de viviendas y reduciéndose el área destinada a la agricultura (cfr. FITTING, 2011, p. 194).

En suma, San José Miahuatlán es parte de un campo social transnacional que vincula la gente que permanece en el pueblo con quienes se van, mediante lazos afectivos, transacciones financieras, responsabilidades con la unidad doméstica, celebraciones comunitarias y afiliaciones políticas (cfr. FITTING, 2011, p. 180).

\section{Explicación del aparato reconstructor}

Con el aparato empleado, el modelo adquiere la forma de un diagrama de nodos y flechas (ver figura 8). En gran medida, el esquema se inspira en la introducción a la teoría de categorías de Lawvere y Schanuel (2002). Los nodos representan conceptos abstractos -para ser más precisos, las extensiones de dichos conceptos, es decir, conjuntos-; las flechas son funciones (también se usará los términos de mapeos o morfismos) entre los diferentes conjuntos. En aras de facilitar la comprensión de aquello denominado mapeo, las figuras 2 a 4 muestran algunos ejemplos ilustrativos.

La figura 2, panel 2.0, muestra cuatro colecciones -O, P, Q, S- que servirán para la exposición en curso. El recuadro 2.1 expone un morfismo o mapeo que, por darle un nombre, se le denomina $f_{O P}$, entre el conjunto $\mathrm{O}$ (el dominio de $f_{O P}$ ) y el conjunto $\mathrm{P}$ (el codominio de $\left.f_{O P}\right)$. Aparecen dos versiones de esta función: una, con el rótulo de "diagrama interno", ilustra en detalle a qué elementos del codominio (P) fOP asigna los elementos del dominio (O); la 
otra, con el nombre de "diagrama externo", solo pone de relieve que $\mathrm{O}$ es el dominio (el origen de la flecha) de $f_{O P}$ y $\mathrm{P}$ es su codominio (el destino de la saeta). Puesto que O contiene tres integrantes y $\mathrm{P}$ contiene cuatro, la cantidad de morfismos posibles entre estas dos colecciones asciende a $4^{3}$, o sea $64 ; f_{O P}$ es sólo una de estas posibilidades. Los paneles 2.2 y 2.3 presentan los mapeos $f_{P Q}$ y $f_{Q S}$, respectivamente, también con sus versiones internas y externas. Nótese que, en los tres ejemplos, todo elemento del dominio es asignado a un elemento (y solo un elemento) del codominio; tal univocidad es una propiedad general de todo morfismo. Sin embargo, es posible que no todo elemento del codomino sea blanco de una asignación, como ocurre con $f_{O P}$ y $f_{Q S}$.

Cuando el codomino de una función es el domino de otra, estos dos mapeos se pueden componer: los paneles 2.4 y 2.5 ofrecen dos ejemplos del caso. En la notación $f_{P Q} \circ f_{O P}$ (ver 2.4), el símbolo ○ indica la concatenación de las funciones involucradas: primero se aplica $f_{O P}\left(\right.$ cuyo codominio es $\mathrm{P}$ ) y luego se ejecuta $f_{P Q}$ (cuyo dominio es $\left.\mathrm{P}\right) .{ }^{6}$ Es importante señalar que las composiciones son también morfismos.

El esquema del panel 2.6 destaca que la composición es asociativa: da igual si se ejecuta primero $f_{O P}$ y después la composición $f_{Q S} \circ f_{P Q}$ o si se aplica la concatenación $f_{P Q} \circ$ $f_{O P}$ y luego el mapeo $f_{Q S}$, el resultado es el mismo. En 2.7 se ilustran los morfismos de identidad para los conjuntos $\mathrm{Q}$ y $\mathrm{S}$, funciones que se nombran con los signos $1_{Q}$, y $1_{S}$ respectivamente. La ley de identidad asienta que para cualquier morfismo $f$ ocurre que $f=f \circ 1_{\text {Domino def }}=1_{\text {Codominio def }} \circ f$. En el panel 2.8 si ilustra el caso para el mapeo $f_{Q S}$.

Hasta aquí se ha ejemplificado lo que los libros de texto introductorios a la teoría de categorías proponen son los aspectos principales, comunes a cualquier categoría, a saber: i) una colección de objetos; ii) una colección de flechas (morfismos) de modo que a cada saeta le corresponde un objeto de origen -su dominio- y un objeto destino -su codominio-; iii) un operador de composición ( ${ }^{\circ}$ ) que permite componer dos flechas -si acaso el dominio de una es el codominio de la otra-, y que satisface una ley asociativa (como se muestra en el panel 2.6); iv) una flecha de identidad para cada objeto; y v) una ley de identidad para cada mapeo.

Si bien el presente trabajo se limita a la categoría de los conjuntos -los objetos son conjuntos y las flechas son funciones-, se debe advertir que hay otras categorías, con otras

\footnotetext{
${ }^{6}$ La lectura de derecha a izquierda es una convención usual de las obras sobre teoría de categorías. El siguiente ejemplo quizá ilustre por qué se ha establecido así: en la figura 2.1 se plantea que $f_{O P}\left(\mathrm{o}_{1}\right)=\mathrm{p}_{1}$, la figura 2.2 indica que $f_{P Q}\left(\mathrm{p}_{1}\right)=\mathrm{q}_{1}$, por tanto, $f_{P Q}\left(f_{O P}\left(\mathrm{o}_{1}\right)\right)=\mathrm{q}_{1}$.

Perspectivas - Revista do Programa de Pós-Graduação em Filosofia da UFT - n. 2 - 2018
} 
clases de objetos, los cuales tienen estructuras internas más ricas que la mera colección, y entre los cuales los morfismos son más complejos. Existen también mapeos entre categorías, llamados functores, y mapeos entre functores denominados transformaciones naturales. Por tanto, lo que se desarrolla en estas páginas es apenas la parte más superficial de la herramienta categorial.

Para la comprensión del modelo que se pormenoriza más adelante, conviene definir los conceptos de isomorfismo, retracción y sección. Si a un mapeo $f$ le corresponde un morfismo que corre en dirección contraria, desígnese $f^{-1}$, de modo que el dominio y codominio del primero son, respectivamente, el codominio y dominio del segundo, y además sucede que $f^{-1} \circ f=1_{\text {Dominio def }} \mathrm{y} f \circ f^{-1}=1_{\text {Dominio def }}{ }^{-1}$, entonces $f$ es un isomorfismo cuyo inverso es $f^{-1}$ (este último también es un isomorfismo, pero su inverso es $f$ ). En la figura 3 (panel 3.1) se muestran los diagramas internos y externos del isomorfismo $f_{Q W}$ y su inverso $f_{Q W}{ }^{-1}$ : nótese que si a cualquier elemento de $\mathrm{Q}$ se le aplica $f_{Q W}$ y al resultado se le aplica $f_{Q W^{-1}}$, se retorna a ese mismo elemento de Q. Es como si se le hubiera aplicado el morfismo de identidad de Q (ver figura 2 (2.7)). De manera similar, si a cualquier elemento de W se le aplica $f_{Q W} \circ f_{Q W}{ }^{-1}$ es como si se aplicara $1_{W}$ a ese elemento. 


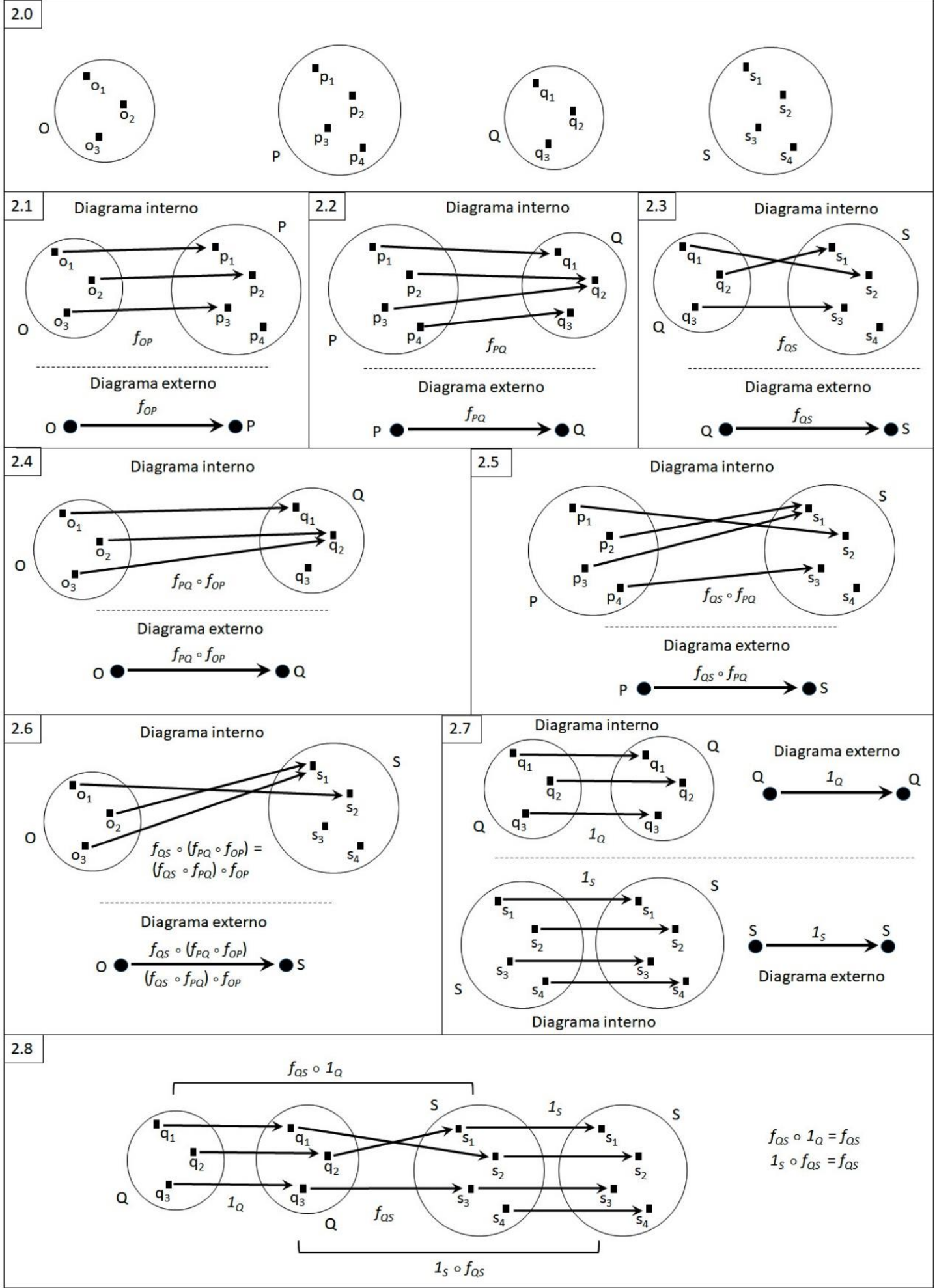

Figura 2. Objetos, morfismos, composición de morfismos, asociatividad y ley de identidad. Elaboración propia 


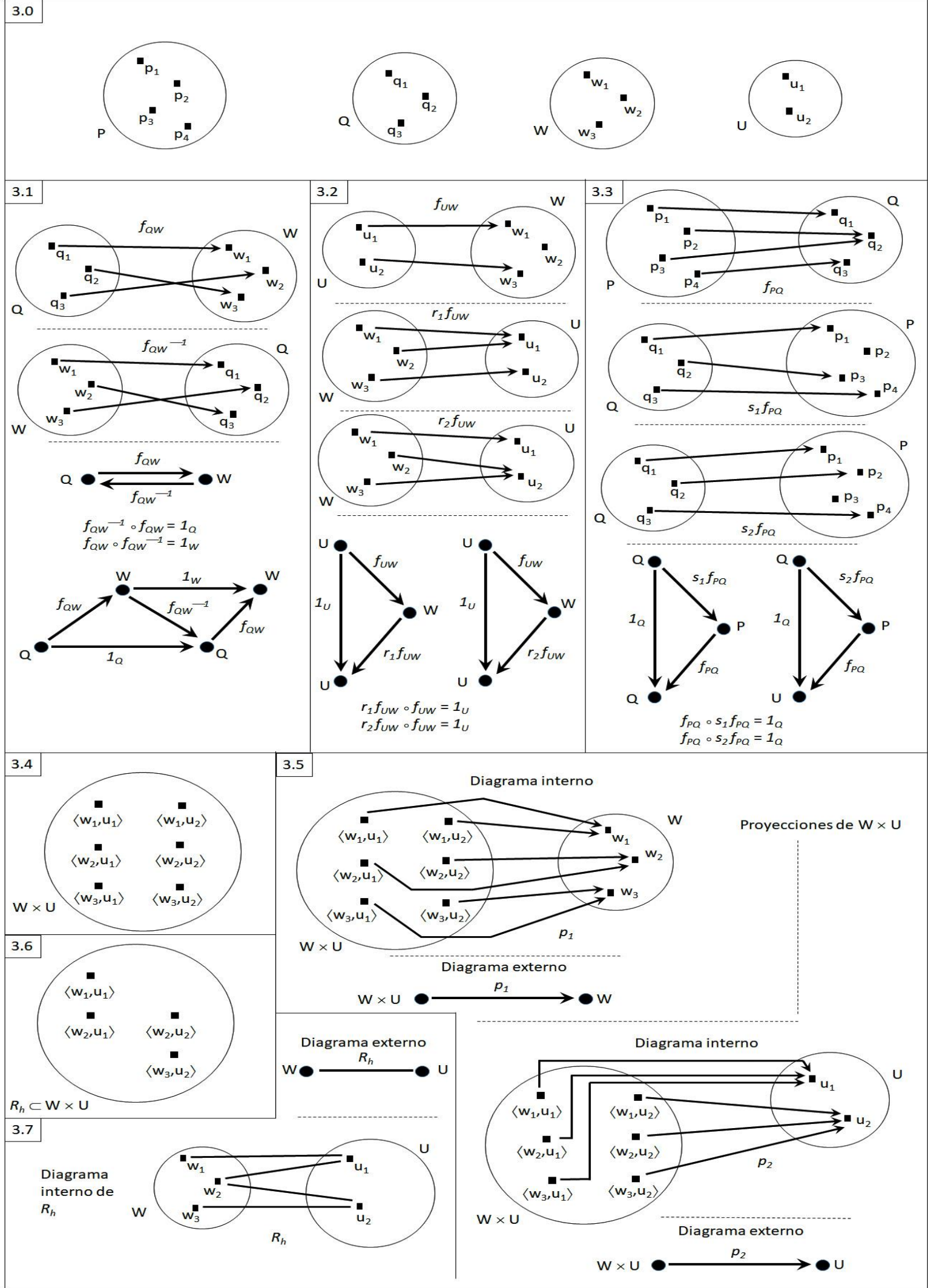

Figura 3. Isomorfismos, retracciones, secciones, productos y relaciones. Elaboración propia. 
Un isomorfismo pone de relieve que su dominio y codominio son objetos isomorfos, es decir, tienen la misma forma; tratándose de conjuntos esto significa que tienen el mismo número de elementos. Ahora bien, si el dominio y codominio de un morfismo $f$ no son isomorfos, aún puede existir algún mapeo en contra sentido cuya composición con $f$ da lugar a la identidad, ya sea del dominio o del codominio de $f$. Puede ser el caso de que $f$ tiene una retracción $r$ tal que $r \circ f=1_{\text {Domino de } f}$; o bien $f$ puede tener una sección $s$ tal que $f \circ s=$

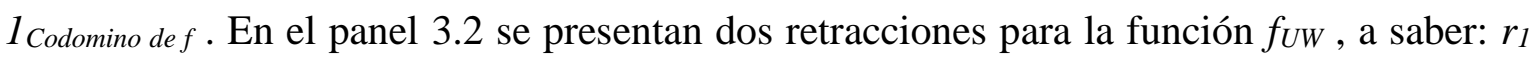
$f_{U W}$ y $r_{2} f_{U W}$. Por tanto, $r_{1} f_{U W} \circ f_{U W}=1_{U}$ y $r_{2} f_{U W} \circ f_{U W}=1_{U}$. Con base en estas fórmulas se puede afirmar que conmutan los dos diagramas triangulares en la porción inferior del panel, pues si se parte de algún elemento determinado de $U$ y se recorre la ruta constituida por las flechas $f_{U W}$ y $r_{1} f_{U W}$ (o bien $f_{U W}$ y $r_{2} f_{U W}$ ) se llega al mismo destino en $\mathrm{U}$ que si se recorre la ruta marcada por la saeta $1_{U}$ (nótese que, en lo concerniente a isomorfismos, el diagrama de cuatro nodos en la parte inferior del panel 3.1 yuxtapone dos esquemas triangulares conmutativos).

El panel 3.3 ilustra las dos secciones correspondientes al morfismo $f_{P Q}$, con el cual también dan lugar a esquemas triangulares conmutativos. Las secciones son monomorfismos ya que cualesquiera dos elementos del dominio se mapean a elementos distintos del codominio (en la categoría de los conjuntos las secciones son funciones inyectivas); las retracciones son epimorfismos ya que para todo elemento del codominio hay algún elemento del dominio que se mapea a él (en la categoría de los conjuntos, son funciones suprayectivas) Finalmente, los isomorfismos son tanto mono como epimorfismos (en lo concerniente a conjuntos son funciones biyectivas, ya que son a la vez inyectivas y suprayectivas). Cabe adelantar que la noción de rutas conmutativas juega un papel muy importante en la reconstrucción del modelo de Fitting (de hecho, en la reconstrucción de cualquier modelo o teoría científica), como se pondrá de relieve en la sexta sección del presente escrito.

Los siguientes recuadros de la figura 3 tratan sobre la representación de relaciones, la cual es importante para la comprensión del modelo de Fitting (MdF) que se presenta más adelante. El panel 3.4 muestra el producto cartesiano de $\mathrm{W}$ y U, es decir, el conjunto de todos los pares ordenados posibles, donde el primer integrante de cada pareja es un elemento de W y el segundo es un miembro de U. Cabe señalar que todo conjunto de series (pares, tríadas, tétradas, etc.) es domino de mapeos que se denominan proyecciones, las cuales se simbolizan con la letra $p$, acompañada de un subíndice indicativo de la proyección en cuestión. Así $p_{1}$ mapea el conjunto de series a la colección de los primeros integrantes de ellas, $p_{2}$ al conjunto 
de segundos integrantes, etc. Nuevamente cabe adelantar que las proyecciones juegan un papel importante en la reconstrucción de MdF. En 3.5 se ilustran los morfismos correspondientes a la primera y segunda proyección del conjunto $\mathrm{W} \times \mathrm{U}$. Ahora bien, una relación entre dos colecciones se define como un subconjunto del producto cartesiano de ambas, por consiguiente, $R_{h}$ en el panel 3.6 constituye una relación hipotética. Hay otra manera de representar $R_{h}$, la cual es más afín a la noción de mapeo. Se presenta en 3.7, bajo el rótulo "Diagrama interno": ahí se ilustra, mediante aristas sin punta de flecha, los vínculos entre los elementos de W y de $\mathrm{U}$, que establece la relación $R_{h}$. No se representan como saetas, pues las relaciones no son mapeos unívocos (esto es, a un elemento del dominio le corresponde solamente un elemento de codominio); nótese que $w_{2}$ se vincula con dos elementos de U, en el panel 3.7. La parte superior de 3.7 destaca el modo de representar el diagrama externo de $R_{h}$ : un segmento, en lugar de flecha, que asocia $\mathrm{W}$ con $\mathrm{U}$.

Para terminar con esta sección, la figura 4 muestra que el ser subconjunto de otra colección y la pertenencia de un elemento a un conjunto pueden ser ambos expresados como morfismos. El panel 4.0 brinda un ejemplo respecto de la noción de subconjunto: el mapeo allí representado indica que $\mathrm{O}^{*}$ es un subconjunto de $\mathrm{O}$. Una convención usual en los textos introductorios a la teoría de categorías es presentar los diagramas externos de esta clase de morfismos con flechas en forma de bastón, para así indicar que el dominio es parte del codominio. En el presente trabajo se les da, además, el nombre genérico de $i$, en aras de incluirlas en fórmulas que emplean el operador o para expresar la composición de tales o cuales funciones. En 4.1 se revela que la relación de pertenencia-usualmente indicada con el signo $\in$ en la teoría de conjuntos- se puede expresar como un mapeo. Para ello es menester introducir un conjunto especial, $\mathbf{1}$, denominado singulete que consta de solo un punto abstracto. Todo morfismo que tenga por dominio al singulete identifica un elemento particular del codominio. Por tanto, expresiones como $f(x)$ pueden reformularse así: $f \circ x$. Existe una clase de mapeos, representados con el signo de exclamación, !, que tienen al singulete por codominio y asignan todos los elementos del dominio al único punto del singulete. Se ilustra el caso del conjunto $\mathrm{O}$ en 4.2, y puesto que el dominio es $\mathrm{O}$, el nombre de la función es $!_{O}$. El recuadro 4.3 muestra lo que sucede cuando se compone !o con el morfismo indicativo del elemento $\mathrm{o}_{1}$ de $\mathrm{O}$ : todos los integrantes de $\mathrm{O}$ se mapean a $\mathrm{o}_{1}$. Este recurso es muy útil en la modelización, cuando se quiere identificar un elemento particular de una colección a partir de otra. De hecho, lo que se ilustra en los paneles 4.0-4.3 juega un 
papel importante para poner de relieve las inferencias más significativas que se derivan del modelo que se construye en las páginas siguientes.

Mención aparte merece el panel 4.4: incluirlo tiene la intención de mostrar que los elementos de un conjunto a su vez pueden ser entidades complejas. Aquí X es un conjunto de series, y nótese que las series están compuestas de ítems tan variados como unidades individuales, intervalos de años y colecciones. Por su parte, $\mathrm{Y}$ es un conjunto de conjuntos y $f_{X Y}$ es un morfismo que mapea series a conjuntos. Se presentan dos modalidades de diagrama interno con el afán de introducir una convención - propia del presente trabajo- que se utilizará en las páginas siguientes. En el diagrama interno del margen izquierdo del panel 4.4 se incluyen puntos representativos de tal serie de $\mathrm{X}$ o tal conjunto de $\mathrm{Y}$ que tienen a su lado; de ellos parten o a ellos arriban las flechas indicativas de la asignación. Este es un recurso expositivo común en libros de texto como el de Lawvere y Schanuel (2002). En el diagrama interno del margen derecho se eliminan tales puntos, y las asignaciones se dibujan directamente, de serie en X a conjunto en Y. Más adelante, al pormenorizar los morfismos que constituyen al modelo de Fitting, se emplea (dado el caso) la convención planteada en el lado derecho de 4.4, para ilustrar, con semblanzas de diagramas internos parciales, de qué tratan dichos morfismos.

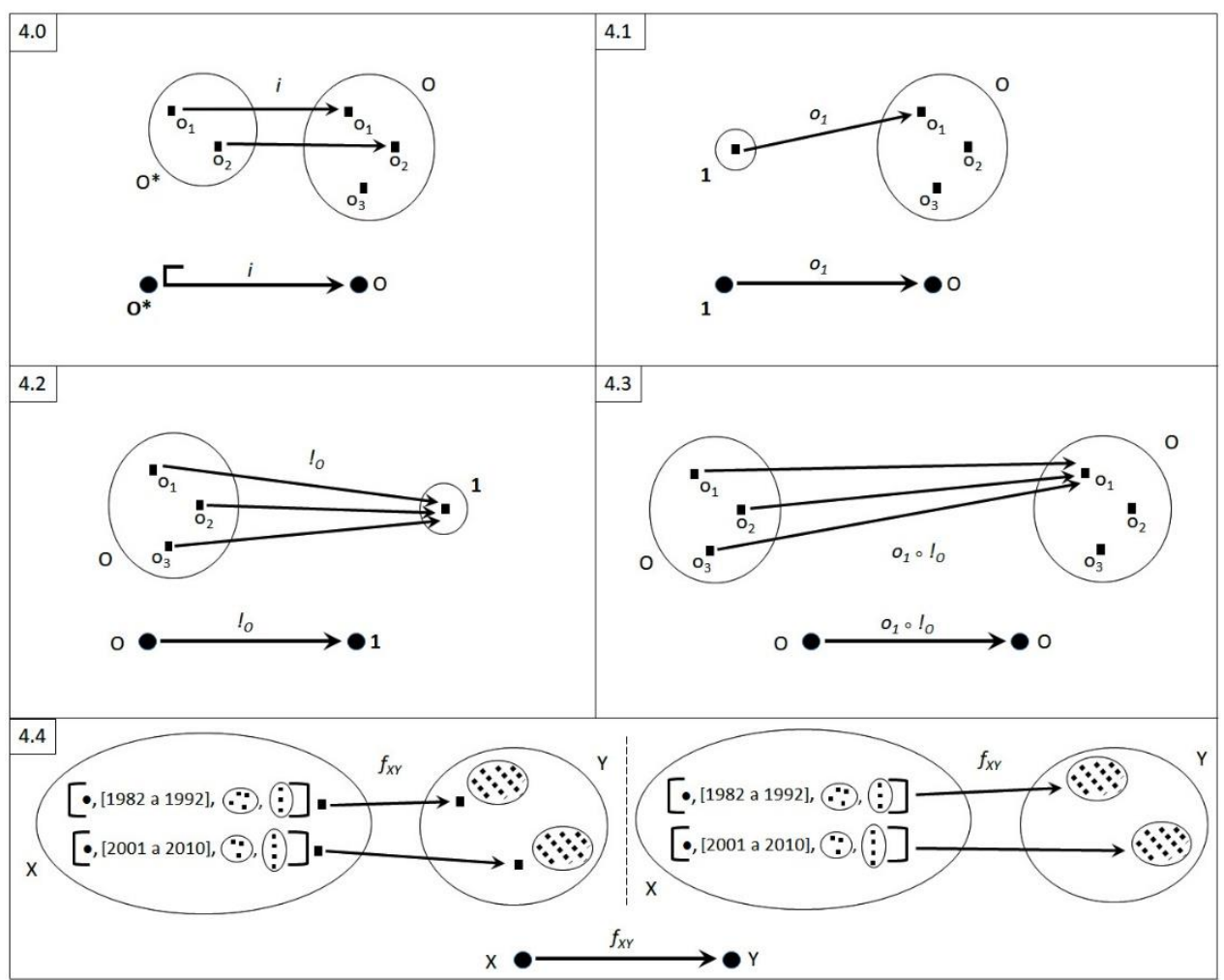

Figura 4. Mapeos de subconjunto, pertenencia y a objeto terminal. Elaboración propia.

Perspectivas - Revista do Programa de Pós-Graduação em Filosofia da UFT - n. 2 - 2018 
Por último, aunque el grueso de la exposición a continuación es con base en la notación de la teoría de categorías, hay algunos pasajes -pocos- donde se utilizan, con la finalidad de ahorrar espacio, los símbolos conjuntistas convencionales de pertenencia, $\in$; de subconjunto, $\subset$ y $\subseteq$; de intersección, $\cap$; y de unión, $\cup$. Además, se emplea la notación del tipo $f(x)=y$ para indicar que la función $f$ mapea el integrante $x$ de su dominio al elemento $y$ de su codominio. También, se hará uso de la fórmula: $\mathrm{A}=\{x / x$ es una entidad fulana $\}$, para introducir el conjunto A de entidades fulanas.

\section{Preludio a la reconstrucción del modelo de Fitting (MdF)}

The Struggle for Maize otorga un papel importante a ciertos conceptos que aluden a entidades formadas de varios componentes, como es el caso del concepto de unidad doméstica, el cual articula personas de ambos sexos en grupos familiares/residenciales, viviendas, medios de producción y otras cuestiones. La reconstrucción que se propone trata estos conglomerados como conjuntos de series que se proyectan a los conjuntos de los elementos constitutivos de cada serie; en ocasiones se estipulan inclusiones y otros morfismos auxiliares, además de las proyecciones. Se ha optado por presentar, primero, cada uno de estos conceptos compuestos con sus respectivas proyecciones y morfismos auxiliares, y luego, en la siguiente sección, presentar el esquema correspondiente al modelo completo de Fitting, con todos sus términos, pero dejando sobre entendidas o implícitas las múltiples proyecciones y relaciones auxiliares antes dichas. Las figuras que se muestran en seguida (5 a 7) se corresponden con los conceptos de unidad doméstica, comunidad, integrante productivo de unidad doméstica, experiencia migratoria y régimen agroalimentario. Conviene aclarar que tanto estos esquemas como los que se presentan en páginas subsecuentes pretenden brindar una interpretación general que no necesariamente es privativa de la situación del sur del valle de Tehuacán, aunque Fitting haya privilegiado esta zona para realizar su trabajo de campo. Al abstraer el lugar del cual se versa a una región indeterminada, X, se abre la posibilidad de explorar si la propuesta de Fitting se puede aplicar a otras regiones y/o comunidades de México y el mundo.

La figura 5A, panel 5.A, ilustra, a modo de una constelación de diagramas externos, las proyecciones del conjunto $\mathrm{Ud}_{\mathrm{Rx}}$, el cual reúne las unidades domésticas de la región $\mathrm{X}$ en los últimos 150. El diagrama que aparece en el panel 5.A.0 brinda una vista parcial abstracta de la colección $\mathrm{Ud}_{\mathrm{Rx}}$, y la definición adjunta indica que cada integrante de ella es una serie compuesta por un conjunto de personas -la familia que vive bajo un mismo techo-, un 
determinado año, una vivienda y un conjunto de medios de producción (tierras para el cultivo, aperos de labranza, semillas, etc.). Los paneles 5.A.1 a 5.A.4 ilustran los conjuntos a los cuales se proyectan los miembros de $\mathrm{Ud}_{\mathrm{Rx}}$. Por lo regular, las personas que viven bajo un mismo techo están emparentadas, pero cabe la posibilidad de que algunas de ellas no tengan lazos de sangre con los demás y tampoco sean el conyugue de otro integrante; simplemente son personas que por alguna razón han sido adoptadas por la familia en cuestión. También conviene señalar la posibilidad de que algún miembro esté ausente porque ha migrado temporalmente fuera de la comunidad en búsqueda de trabajo; de cualquier manera, sigue formando parte del grupo familiar y tendrá su lugar en la unidad doméstica cuando regrese. Para fines de la reconstrucción se ha estipulado considerar cada unidad doméstica por año, periodo que, a groso modo, se corresponde con un ciclo económico. Sin embargo, no debe perderse de vista que los intervalos del conjunto Cal (panel 5.A.3) pueden ser de mayor extensión, incluso de décadas, pues otras entidades del modelo de Fitting también se periodizan, pero los intervalos correspondientes pueden abarcar hasta 30 años o más. Puesto que familias campesinas también pueden dedicarse a la producción artesanal, el conjunto de medios de producción también puede incluir las herramientas y materiales necesarias para tal actividad. Nótese que en la viñeta del panel 5.A.4, la colección de medios de producción $(\mathrm{H})$, contiene un conjunto vacío: esto es así para dar cabida a hogares que ya no cuentan con tierras de labor o talleres artesanales, pues sus integrantes están completamente proletarizados.

La figura 5.B alude a la entidad "comunidad": el conjunto Com engloba las comunidades de la región $\mathrm{X}$ en los últimos 150 años, y en el panel 5.B se muestra que Com tiene varias proyecciones. Una comunidad es una entidad dinámica cuya población, configuración espacial, edificios públicos, giros comerciales y asociaciones civiles cambian con el paso de los años. Según el razonamiento de Fitting, los sucesivos regímenes agroalimentarios generan efectos y dejan su marca, por así decir, a nivel local; por ende, influyen en las dinámicas comunitarias. Por eso, en el panel 5.B.0 se estipula que los integrantes del conjunto Com constituyen series, compuestas de: i) el nombre del asentamiento en cuestión; ii) su localización geográfica; iii) un marcador anual; iv) el número de habitantes en ese año; v) la traza del sitio, que incluye disposición de terrenos agrícolas, casas, solares, calles, redes de servicio (en su caso), caminos a otras localidades, giros comerciales y manufacturas (en su caso ) y edificios públicos; vi) estructura del gobierno local; vii) las asociaciones civiles que operan en la comunidad en cuestión (para el 


\begin{tabular}{|c|c|c|c|c|c|c|}
\hline \multicolumn{2}{|c|}{ 5. A. El conjunto alusivo a las unidades domésticas de la región $\mathrm{X}$, y los conjuntos correspondientes a sus proyecciones } \\
\hline 5.A.
\end{tabular}

una temporada agrícola/artesanal\}. Nota. Nótese que en la viñeta la colección H contiene un conjunto vacío: esto es así para dar cabida a hogares que ya no cuentan con tierras de labor o talleres artesanales, pues sus integrantes están completamente proletarizados.

5. B. El conjunto alusivo a las comunidades de la región $X, y$ los conjuntos correspondientes a sus proyecciones

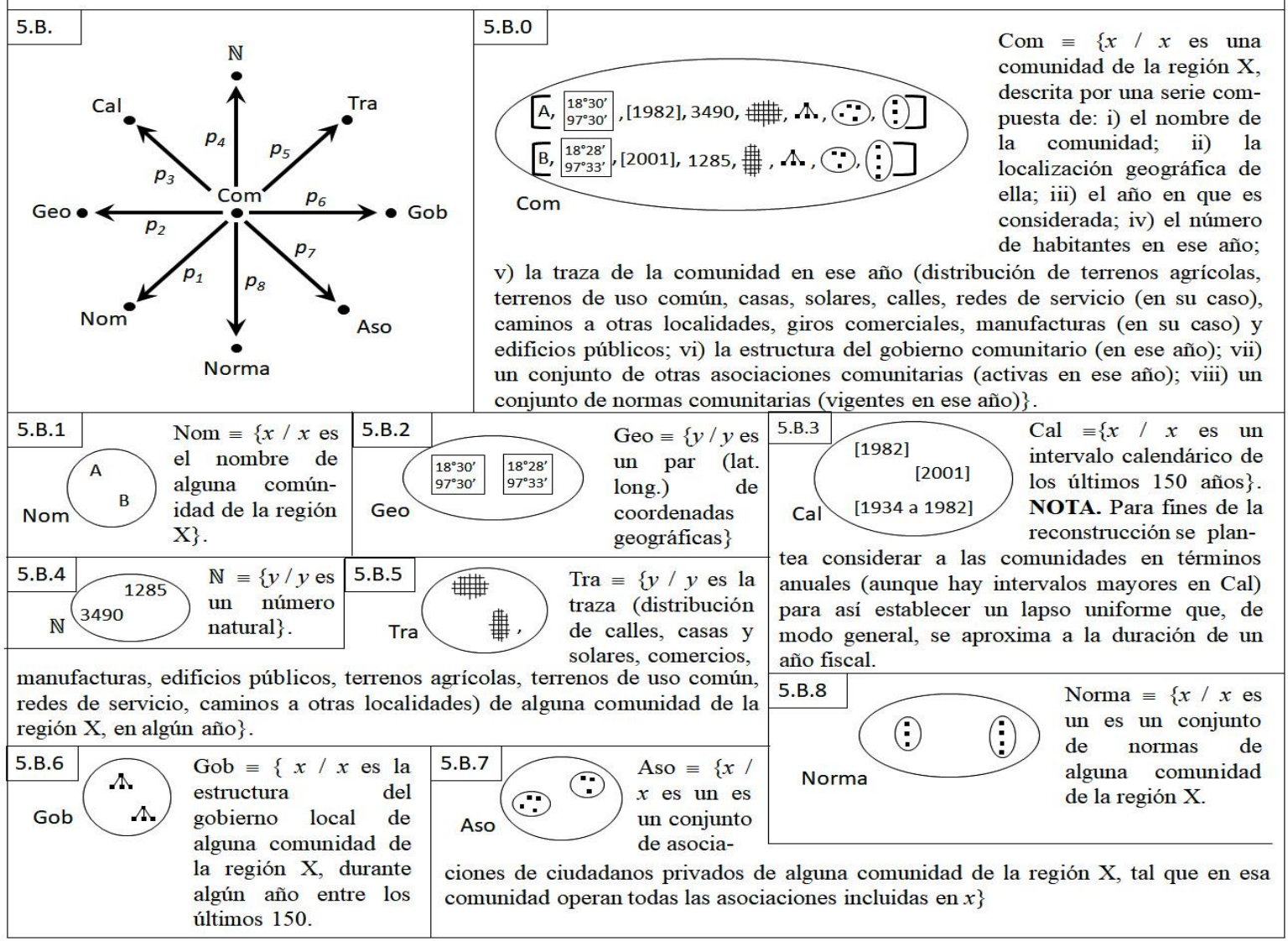

Figura 5. Conjuntos alusivos a unidad doméstica y comunidad, y sus respectivas proyecciones. Elaboración propia.

Perspectivas - Revista do Programa de Pós-Graduação em Filosofia da UFT - n. 2 - 2018 


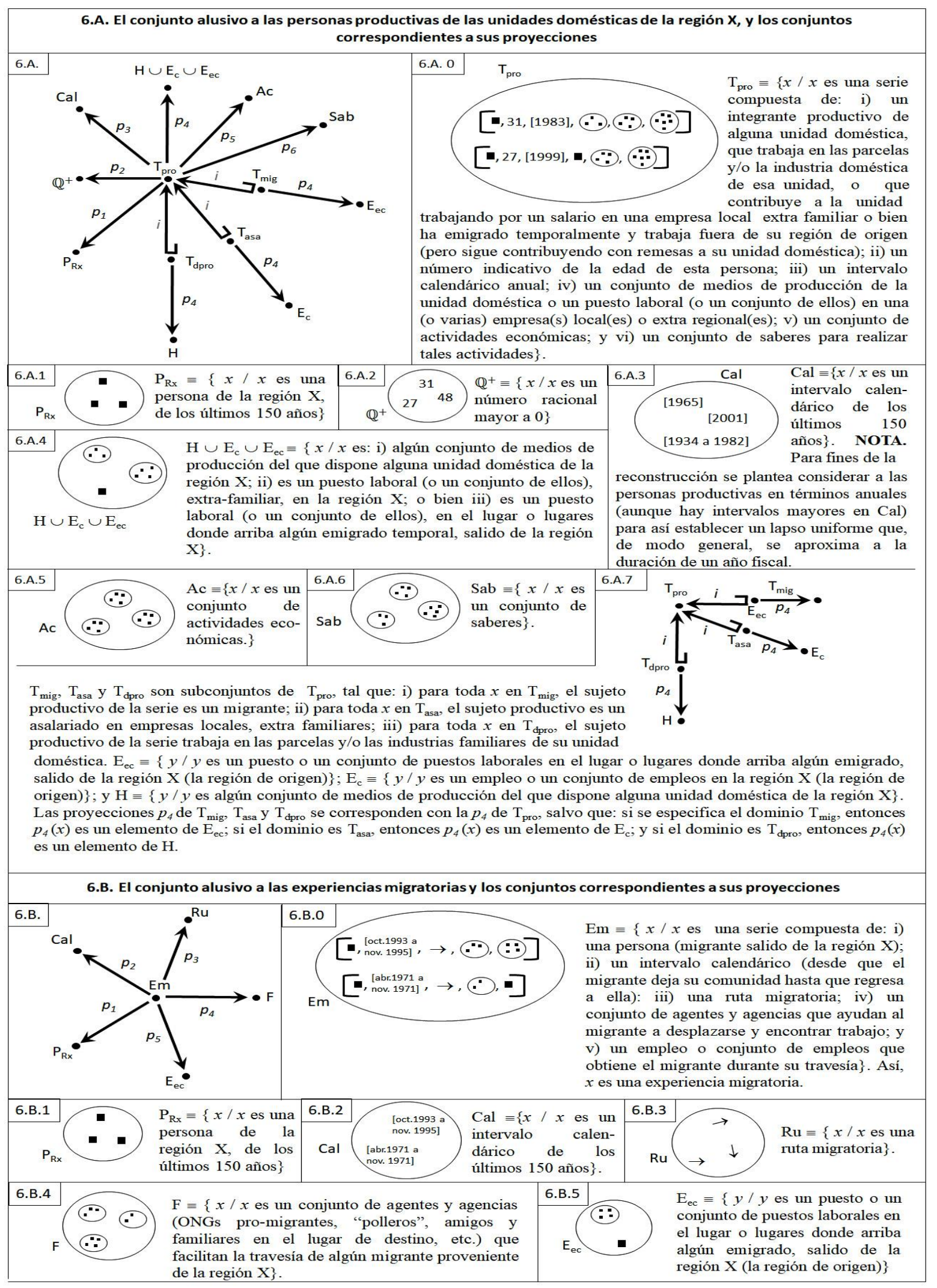

Figura 6. Conjuntos alusivos a persona productiva y experiencia migratoria. Elaboración propia 
caso del sur del valle de Tehuacán, Fitting hace especial mención de las asociaciones de agua); y viii) la normatividad social aceptada que rige la convivencia ente vecinos. Los paneles 5.B.1 a 5.B.8 definen e ilustran parcialmente los conjuntos a los cuales se proyectan las series de Com.

La figura 6 revela las estructuras concernientes a los integrantes productivos de las unidades domésticas de la región X (parte 6.A) y a lo que se ha denominado aquí como experiencias migratorias (parte 6.B). En lo concerniente a la parte 6.A, el panel 6.A destaca que el conjunto $\mathrm{T}_{\text {pro }}$, la colección alusiva a personas productivas, tiene varias proyecciones, $\mathrm{y}$ tres subconjuntos suyos $-\mathrm{T}_{\text {dpro, }}, \mathrm{T}_{\text {asa }} \mathrm{y} \mathrm{T}_{\mathrm{mig}}-$ son indicativos de distintos tipos de personas productivas. La definición de $\mathrm{T}_{\text {pro, }}$ en el panel 6.A.0 indica que cada integrante suyo es una persona de determinada edad que en determinado año realiza un conjunto de actividades económicas, para las cuales pone en práctica un conjunto de conocimientos. Esto es, cada sujeto productivo se entiende como una serie. Por otra parte, puede ser un agricultor/artesano que labora en su parcela de tierra y/o su taller, o bien puede ser un trabajador asalariado en una empresa extrafamiliar, pero local; o bien un migrante que trabaja lejos de su comunidad, pero manda remesas a su familia.

$\mathrm{Si}$ es agricultor/artesano emplea sus propios medios de producción (o bien medios rentados); si es asalariado (empleado localmente o migrante) tiene un puesto laboral (o quizá varios a lo largo del año). Nótese que una mismo individuo puede estar representado en más de una serie de $\mathrm{T}_{\text {pro; }}$; en primer lugar, porque dichas series son anuales, $\mathrm{y}$, además, porque una persona puede desempeñar varios roles productivos. El conjunto de campesinos/artesanos que se emplean a sí mismos, $\mathrm{T}_{\mathrm{dpro}}$, el de asalariados locales, $\mathrm{T}_{\text {asa }}$, y el

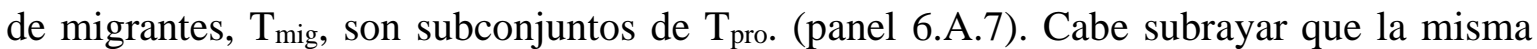
persona puede figurar en series de estos tres subconjuntos, porque de un año a otro cambia de rol productivo o bien realiza más de un rol productivo en un año.

The Struggle for Maize dedicada varias páginas a la emigración y el efecto que este fenómeno tiene sobre las unidades domésticas de San José Miahuatlán y el cultivo del maíz en la zona. La mayoría de los testimonios que reúne la autora describen situaciones de migración temporal y reiterativa; además, dejan entrever que la modalidad ha cambiado en la historia reciente de la comunidad. Han surgido nuevas rutas migratorias que siguen los sanjosepeños a Estados Unidos, los tiempos de ausencia se han extendido, ha cambiado el sector en el que se emplean una vez llegados a sus destinos. Con base en lo expuesto por 
Fitting, se sugiere en la presente reconstrucción la categoría de "experiencia migratoria", representada por el conjunto Em de la figura 6 parte B.

Según establece el recuadro 6.B.0, cada integrante de Em es una seria compuesta por: el migrante en cuestión, el intervalo entre la fecha que abandona su comunidad hasta la fecha en que regresa a ella, la ruta migratoria o periplo que sigue durante ese tiempo, los agentes y agencias que le facilitan el traslado y/o la obtención de empleo en los lugares de destino, y el (o los) puesto(s) laboral(es) que consigue en esos sitios de arribo. Cabe señalar que una misma persona, especialmente quien migra reiteradamente, puede vivir varias experiencias migratorias, diferenciadas por las fechas en las cuales se realizan. Puesto que el sujeto de una experiencia migratoria también puede ser un integrante productivo -en ausencia- de alguna unidad doméstica, conviene señalar algunas diferencias en lo concerniente a persona y temporalidad entre las series constitutivas del conjunto Em y las series incluidas en el conjunto $\mathrm{T}_{\mathrm{mig}}$ (discutido en el panel 6.A.7). La persona que figura en una serie de Em puede aparecer en varias series de $\mathrm{T}_{\mathrm{mig}}$, pues la temporalidad asociada a éstas últimas se limita a un año, mientras que la de una serie de Em puede abarcar varios años, en caso de una ausencia prolongada de la comunidad de origen.

La entidad "régimen agroalimentario" se desarrolla en la figura 7, donde se muestra que cada uno de tales regímenes (elementos del conjunto ReAA) se reconstruye aquí (ver panel como una serie, cuyos componentes son: i) un conjunto de acuerdos y normas, tanto internacionales como nacionales y regionales, sobre la producción y comercio alimentario; ii) un conjunto de centros productores mundiales de alimentos; iii) un conjunto de redes de distribución mundiales de alimento; iv) un conjunto de tecnologías de producción y conservación de alimentos; y v) un conjunto de precios estables de los principales alimentos que se venden en mercados internacionales. Se podría haber incluido un intervalo calendárico en cada serie, pero se ha optado mapear, mediante la función $f_{R C}$ (ver más adelante), los integrantes de ReAA a los intervalos de Cal.

\section{El modelo de Fitting (MdF)}

El armazón del modelo que se puede sustraer a la segunda parte de The Struggle for Maize se ilustra en la figura 8, a modo de un diagrama externo de una constelación de mapeos. El hecho de que algunas saetas muestren doblamientos no les confiere ninguna cualidad especial, representan morfismos (los nodos conjuntos) y los dobleces son simples artefactos de presentación. La línea punteada que corta la estructura transversalmente atañe a las 
siguientes consideraciones: debajo de ella se ubican las entidades y relaciones correspondientes a la observación histórica/etnográfica; arriba de ella figuran los componentes vinculados a la interpretación de los datos histórico/etnográficos en relación

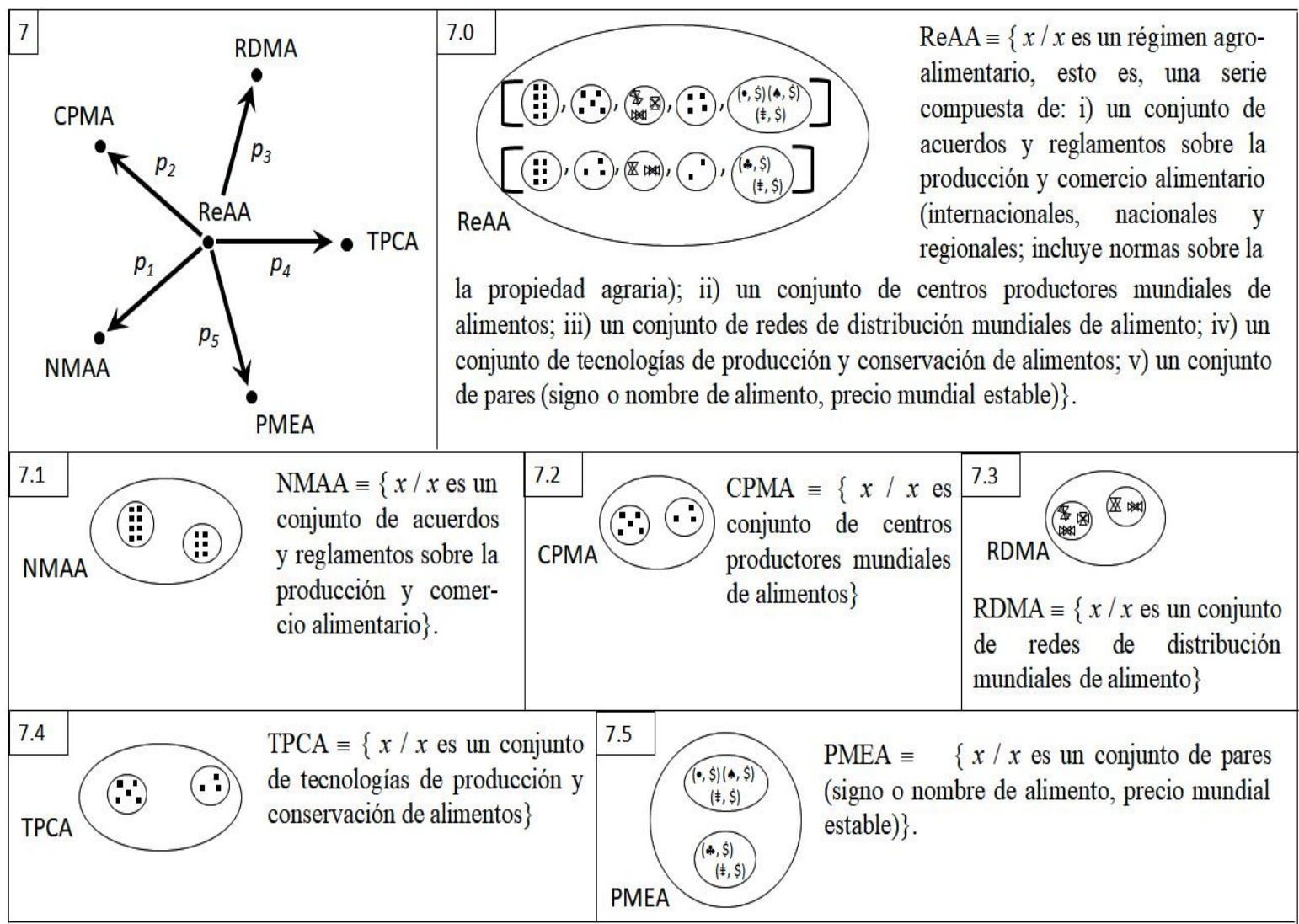

Figura 7. Conjunto alusivo a régimen agroalimentario. Elaboración propia

con la teoría de los regímenes agroalimentarios. Esta segunda porción también incluye las flechas atravesadas por la línea punteada. Las inclusiones $(i)$ y algunas de las proyecciones reseñadas en las figuras 5 a 7 están presentes en la figura 8 para mostrar que se trata de un armazón integrado, sin subestructuras desconectadas. Sin embargo, no aparecen la mayoría de las proyecciones mencionadas anteriormente, en aras de no atiborrar el diagrama. De cualquier manera, debe entenderse que siguen vigentes, aun si están ocultas.

Las figuras 9 a 15 pormenorizan cada uno de los morfismos que se introducen en la figura 8, y para facilitar la lectura se incluye algo semejante a un diagrama interno, en cada caso, pero concebido más como una aproximación abstracta y parcial (en el espacio de estas cuartillas sería muy difícil brindar, por ejemplo, un diagrama interno completo del mapeo entre las decenas o centenares de unidades domésticas de una región y las comunidades en las cuales están ubicadas). Cada figura de la 9 a la 15 aborda entre 6 y 9 flechas, para las Perspectivas - Revista do Programa de Pós-Graduação em Filosofia da UFT - n. 2 - 2018 
cuales se explican los respectivos dominios, codominios y mapeos. Con el propósito de guiar al lector, se incluye una imagen en miniatura de MdF en la cual se resaltan los aspectos a tratar. De la 9 a la 13 se abordan los morfismos que se ubican debajo de la línea punteada, mientras que la 14 y 15 discuten los que están por arriba de la demarcación, así como aquellas funciones que la cruzan. En términos generales, la exposición se hace siguiendo las direcciones izquierda-derecha y abajo-arriba del recorte en cuestión.

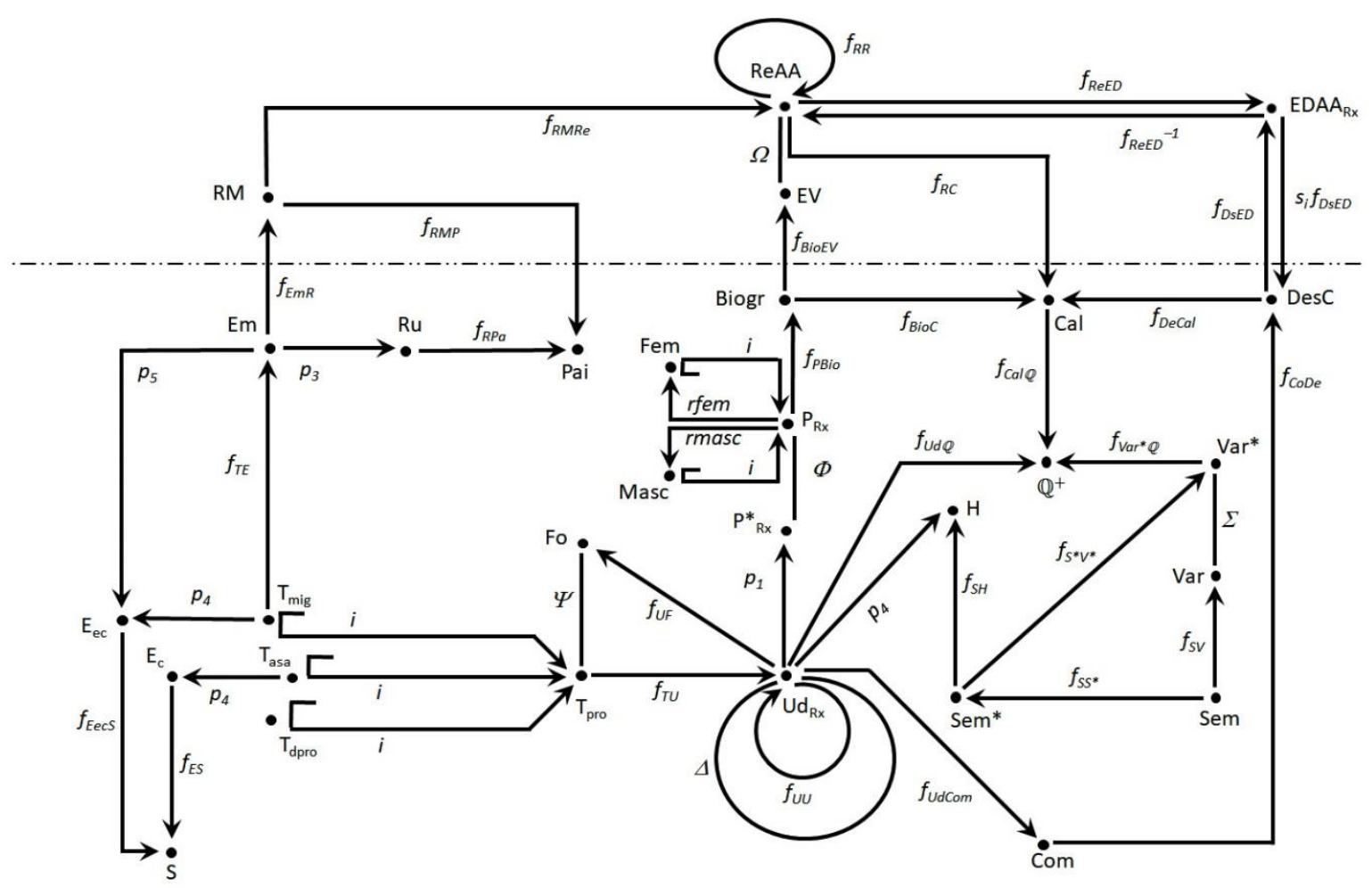

Figura 8. Modelo de Fitting. Elaboración propia.

A pesar del detalle en que se han expuesto los componentes de MdF en las figuras anteriores, vale la pena hacer unos comentarios adicionales respecto de algunas particularidades del modelo. En primer término, conviene abundar un poco más en la importancia del nodo Cal, el conjunto de intervalos calendáricos. En la figura 8 no se aprecia que los nodos Em, $\mathrm{T}_{\text {pro, }}$ $\mathrm{Ud}_{\mathrm{Rx}}$ y Com se mapean directamente al nodo Cal, eso se establece, a modo de proyecciones, en las figuras 5 y 6 . En buena medida, la razón de ello obedece a no atiborrar la figura 8, de por sí bastante cargada, con más flechas. De cualquier manera, el esquema presenta una saeta, $f_{\text {Cal }}$. (explicada en la figura 12, inciso 25 ), que mapea intervalos a números, en aras de incluir un dispositivo que brinde la duración en años de tal o cual periodo. Por supuesto, los intervalos calendáricos contenidos en las series de Em, $\mathrm{T}_{\text {pro, }} \mathrm{Ud}_{\mathrm{Rx}}$ y Com también pueden 


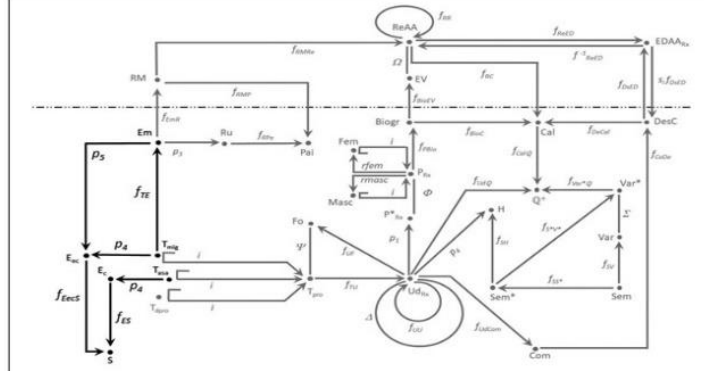

1. $f_{\text {EecS }}$

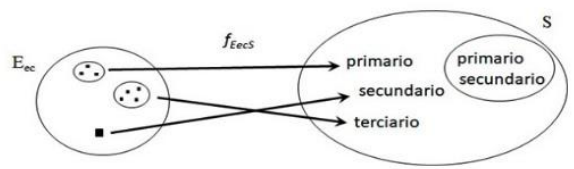

Dominio. $\mathrm{E}_{\mathrm{ec}} \equiv\{x / x$ es un puesto o un conjunto de puestos laborales en el lugar o lugares donde arriba algún emigrado, salido de la región $\mathrm{X}$ (la región de origen) $\}$. Codominio. $\mathrm{S} \equiv\{y$ l $y$ es un sector económico (agropecuario (primario), manufactura (secundario), servicios (terciario)) o $y$ es un conjunto de tales sectores $\}$. Mapeo. $f_{\text {EecS }}(x)=y$ : el empleo foráneo $x$ se corresponde con el sector económico $y$; o bien el conjunto de empleos foráneos $x$ se corresponde con el sector $y$ si la mayoría relativa de los empleos de $x$ son de ese sector; o bien el conjunto de empleos foráneos $x$ se corresponde con el conjunto de sectores $y$ si no se puede establecer una mayoría relativa sectorial respecto de los empleos de $x$, pero la mayoría de tales empleos se corresponden en proporciones iguales a los sectores de $y$.

2. $f_{E S}$

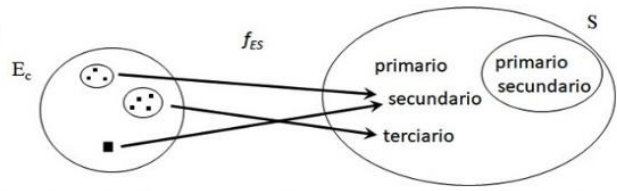

Dominio. $\mathrm{E}_{\mathrm{c}} \equiv\{x / x$ es un empleo o un conjunto de empleos en la región X (la región de origen) \}. Codominio. S (ver 1, esta figura ). Mapeo. $f_{E S}(x)=y$ : el empleo local $x$ se corresponde con el sector económico $y$; o bien el conjunto de empleos locales $x$ se corresponde con el sector $y$ si la mayoría relativa de los empleos de $x$ son de ese sector; o bien el conjunto de empleos locales $x$ se corresponde con el conjunto de sectores $y$ si no se puede establecer una mayoría relativa sectorial respecto de los empleos de $x$, pero la mayoría de tales empleos se corresponden en proporciones iguales a los sectores de $y$.

3. $p_{4}\left(\right.$ dominio $\left.\mathrm{T}_{\text {asa }}\right)$

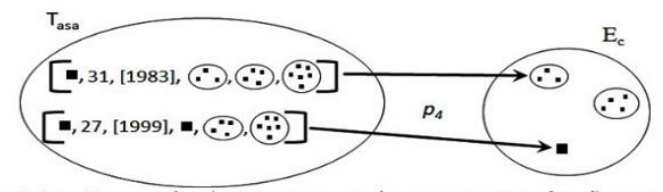

Dominio. $\mathrm{T}_{\text {asa }} \equiv\{x / x$ es una serie compuesta de: i) un integrante productivo de alguna unidad doméstica, que trabaja por un salario en una empresa local extra familiar; ii) un número indicativo de la edad de esta persona; iii) un intervalo calendárico anual; iv) un puesto laboral (o un conjunto de ellos) en una (o varias) empresa(s) local; v) un conjunto de actividades económicas; y vi) un conjunto de saberes para realizar tales actividades\}. Codominio. $\mathrm{E}_{\mathrm{c}}$ (ver inciso 2 en esta figura) Mapeo. $p_{4}(x)=y$ : la serie $x$ tiene por cuarta proyección el puesto laboral o el conjunto de puestos laborales $y$.
4. $p_{4}\left(\right.$ dominio $\left.\mathrm{T}_{\mathrm{mig}}\right)$

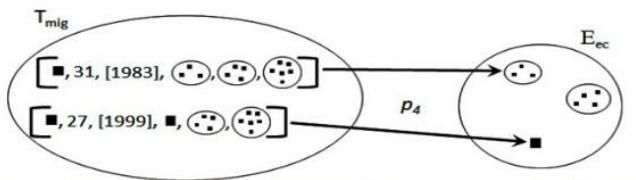

Dominio. $\mathrm{T}_{\operatorname{mig}} \equiv\{x / x$ es una serie compuesta de: i) un integrante productivo de alguna unidad doméstica, que ha emigrado temporalmente y trabaja fuera de su región de origen (pero sigue contribuyendo con remesas a su unidad doméstica); ii) un número indicativo de la edad de esta persona; iii) un intervalo calendárico anual; iv) un puesto laboral (o un conjunto de ellos) en una (o varias) empresa(s) extra regional(es); v) un conjunto de actividades económicas; y vi) un conjunto de saberes para realizar tales actividades\}. Codominio. $\mathrm{E}_{\mathrm{ec}}$ (ver inciso 1 en esta figura) Mapeo. $p_{4}(x)=y$ : la serie $x$ tiene por cuarta proyección el puesto laboral extraregional o el conjunto de puestos laborales extra-regionales $y$.

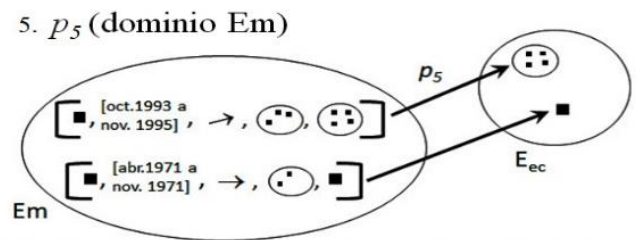

Dominio. Em $\equiv\{x / x$ es una serie compuesta de: i) una persona (migrante salido de la región $\mathrm{X}$ ); ii) un intervalo calendárico (desde que el migrante deja su comunidad hasta que regresa a ella): iii) una ruta migratoria; iv) un conjunto de agentes y agencias que ayudan al migrante a desplazarse y encontrar trabajo; y v) un empleo o conjunto de empleos que obtiene el migrante durante su travesía\}. Así, $x$ es una experiencia migratoria. Codominio. $\mathrm{E}_{\mathrm{ec}}$ (ver inciso 1 , esta figura). Mapeo. $p_{5}(x)=y$ : la serie $x$ (representativa de una experiencia migratoria) tiene por quinta proyección el puesto laboral, extraregión $\mathrm{X}$ (o un conjunto de tales puestos), $y$.

6. $f_{T E} \mathrm{~T}_{\mathrm{mig}}$

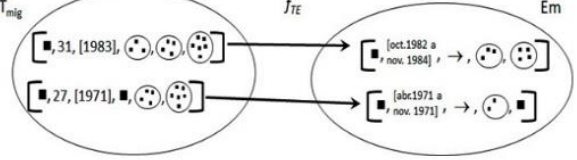

Dominio. $\mathrm{T}_{\mathrm{mig}}$ (ver inciso 4 en esta figura). Codominio. Em (ver inciso 5 en esta figura). Mapeo: $f_{T E}(x)=y$ : la serie $x$ (persona productiva, emigrada de la región $\mathrm{X}$; número indicativo de su edad; intervalo anual; empleo o un conjunto de empleos; conjunto de actividades económicas; conjunto de saberes) se corresponde con la serie $y$, la cual es representativa de una experiencia migratoria.

Conviene subrayar que $f_{T E}(x)=y$ implica que $p_{1}(x)=p_{1}(y)$ : esto es, la primera proyección de ambas series es la misma persona; quien vive la experiencia migratoria representada por $y$ es la persona correspondiente a la serie de $x$ (el migrante). Por otra parte, $p_{3}(x) \subseteq p_{2}(y)$ : el intervalo calendárico correspondiente a la serie $x$ es un subconjunto del intervalo calendárico correspondiente a la experiencia migratoria representada por la serie $y$. Ahora bien, el intervalo de $x$ puede ser igual al de $y$ si acaso la experiencia migratoria en cuestión dura sólo un año. De hecho varias series de $\mathrm{T}_{\text {mig }}$ se pueden mapear a la misma serie de Em, si esas series se remiten a la misma persona en años consecutivos, de tal suerte que la suma de años da el intervalo calendárico correspondiente a la serie de Em. Por tanto, $p_{4}(x) \subseteq p_{5}(y)$ o bien $p_{4}(x)=p_{5}(y)$, pues los puestos laborales que ocupa el migrante durante un año es un subconjunto de los puestos que ocupa en toda su experiencia migratoria, aunque existe la posibilidad de que sea el o los mismos.

Figura 9. Morfismos: $f_{E e c S}, f_{E S}, p_{4}$ (dominios $\left.\mathrm{T}_{\text {asa }} \mathrm{y} \mathrm{T}_{\mathrm{mig}}\right), p_{5} \mathrm{y} f_{T E}$. Elaboración propia.

Perspectivas - Revista do Programa de Pós-Graduação em Filosofia da UFT - n. 2 - 2018 


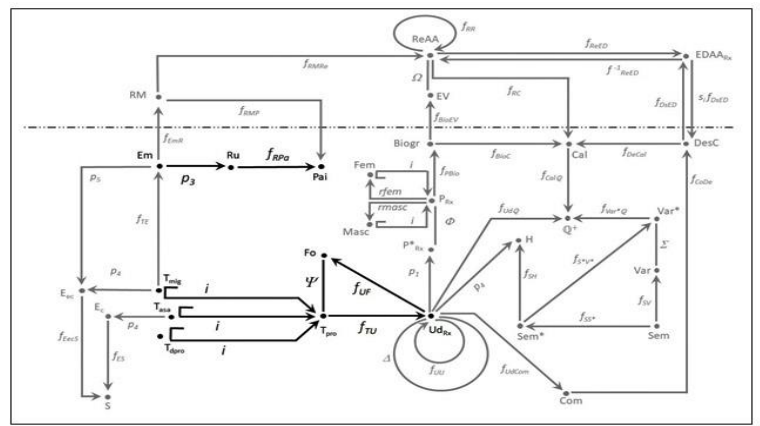

7. $i$ (dominio $\left.\mathrm{T}_{\text {dpro }}\right)$

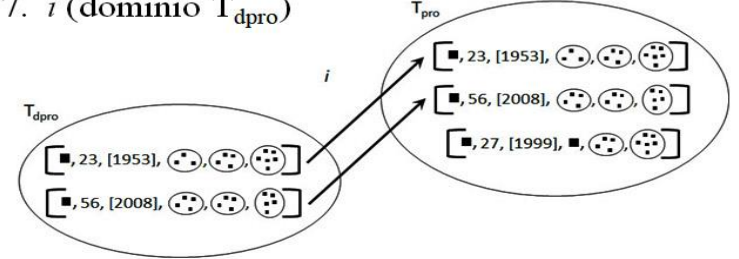

Dominio. $\mathrm{T}_{\text {dpro }} \equiv\{x / x$ es una serie compuesta de: i) una persona productiva (agricultor/artesano) de alguna unidad doméstica de la región $\mathrm{X}$ (un los últimos 150 años), que trabaja en las parcelas $\mathrm{y} / \mathrm{o}$ las industrias familiares de su unidad doméstica; ii) un número indicativo de la edad de esta persona; iii) un intervalo calendárico anual; iv) un conjunto de medios de producción; v) un conjunto de actividades económicas; y vi) un conjunto de saberes para realizar tales actividades $\}$ Codominio. $\mathrm{T}_{\text {pro }} \equiv\{x / x$ es una serie representativa de una persona productiva de alguna unidad doméstica de la región $\mathrm{X}$, en los últimos 150 años\}. Nota. $\mathrm{T}_{\text {pro }}=\mathrm{T}_{\text {dpro }} \cup \mathrm{T}_{\text {asa }} \cup \mathrm{T}_{\text {mig }}$ (ver incisos 3 y 4 de la figura X.1 para $\mathrm{T}_{\text {asa }} \mathrm{y} \mathrm{T}_{\mathrm{mig}}$ ). Mapeo. $i(x)=x$ la serie $x$ de $\mathrm{T}_{\text {dpro }}$ es la serie $x$ de $\mathrm{T}_{\text {pro }}\left(\mathrm{T}_{\mathrm{dpro}} \subseteq \mathrm{T}_{\text {pro }}\right)$.

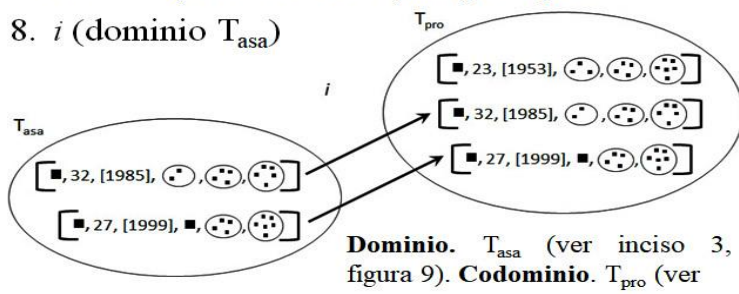

inciso 7, esta figura. Mapeo. $i(x)=x$ : la serie $x$ de $\mathrm{T}_{\text {asa }}$ es la serie $x$ de $\mathrm{T}_{\text {pro }}\left(\mathrm{T}_{\text {asa }} \subseteq \mathrm{T}_{\text {pro }}\right)$.

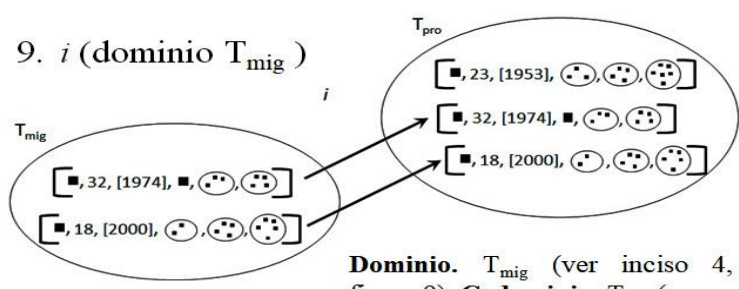
figura 9). Codominio. $\mathrm{T}_{\text {pro }}$ (ver

inciso 7, esta figura. Mapeo. $i(x)=x$ : la serie $x$ de $\mathrm{T}_{\text {mig }}$ es la serie $x$ de $\mathrm{T}_{\text {pro }}\left(\mathrm{T}_{\text {mig }} \subseteq \mathrm{T}_{\text {pro }}\right)$.

10. $p_{3}$ (dominio Em )

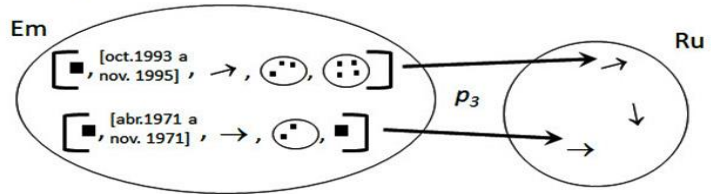

Dominio. Em (ver inciso 5, figura 9). Codominio. $\mathrm{Ru} \equiv\{y / y$ es una ruta migratoria $\}$. Mapeo. $p_{3}(x)=y$ : la serie $x$, representativa de una experiencia migratoria, tiene por tercera proyección la ruta migratoria $y$.

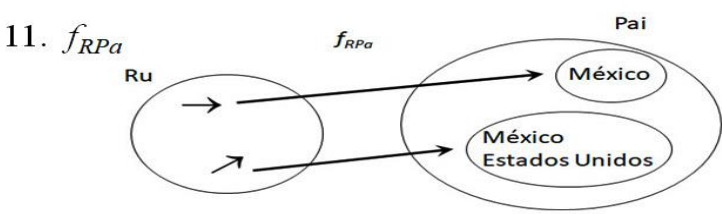

Dominio. $\mathrm{Ru}$ (ver inciso 10, esta figura). Codominio. Pai $\equiv$ $\{y / y$ es un conjunto de países $\}$. Mapeo. $f_{R P a}(x)=y$ : la ruta migratoria $x$ surca el conjunto de países $y$. Nota: Puede darse el caso de que $y$ es un conjunto de sólo un país (estos es, la ruta migratoria solo recorre un país).

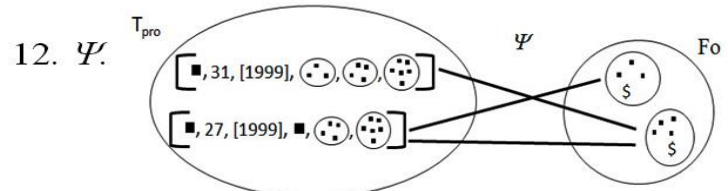

Dominio. $\mathrm{T}_{\text {pro }}$ (ver inciso 7, esta figura). Codominio. Fo $\equiv\{y$ / $y$ es un conjunto de bienes e ingresos monetarios de alguna unidad doméstica de la región $\mathrm{X}$ ( $y$ es el fondo anual de consumo, de reemplazo y de pago de obligaciones comunitarias y extra-comunitarias de alguna unidad doméstica)\}. Mapeo. $x \Psi y$ : la serie $x$-correspondiente a un determinado individuo productivo, con tal edad, en determinado año, etc.- contribuye al fondo $y$ de alguna unidad doméstica. Nota. La razón de estipular este vínculo como una relación se debe a que un individuo productivo puede contribuir a los fondos de dos o más unidades domésticas. Piénsese en un sujeto que contribuye parte de los frutos de su trabajo al fondo de la unidad doméstica a la que pertenece y parte al fondo de la unidad de los padres de su conyugue.

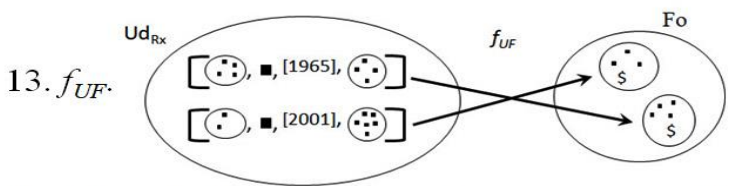

Dominio. $\mathrm{Ud}_{\mathrm{Rx}}$ Dominio. $\mathrm{Ud}_{\mathrm{Rx}} \equiv\{x / x$ es una unidad doméstica de la región $\mathrm{X}$ (últimos 150 años), por tanto $x$ es una serie compuesta por: i) un conjunto de personas (la familia que vive bajo el mismo techo, aunque cabe considerar también a los integrantes que hayan emigrado temporalmente); ii) una vivienda; iii) un intervalo anual (facilita la reconstrucción plantarlo como anual); y iv) un conjunto de medios de producción\}. Codominio. Fo (ver inciso 12 en esta figura). Mapeo. $f_{U F}(x)=y$ : el conjunto $y$ es el fondo de la unidad doméstica representada por la serie $x$. Nota. Puesto que en esta reconstrucción las unidades domésticas se están considerando año por año, cabe entender los conjuntos que componen a Fo como fondos anuales; en consecuencia, $f_{U F}$ tiene un inverso, $f_{U F}^{-1}$.

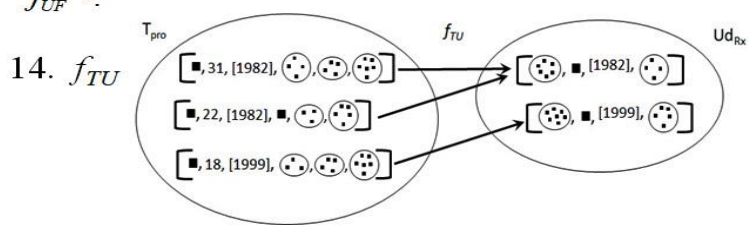

Dominio. $\mathrm{T}_{\text {pro }}$ (ver inciso 7 , esta figura). Codominio. $\mathrm{Ud}_{\mathrm{Rx}}$ (ver inciso 13, esta figura). Mapeo: $f_{T U}(x)=y$ : la serie $x$, representativa de una persona productiva de la región $\mathrm{X}$ (en los últimos 150 años) se corresponde con la unidad doméstica $y$, en tanto que la persona de la serie $x$ pertenece a esa unidad $y$.

Figura 10. Morfismos y relación: $i$ (dominios $\mathrm{T}_{\text {dpro }}, \mathrm{T}_{\text {asa }} \mathrm{y} \mathrm{T}_{\text {mig }}$ ), $p_{3}$ (dominio Em) $f_{R P a}, \Psi, f_{U F}$ y $f_{T U}$. Elaboración propia.

Perspectivas - Revista do Programa de Pós-Graduação em Filosofia da UFT - n. 2 - 2018 


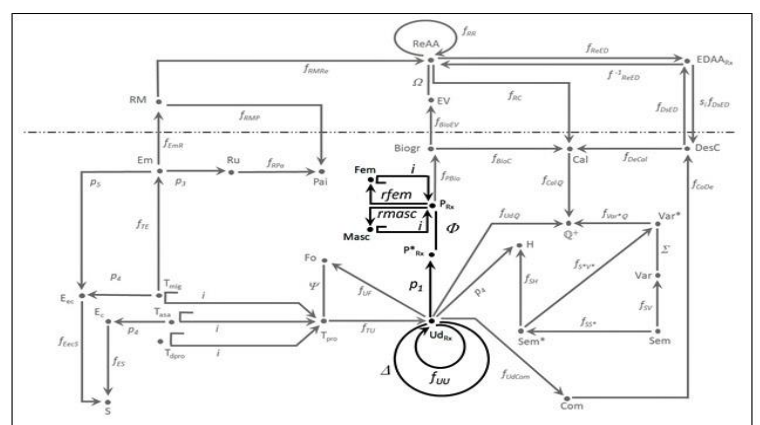

15. $f_{U U}$

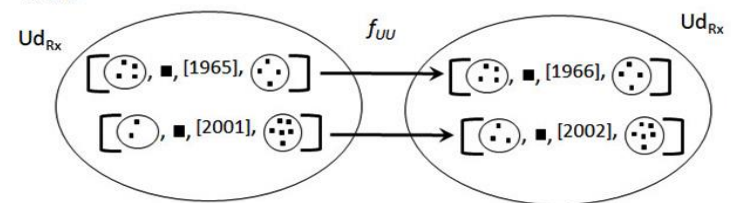

Dominio. $\mathrm{Ud}_{\mathrm{Rx}}$ (ver inciso 13 , figura 10). Codominio. $\mathrm{Ud}_{\mathrm{Rx}}$ (ver inciso 13, figura 10). Mapeo: $f_{U U}(x)=y$ : la serie $x$, correspondiente a una determinada unidad doméstica en un determinado año, da lugar a la serie $y$ que también se refiere a esa unidad, pero del año siguiente. Nota. En aras de poder mapear ciertos movimientos económicos, en esta reconstrucción se estipulan grupos familiares/residenciales por año. Ahora bien, visto en términos de la evolución de una familia que vive bajo un mismo techo, sin la parcelación anual antes dicha, la unidad doméstica es fundada por una pareja y con el transcurso del tiempo van agregándose nuevos integrantes - los hijos de la pareja original y luego, dado el caso, los conyugues de los hijos que van a residir con ellos en la casa de los padres. También hay deserciones, por llamarlas así: por ejemplo, cuando una hija se casa y va a vivir con la familia de su marido, etc; o cuando fallece algún miembro del hogar. La aplicación reiterada de $f_{U U}$ va siguiendo, año con año, un grupo familiar/residencial desde que se funda hasta que muera la pareja fundadora (mejor dicho, hasta que muera el integrante de ese par, que haya vivido más tiempo).

16. $A$.

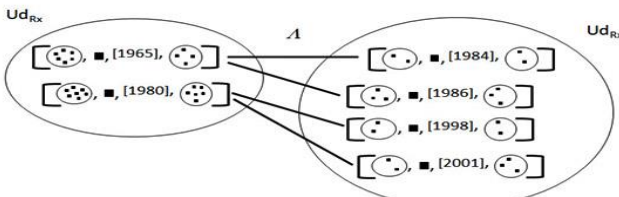

Dominio. $\mathrm{Ud}_{\mathrm{Rx}}$ (ver inciso 13, figura 10). Codominio. $\mathrm{Ud}_{\mathrm{Rx}}$ (ver inciso 13, figura 10). Mapeo. $x \Lambda y$ : la unidad doméstica representada por la serie $y$ desciende de la unidad doméstica representada por la serie $x$. Nota. Mientras que $f_{U}$ va siguiendo una familia/hogar de un año a otro, la relación $\Lambda$ vincula dos unidades domésticas de la región $\mathrm{X}$ si algún miembro de una de ellas ha nacido en el seno de la otra, incluso si desciende de alguien que haya nacido en el seno de la otra (de esta manera, $\Lambda$ es una relación transitiva). Esta relación se entabla cuando los hijos se van de la casa de sus padres para formar sus propios hogares, o una de las hijas se casa y va a vivir con la familia de su marido. Tal como se ha planteado la presente reconstrucción, también entra en juego $\Lambda$ cuando ambos padres mueren y uno de los hijos se hace cargo del

17. $p_{1}$ (dominio $\mathrm{Ud}_{\mathrm{Rx}}$ ).

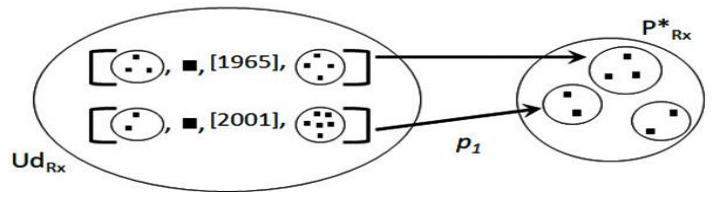

Dominio. $\mathrm{Ud}_{\mathrm{Rx}}$ (ver inciso 13 , figura 10 ). Codominio. $\mathrm{P}_{\mathrm{Rx}} \equiv$ $\{y / y$ es un grupo familiar/residencial, es un conjunto de personas que han vivido bajo el mismo techo en la región $\mathrm{X}$, en los últimos 150 años\}. Mapeo. $p_{1}(x)=y$ : la serie $x$, relativa a una determinada unidad doméstica, tiene por primera proyección el conjunto de personas $y$ (la familia que compone a esa unidad).

18. $\Phi$.

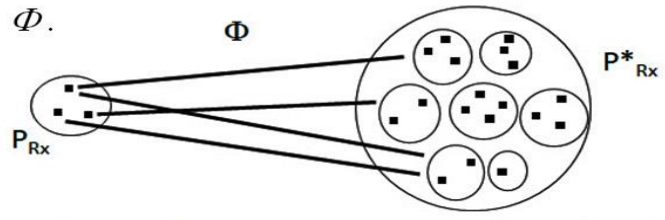

Dominio. $\mathrm{P}_{\mathrm{Rx}} \equiv\{x / x$ es una persona que ha vivido en la región $\mathrm{X}$, en los últimos 130 años $\}$. Codominio $\mathrm{P}_{\mathrm{Rx}}$ (ver inciso 17 , esta figura). Nota. $\mathrm{P}_{\mathrm{Rx}} \subset \operatorname{pot}\left(\mathrm{P}_{\mathrm{Rx}}\right)\left(\operatorname{pot}\left(\mathrm{P}_{\mathrm{R}_{\mathrm{x}}}\right)\right.$ es el conjunto potencia de $\mathrm{P}_{\mathrm{Rx}}$ : el conjunto de todos los subconjuntos de $\mathrm{P}_{\mathrm{Rx}}$ ). Mapeo. $x \Phi y:$ la persona $x$ pertenece al grupo de residencia familiar $y$. Nota. Una persona puede pertenecer a varios grupos de residencia familiar a lo largo de su vida, por eso se plantea que $\Phi$ es una relación.

\section{9. $i$ (dominio Mase)}

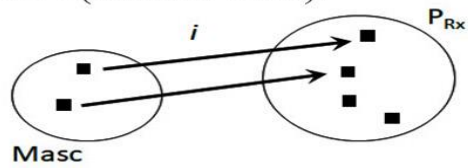

Dominio. Masc $\equiv$ $\{x / x$ es un varón que ha vivido en la región $\mathrm{X}$, en los últimos 150 años \}. Codominio. $\mathrm{P}_{\mathrm{Rx}}$ (ver inciso 18 , esta figura). Mapeo. $i(x)=x$ : el varón $x$ es la persona $x$ (la flecha indica que Masc es un subconjunto de $\left.\mathrm{P}_{\mathrm{Rx}}\right)$.

20. rmasc.

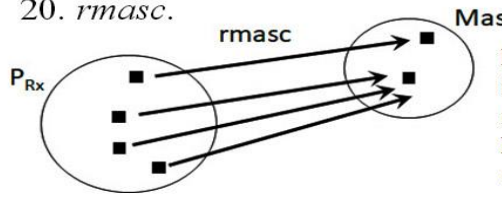

Dominio. $\mathrm{P}_{\mathrm{Rx}} \quad$ (ve inciso 18, esta figura). Codominio. Masc (ver inciso 19 esta figura). Mapeo.

$\operatorname{rmasc}(x)=y$ : a la persona $x$ le corresponde el varón $y$. Si $x$ es varón entonces $x=y$; si $x$ es mujer entonces $y$ es algún varón arbitrario de la región X. NOTA: rmasc es una retracción de $i$ $\left(1_{\text {Masc }}=\operatorname{rmasc}^{\circ} i\right)$. Por tanto, si $1_{P R_{x}}(x)=i^{\circ} \operatorname{rmasc}(x)$ entonces $x$ es varón. En cambio, si $1_{P R x}(x) \neq i{ }^{\circ} \operatorname{rmasc}(x)$ entonces $x$ es mujer.

21. rfem.

Dominio. $\mathrm{P}_{\mathrm{Rx}} \quad$ (ver

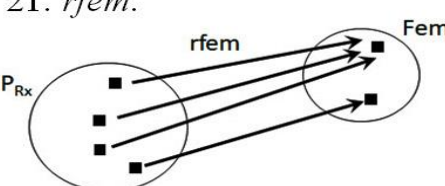
inciso 18 , esta figura). Codominio. Fem $\equiv\{y / y$ es una mujer que ha vivido en la región $\mathrm{X}$, en los últimos 150 años

Mapeo. $\operatorname{rfem}(x)=y$ : a la persona $x$ le corresponde la mujer $y$. Si $x$ es mujer entonces $x=y$; si $x$ es varón entonces $y$ es alguna mujer arbitraria de la región $\mathrm{X}$.

\section{2. $i$ (dominio Fem)}

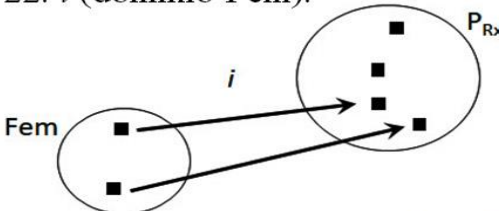

Rx Dominio. Fem (ver inciso 21, esta figura. Codominio. $\mathrm{P}_{\mathrm{R}}$ (ver inciso 18 en esta figura. Mapeo. $i(x)=y$ : la mujer $x$ es la persona $y$ (la flecha indica que Fem es un subconjunto de $\mathrm{P}_{\mathrm{R}_{\mathrm{x}}}$ ). NOTA: $r$ fem es una retracción de $i$ en el inciso $21\left(1_{\mathrm{Fem}}=\mathrm{rfem}^{\circ} i\right)$. Por tanto, si $1_{P R x}(x)=i \circ \mathrm{rfem}(x)$ entonces $x$ es mujer. En cambio, si $1_{P R x}(x) \neq i$ 。 rfem $(x)$ entonces $x$ es varón.

Figura 11. Morfismos y relaciones: $f_{U U}, \Lambda, p_{I}$ (dominio $\mathrm{Ud}_{\mathrm{Rx}}$ ), $\Phi . i$ (dominios Masc y Fem), rmasc y rfem. Elaboración propia. 


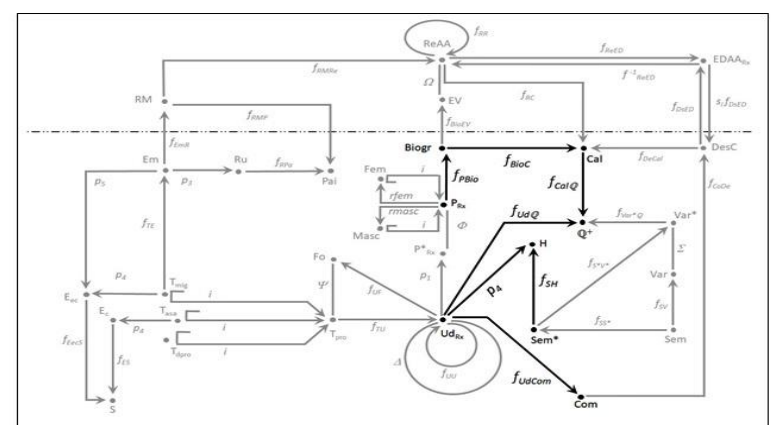

23. $f_{P B i o}$.

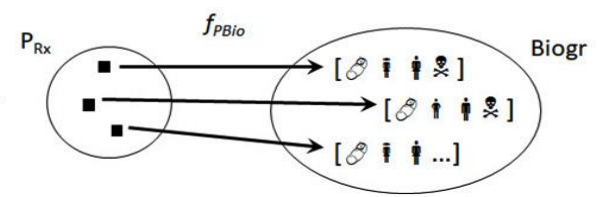

Dominio. $\mathrm{P}_{\mathrm{Rx}}$ (ver inciso 18, figura 11). Codominio. Biogr $\equiv$ $\{y / y$ es la biografia de alguna persona de la región $\mathrm{X}$, de los últimos 150 años\}. Mapeo. $f_{P B i o}(x)=y$; a la persona $x$ le corresponde la biografía $y$. Nota. En la viñeta alusiva al diagrama interno de $f_{P B i o}$ se representan las biografias como secuencias de fases de vida (nacimiento, juventud, adultez y, en su caso, muerte), pero eso es sólo con fines ilustrativos.

24. $f_{\text {BioC }}$

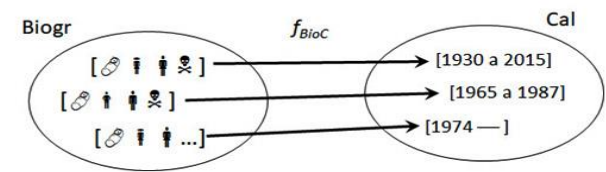

Dominio. Biogr (ver inciso 23, en esta figura). Codominio. $\mathrm{Cal} \equiv\{y / y$ es un intervalo calendárico de los últimos 150 años\}. Nota. Los integrantes de Cal pueden ser intervalos calendáricos de diversa extensión, desde un año a varias décadas). Mapeo. $f_{B i o C}(x)=y$ : a la biografia $x$ le corresponde el intervalo calendárico $y$ (el intervalo que abarca la vida de la persona cuya biografia es $x$ )

25. $f_{\text {Cal } \mathbb{Q}}$

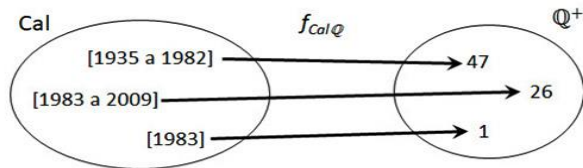

Dominio. Cal (ver inciso 24, en esta figura). Codominio. $\mathbb{Q}^{+} \equiv$ $\{y / y$ es un número racional mayor a cero $\}$. Mapeo. $f_{\text {CalQ }}(x)=$ $y$ : el intervalo calendárico $x$ dura $y$ número de años (dado el caso, $x$ puede durar $y$ número de años y fracción de año: por ejemplo, el intervalo [ 1 de enero de 1980 a 30 de junio de 1990] dura 10.5 años).

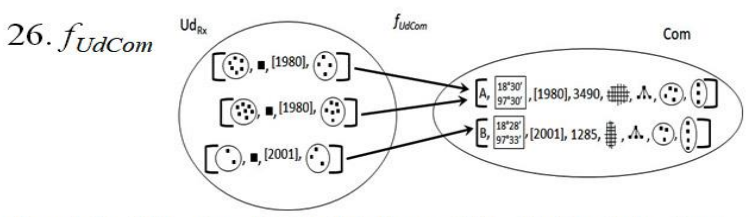

Dominio. $\mathrm{Ud}_{\mathrm{Rx}}$ (ver inciso 13 , figura 10 ). Codominio. Com $\equiv$ $\{y / y$ es una comunidad de la región $\mathrm{X}$, descrita por una serie compuesta de: i) el nombre de la comunidad; ii) la localización geográfica de ella; iii) el año en que es considerada; iv) el número de habitantes en ese año; v) la traza de la comunidad en ese año (distribución de casas, comercios, edifícios públicos, terrenos agrícolas, terrenos de uso común); vi) la estructura del gobierno comunitario (en ese año); vii) un conjunto de otras asociaciones comunitarias (activas en ese año); viii) un conjunto de normas comunitarias (vigentes en ese año)\}. Mapeo. $f_{\text {UdCom }}(x)=y$ : la unidad doméstica representada por la serie $x$ se ubica en la comunidad representada por la serie $y$. Debe subrayarse que el intervalo calendárico contenido en la serie $x$ es igual al intervalo contenido en la serie $y$; dicho de otro modo, $p_{3}(x)=p_{3}(y)$

\section{7. $p_{4}$ (dominio $\left.\mathrm{Ud}_{\mathrm{Rx}}\right)$}

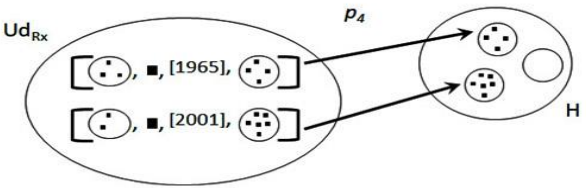

Dominio. $\mathrm{Ud}_{\mathrm{Rx}}$ (ver inciso 13 , figura 10 ). Codominio. $\mathrm{H} \equiv$ $\{y / y$ es un conjunto de medios de producción (terrenos cultivables, animales de tiro, semillas, herramientas agrícolas y/o herramientas para elaborar artesanías, etc.) que emplea alguna unidad doméstica durante una temporada agrícola/artesanal\}. Nota. Nótese que en la viñeta la colección $\mathrm{H}$ contiene un conjunto vacío: esto es así para dar cabida a hogares que ya no cuentan con tierras de labor o talleres artesanales, pues sus integrantes están completamente proletarizados. Mapeo. $p_{4}(x)=y$ : la serie $x$ (la cual es constitutiva de una unidad doméstica) tiene por cuarta proyección un conjunto de medios de producción $y$.

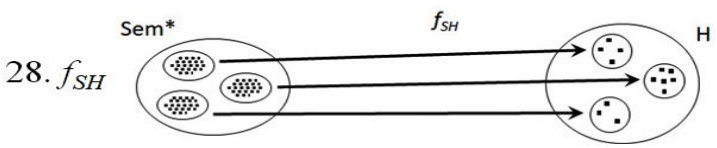

Dominio. Sem* $\equiv\{x / x$ es un conjunto de semillas, (que se corresponde con la colección total de semillas para sembrar que posee alguna unidad doméstica de la región $\mathrm{X}$, de los últimos 150 años)\}. Codominio. H (ver inciso 27 en esta figura). Mapeo. $f_{S H}(x)=y$ : el conjunto de semillas $x$ forma parte del conjunto de medios de producción $y$.

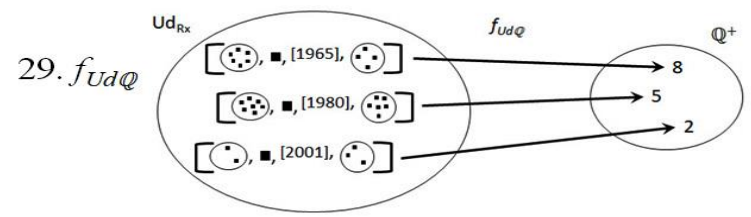

Dominio. $\mathrm{Ud}_{\mathrm{R}_{\mathrm{x}}}$ (ver inciso 13 , figura 10 ). Codominio. $\mathbb{Q}^{+} \equiv$ $\{y / y$ es un número racional mayor a cero $\}$. Mapeo. $f_{U d \mathbb{Q}}(x)$ $=y$ : la unidad doméstica representada por la serie $x$ se corresponde con el número racional $y$, el cual es el valor de un índice de agrobiodiversidad. Nota. Existen diversos índices de agrobiodiversidad, cuyos valores se pueden corresponder con los números naturales, o bien con los números racionales mayores o iguales a cero. Aquí se han privilegiado los segundos, pues los naturales están incluidos entre ellos. A fin de cuentas lo que se pretende destacar es la diversidad de variedades distintas que siembra alguna unidad doméstica: si dicho valor es un número natural, también es un número racional positivo.

Figura 12. Morfismos: $f_{P B i o}, f_{B i o C}, f_{C a l Q}, f_{U d C o m}, p_{4}\left(\right.$ dominio $\left.\mathrm{Ud}_{\mathrm{Rx}}\right), f_{S H}$ y $f_{U d \mathrm{Q}}$. Elaboración propia. 

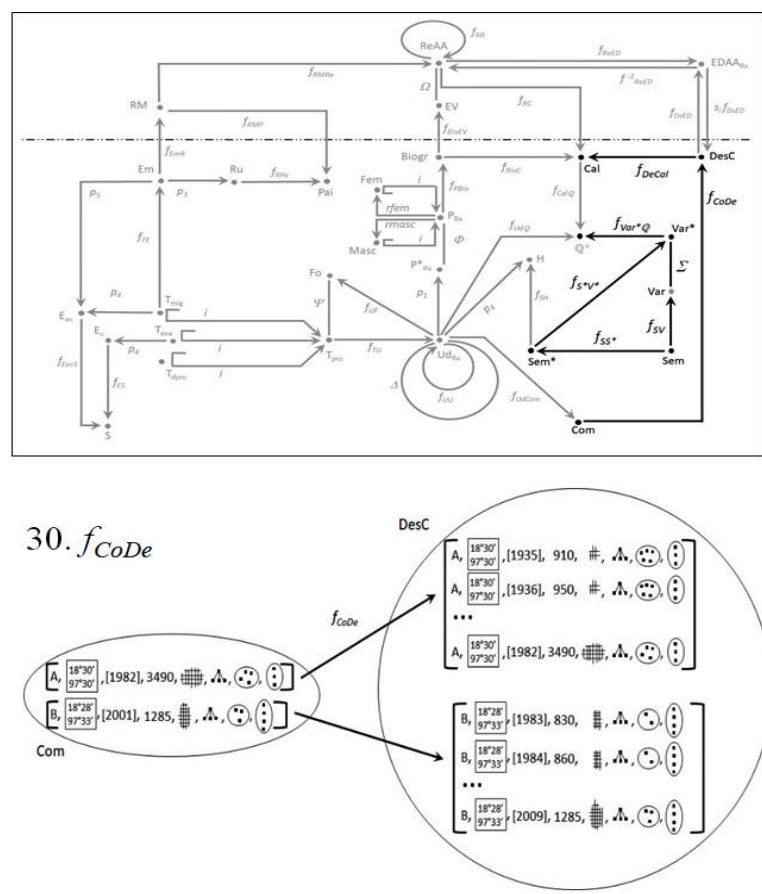

Dominio. Com (ver inciso 26, figura 12). Codominio. DesC $\equiv$ $\{y / y$ es una serie de a series de Com, tal que todas las series que integran a $y$ se refieren a la misma comunidad, pero cada serie de $y$ se refiere a un año distinto, de modo que la serie de series $y$ recorre varios años consecutivos, desde el año correspondiente al primer integrante de $y$ hasta el año correspondiente al último integrante de $y$ \}. Nota. Cabría entender DesC como un conjunto de desarrollos comunitarios. Mapeo. $f_{C o D e}(x)=y$; la serie $x$, representativa de una determinada comunidad en determinado año, forma parte de la serie de series $y$, la cual representa el desarrollo de esa comunidad de tal año a tal año. Nota. Plantear el mapeo de este modo implica que en DesC no hay desarrollos comunitarios "solapados", es decir, que un elemento de Com no puede ser constitutivo de dos elementos de DesC.

31. $f_{S S^{*}}$

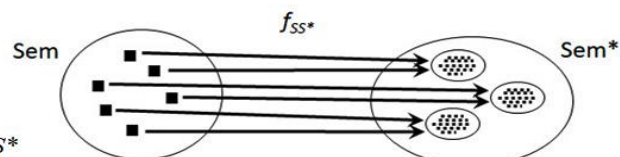

Dominio. Sem $\equiv\{x / x$ es una semilla de alguna planta que se ha cultivado en la región $\mathrm{X}$, en los últimos 150 años\}. Codominio. Sem* (ver inciso 28 , figura 13). Mapeo. $f_{S S^{*}}(x)=$ $y$ : la semilla $x$ está incluida en el conjunto de semillas $y$ del que dispone alguna unidad doméstica de la región $\mathrm{X}$ para sembrar.

32. $f_{S V}$

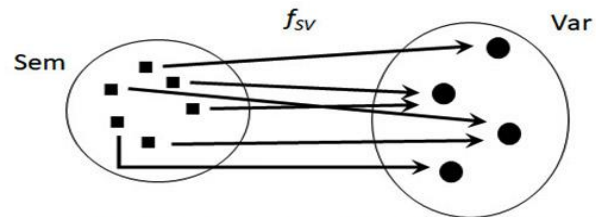

Dominio. Sem (ver inciso 31, en esta figura). Codominio. Var $\equiv\{y / y$ es una variedad de alguna especie de planta cultivable $\}$. Mapeo.. $f_{S V}(x)=y$ : la semilla $x$ es de la variedad $y$.

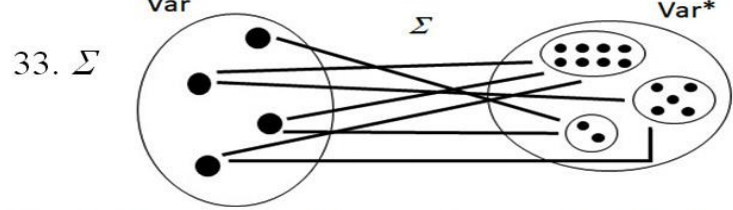

Dominio. Var (ver inciso 32 en esta figura). Codominio. Var* $\equiv\{y / y$ es un conjunto de variedades que siembra $\mathrm{y} / \mathrm{o}$ ha sembrado alguna unidad doméstica de la región $\mathrm{X}$ durante los últimos 150 años\}. Mapeo. $x \Sigma y$ : la variedad $x$ está incluida en el conjunto de variedades $y$.

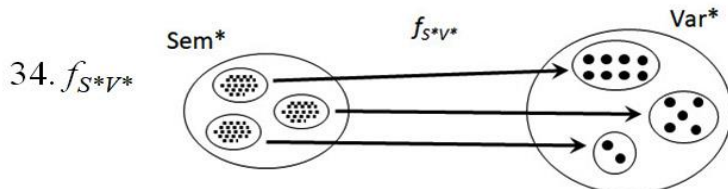

Dominio. Sem* (ver inciso 28, figura 12). Codominio: Var* (ver inciso 33, en esta figura). Mapeo. $f_{S^{*} V^{*}}(x)=y$; el conjunto de semillas $x$ se corresponde con el conjunto de variedades $y$.

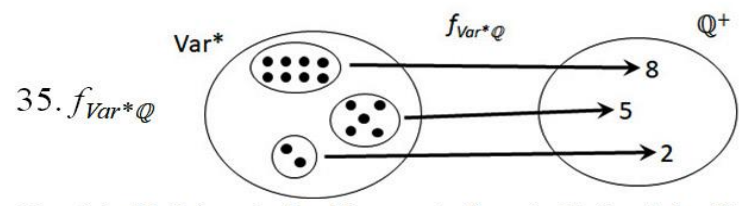

Dominio.Var* (ver inciso 33, en esta figura). Codominio. $\mathbb{Q}^{+}$ (los números racionales positivos, ver inciso 25, figura 13). Mapeo: $f_{\text {Var*o }}(x)=y$; el conjunto de variedades $x$ contiene $y$ número de variedades distintas.

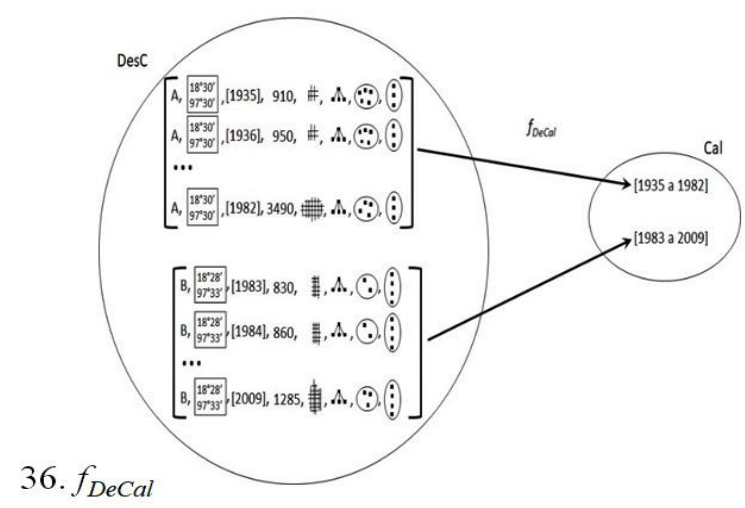

Dominio. DesC (ver inciso 30, en esta figura). Codominio. $\mathrm{Cal}$ (ver inciso 24, figura 12; recuérdese que los integrantes de Cal pueden ser intervalos calendáricos de diversa extensión, desde un año a varias décadas). Mapeo. $f_{\text {DeCal }}(x)=y$ : la serie de series $x$, representativa de un desarrollo comunitario, se corresponde con el intervalo calendárico $y$ (el intervalo de años correspondientes a las series que integran a $x$ ).

Figura 13. Morfismos y relación; $f_{C o D e}, f_{S S^{*}}, f_{S V}, \Sigma, f_{S^{*} V^{*}}, f_{V a r}{ }^{*} \mathrm{Q}$ y $f_{\text {DeCal }}$. Elaboración propia.

Perspectivas - Revista do Programa de Pós-Graduação em Filosofia da UFT - n. 2 - 2018 

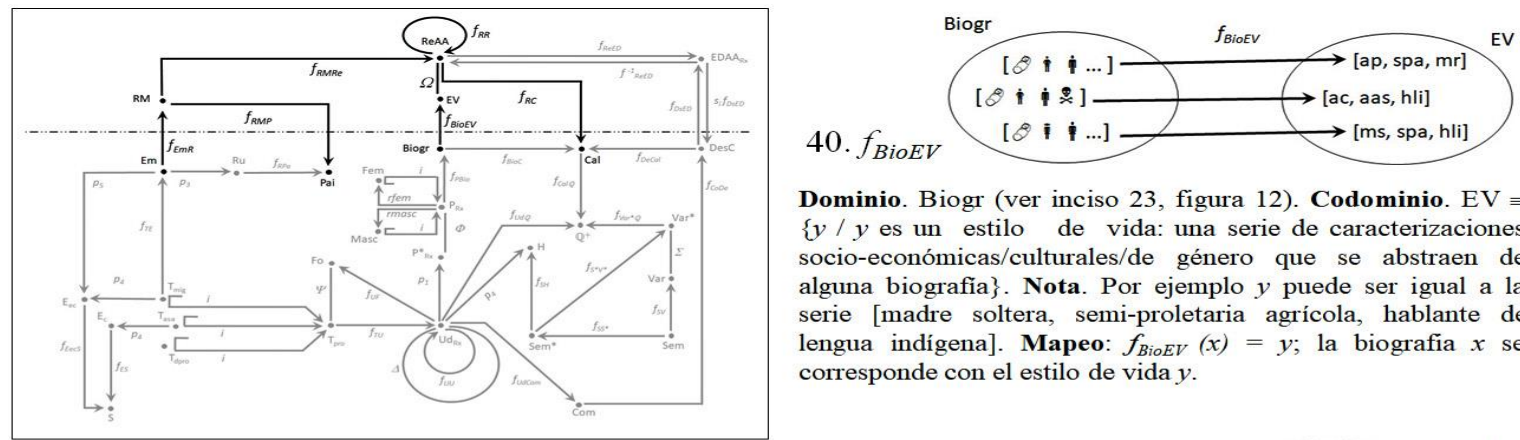

Dominio. Biogr (ver inciso 23, figura 12). Codominio. EV $\equiv$ $\{\boldsymbol{y} / \boldsymbol{y}$ es un estilo de vida: una serie de caracterizaciones socio-económicas/culturales/de género que se abstraen de alguna biografia\}. Nota. Por ejemplo $y$ puede ser igual a la serie [madre soltera, semi-proletaria agrícola, hablante de lengua indigena]. Mapeo: $f_{\text {BioEV }}(x)=y$; la biografia $x$ se corresponde con el estilo de vida $y$.
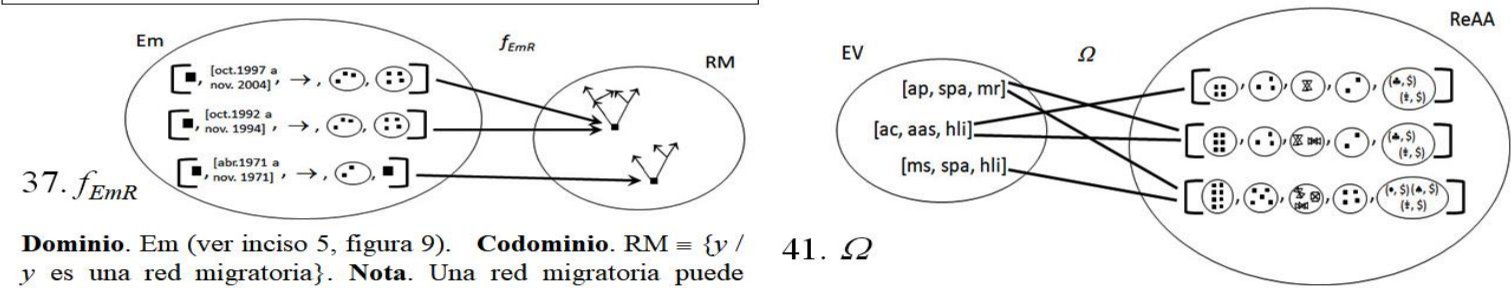

Dominio. Em (ver inciso 5, figura 9). Codominio. $\mathrm{RM} \equiv\{y\}$ $y$ es una red migratoria\}. Nota. Una red migratoria puede entenderse como un patrón emergente de la composición de rutas que siguen emigrados de la región $\mathrm{X}$, durante un periodo definido de años (por ejemplo, el patrón emergente de la composición de rutas de todas las experiencias migratorias (de personas oriundas de la región $\mathrm{X}$ ) de la década de los noventa del siglo XX). Mapeo. $f_{E m R}(x)=y$ : la serie $x$, representativa de una determinada experiencia migratoria, se corresponde con la red migratoria $y$. Nota. Otra manera de expresar lo anterior es que la ruta correspondiente al tercer integrante de la serie $x$ forma parte de la red migratoria $y$.

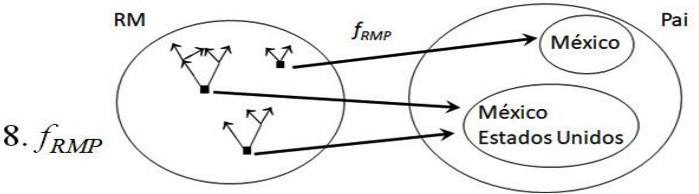

Dominio. RM (ver inciso 37, en esta figura). Codominio. Pai (ver inciso 11, figura 12). Mapeo. $f_{R M P}(x)=y$; la red migratoria $x$ recorre el conjunto de países $y$.

39. $f_{R M R e}$

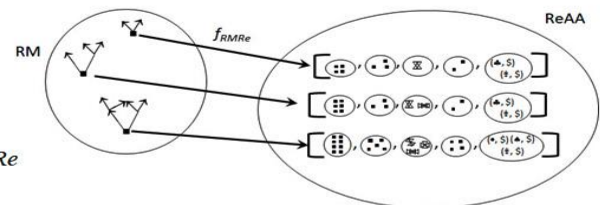

Dominio. RM (ver inciso 37 en esta figura). Codominio. $\operatorname{ReAA} \equiv\{y / y$ es un régimen agro-alimentario, esto es, una serie compuesta de: i) un conjunto de acuerdos y reglamentos sobre la producción y comercio alimentario (internacionales, nacionales y regionales; incluye normas sobre la propiedad agraría); ii) un conjunto de centros productores mundiales de alimentos; iii) un conjunto de redes de distribución mundiales de alimento; iv) un conjunto de tecnologías de producción y conservación de alimentos; v) un conjunto de pares (signo o nombre de alimento, precio mundial estable)\}. Mapeo. $f_{R M R}$ $(x)=y$ : la red migratoria $x$ se corresponde con el régimen agro-alimentario $y$. Nota. Los regímenes agro-alimentarios influyen en la configuración de redes migratorias, por eso cabe mapear dichas redes a tales regímenes. La viñeta alusiva al diagrama interno parece sugerir que $f_{R M R e}$ es un isomorfísmo (una red por cada régimen), pero esto es un mero artefacto ilustrativo pues es posible que existan varias redes que parten de una misma región y se correspondan con el mismo régimen agro-alimentario.

\section{2. $f_{R R}$}

Dominio. EV (ver inciso 40 en esta figura). Codominio. ReAA (ver inciso 39, en esta figura). Mapeo. $x \Omega y$ : el estilo de vida $x$ es generado por o congruente con el régimen agro-alimentario $y$. Nota. A pesar de que los regímenes agro-alimentarios imponen estilos de vida a los productores de alimento, $\Omega$ se plantea como una relación y no como un morfísmo pues existe la posibilidad de que algún estilo de vida perdure al pasar de un régimen agro-alimentario a otro. Semi-proletarios agrícolas indígenas existen en la actualidad y también existían en la década de los sesenta del siglo pasado, aunque según McMichaels estos dos periodos se corresponden con regímenes distintos. Sin embargo, Fitting señala que, bajo lo que ella llama el régimen neo-liberal del maíz, en San José Miahuatlán las mujeres están ocupando roles que antes eran competencia exclusiva de los varones, lo cual indica el surgimiento de un nuevo estilo de vida femenino que era inexistente o marginal en épocas anteriores, por lo menos en el sur del valle de Tehuacán.

Dominio. ReAA (ver inciso 39. en esta figura). Codominio. ReAA (ver inciso 39, en esta figura). Mapeo. $f_{R P}(x)=y$ : el régimen agro-alimentario $y$ sucede al régimen agro-alimentario $x$. Nota. Puesto que el régimen actual aún no tiene sucesor, $f_{R R}$ lo mapea a sí mismo.

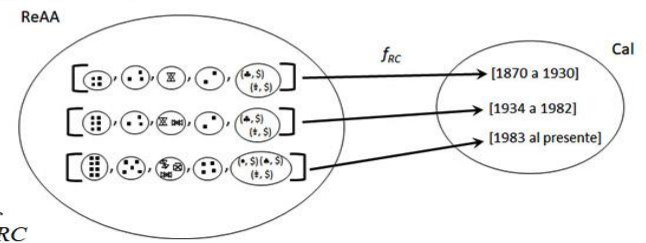

43. $f_{R C}$

Dominio. ReAA (ver inciso 39 , en esta figura). Codominio. Cal (ver inciso 24, figura 13). Mapeo. $f_{R C}(x)=y$; a la serie $x$, indicativa de un determinado régimen agro-alimentario, le corresponde el intervalo calendárico $y$. Nota. El intervalo abarca el surgimiento, consolidación y declive del régimen en cuestión.

Figura 14. Morfismos y relación: $f_{E m R}, f_{R M P}, f_{R M R e}, f_{B i o E V}, \Omega, f_{R R}$ y $f_{R C}$. Elaboración propia.

Perspectivas - Revista do Programa de Pós-Graduação em Filosofia da UFT - n. 2 - 2018 

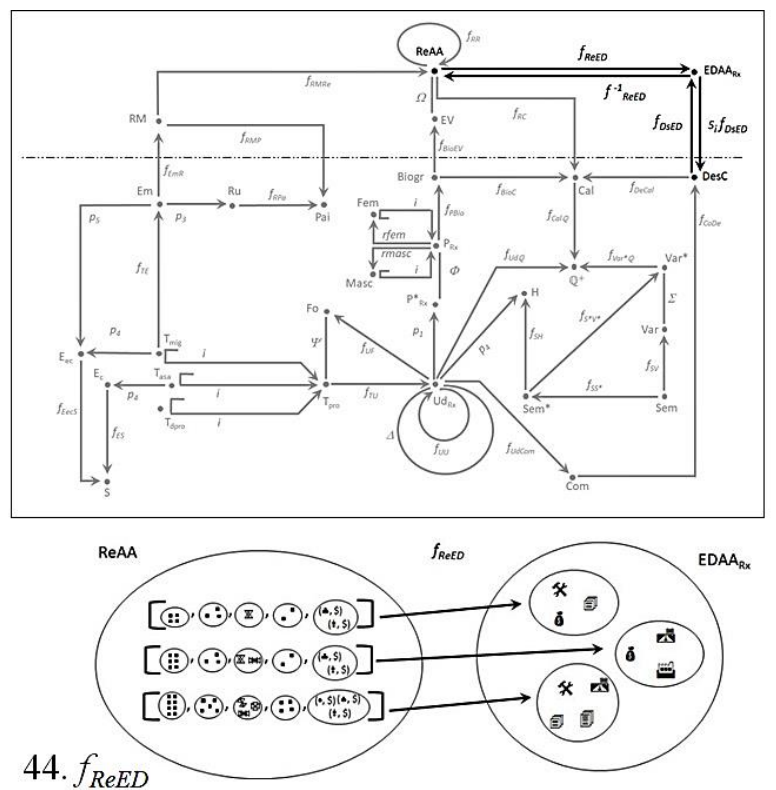

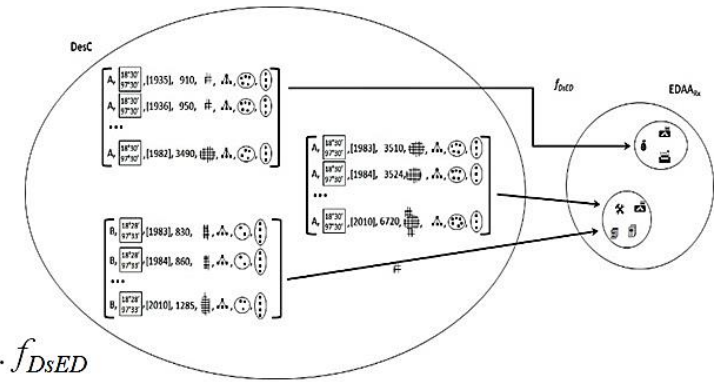

Dominio. DesC (ver inciso 30, figura 13). Codominio. $\mathrm{EDAA}_{\mathrm{Rx}}$ (ver inciso 44 en esta figura). Mapeo. $f_{D s E D}(x)=y$ : la serie $x$, representativa de un desarrollo comunitario, se corresponde con el conjunto de proyectos y procesos $y$. Nota. El morfimso $\quad s_{i} f_{D_{s} E D}$ es una sección (ver figura 3, panel 3.3) de $f_{D_{s} E D}$; se incluye en la figura 8 pues las secciones de $f_{D S E D}$ vinculan efectos en la región $\mathrm{X}$ de algún régimen agroalimentario con desarrollos comunitarios específicos.

Dominio: ReAA (ver inciso 39, figura 14). Codominio: $\operatorname{EDAA}_{\mathrm{Rx}} \equiv\{y / y$ es un conjunto de proyectos de infra-estructura realizados y procesos económicos operantes, vinculados con la producción, transporte y distribución de alimentos en la región $\mathrm{X}$, que se ejecutaron o acontecieron durante el periodo correspondiente a algún régimen agro-alimentario $\}$ Nota. $y$ es el conjunto de impactos, en la región $\mathrm{X}$, de la dinámica de algún régimen agro-alimentario. Mapeo. $f_{\text {ReED }}(x)=y$ : la serie $x$, indicativa de un régimen agro-alimentario determinado, genera (o generó) el conjunto de proyectos y procesos $y$. Nota: $f_{\text {ReED }}^{-1}$ es la inversa (ver figura 3, panel 3.1) de $f_{\text {ReED }}$.

Figura 15. Morfismos $f_{R e E D}, f_{R e E D}{ }^{-1}, f_{D s E D}$ y $s_{i} f_{D s E D}$. Elaboración propia.

convenido "temporalizar" por año a las unidades domésticas. En cambio, si $x$ es una serie representativa de una experiencia migratoria, esto es, $x \in$ Em entonces la expresión $f_{\text {CalQ }}$ 。 $p_{2}(x)=3.5$ indica que la experiencia representada por $x$ tuvo una duración de 3 años y seis meses (la segunda proyección de $x$ es un intervalo calendárico, ver figura 6.B).

Respecto de las redes migratorias, RM, la explicación que se da en el inciso 37, figura 14, señala que dichas tramas son patrones emergentes de las rutas de múltiples experiencias migratorias. Ahora bien, puede darse el caso de que una experiencia se mapea a una red, pero la ruta correspondiente a la primera abarca solo una porción de la segunda. Imagínese que, durante un periodo histórico determinado, los itinerarios de los migrantes salidos de la región X trazan una red que abarca Baja California Norte y el sudoeste de California. Bien puede darse el caso de una experiencia migratoria que sólo llega hasta la frontera MéxicoEstados Unidos, pero no la cruza; sin embargo, el patrón que emerge de todas las experiencias consideradas dibuja una red que traspasa la frontera.

En lo concerniente a la saeta $f_{R C}$ (ver inciso 43, figura 14), cabe notar que el intervalo al que se mapea un determinado régimen agroalimentario abarca el surgimiento, consolidación y declive de este. Ciertamente hay algo que se antoja simplista en cómo el reconstructor concibe este mapeo, pues parece sugerir que un determinado régimen tiene un

Perspectivas - Revista do Programa de Pós-Graduação em Filosofia da UFT - n. 2 - 2018 
año preciso de inicio y un año preciso de término. Por supuesto, no es así: la periodización que ofrece McMichael (2014), por ejemplo, es más bien borrosa, en cuanto a los comienzos y fines de los tres regímenes que describe. El británico, por mencionar uno, mantiene estable el precio mundial del trigo entre 1870 y 1913, pero en diversos pasajes el autor plantea que dicho régimen perdura, aunque ya en proceso de deterioro, todavía en la década de los veinte del siglo pasado. Sería posible incluir tales emborronamientos en la reconstrucción -quizá incluyendo objetos y morfismos de la categoría de conjuntos difusos, o algo por el estilopero se introduciría una complicación técnica que el reconstructor no domina bien. Por eso, aquí se ha optado por una aproximación simplista respecto del mapeo $f_{R C}$.

Parte importante del poder explicativo de MdF descansa en la composición de mapeos y la conformación de rutas conmutativas (rutas que convergen en los mismos elementos al interior de un nodo), sobre todo los trayectos que vinculan componentes arriba de la línea punteada de la figura 8 con nodos por debajo de dicha demarcación. En la siguiente sección (6. Rutas inferenciales destacadas del $\mathrm{MdF}$ ) se abundará sobre esto, pero por lo pronto conviene adelantar cuatro ejemplos, los cuales ilustran las constricciones a las que está sujeto MdF. En cada caso se presenta primero, a modo de fórmulas, las composiciones de mapeos pertinentes y luego una explicación en lenguaje natural, con indicaciones entre paréntesis respecto del lugar, en las figuras anteriores, donde se desglosan los morfismos en cuestión.

Si $y=f_{U F} \circ f_{T U}(x)$ entonces $x \Psi y$. Dicho de otro modo: si la serie $x$, representativa de una persona productiva, se mapea a una determinada unidad doméstica $\left(f_{T U}\right.$ inciso 14 , figura 10) y a dicha unidad le corresponde el fondo de consumo y ( $f_{U F}$, inciso 13, figura 10), entonces la persona productiva en cuestión contribuye a ese fondo (relación $\Psi$, ver inciso 12, figura 10). Ahora bien, la fórmula es inválida en MdF si se invierten antecedente y consecuente: si $x \Psi y$ entonces $y=f_{U F} \circ f_{T U}(x)$ no necesariamente se sostiene, pues la persona aludida en la serie $x$ también puede contribuir a fondos de hogares a los que no pertenece, como se explica en el inciso 12 de la figura 10.

Si $f_{T U} \circ i \circ 1_{\text {Tdpro }}(x)=y$, entonces $p_{4}(x) \subseteq p_{4}(y)$. En otras palabras: si $x$ es una serie representativa de un determinado agricultor/artesano y y es la unidad doméstica correspondiente a ese agricultor/artesano $\left(f_{T U}\right.$-ver incisos 14 , figura 10 - mapea personas productivas a unidades domésticas, e $i \circ 1_{\text {Tdpro }}(x)$ establece que $x$ está en el dominio de $f_{T U}-$ ver figuras 2 y 4 para repasar las nociones de morfismo de identidad y morfismo de inclusión-), entonces los medios de producción que emplea la persona correspondiente con 
la serie $x\left(p_{4}(x)\right.$, ver figura 6.A) son medios de producción de los que dispone la unidad doméstica $y\left(p_{4}(y)\right.$, ver figura 5.A), unidad a la que pertenece dicha persona. Nótese que la expresión $p_{4}(x) \subseteq p_{4}(y)$ no obliga a que el sujeto en cuestión emplee todos los medios que dispone su unidad doméstica, puede emplear solo una parte de ellos (por ejemplo, es posible que una determinada herramienta o terreno que posee la unidad no se use en un determinado año; o el sujeto en cuestión es el artesano de la familia y, por tanto, no utiliza los aperos de labranza del grupo residencial).

$$
\text { Si } f_{S H}(y)=p_{4} \circ 1_{U d_{R x}}(x) \text {, entonces } f_{U d Q}(x)=f_{V a r^{*}} \circ f_{S^{*} V^{*}}(y) \text {. En términos más }
$$

coloquiales: si el conjunto de semillas para sembrar, $y$, forma parte del conjunto de medios de producción del que dispone la unidad doméstica representada por la serie $x\left(f_{S H}\right.$-inciso 28, figura 12- mapea conjuntos de semillas a conjuntos de medios de producción; la expresión $1_{U d_{R x}}(x)$ delata que $x$ es una serie representativa de una determinada unidad doméstica, y la cuarta proyección de esa serie, $p_{4}$, es el conjunto de medios de producción del que dispone la unidad en cuestión -ver figura 5.A-), entonces la agrobiodiversidad que maneja la unidad representada por $x$ se corresponde con la cantidad de variedades distintas que contiene el conjunto de semillas y $\left(f_{U d Q}\right.$-inciso 29, figura 12- mapea series representativas de unidades domésticas a índices de agrobiodiversidad; $f_{S^{*} V^{*}}$-inciso 34 , figura 13-asigna conjuntos de semillas a conjuntos de variedades; y $f_{\text {Var }} * \mathrm{Q}$-inciso 35 , figura 13- destina conjuntos de variedades a números indicativos de agrobiodiversidad).

$f_{\text {DeCal }}=f_{R C} \circ f_{R e E D}{ }^{-1} \circ f_{D S E D}$. En palabras llanas: la asignación de desarrollos comunitarios a intervalos calendáricos ( $f_{\text {DeCal }}$, ver inciso 36, figura 13) es igual a la composición de mapeos que lleva los desarrollos comunitarios a regímenes agroalimentarios y de allí a los intervalos calendáricos correspondientes a dichos regímenes ( $f_{D S E D}-$ inciso 45 , figura 15- asigna desarrollos comunitarios a conjuntos de dinámicas económicas que han operado en la región $\mathrm{X}$, en los últimos 150 años; $f_{R e E D}{ }^{-1}$-inciso 44, figura 15- mapea conjuntos de dinámicas económicas a regímenes agroalimentarios, en tanto que identifica de qué régimen es consecuencia tal o cual conjunto de dinámicas locales; $f_{R C}$-inciso 43 , figura 14- destina regímenes agroalimentarios a intervalos calendáricos). ${ }^{7}$

\footnotetext{
${ }^{7}$ Ciertamente la temporalidad de los desarrollos comunitarios es un artefacto de la presente reconstrucción, en aras de hacerlos compatibles con regímenes agroalimentarios. Nuevamente, sale a colación el problema de periodizar con límites estrictos lo que en el libro de Fitting se antoja más como periodizaciones con límites difusos. No es que la idea de desarrollos comunitarios, como se propone en esta reconstrucción, esté ausente en The Struggle for Maize: la autora sí plantea que el desarrollo social de San José Miahuatlán -la comunidad donde realizó la mayor parte de su trabajo de campo-, ha seguido un curso distinto bajo el régimen de maíz neoliberal, que el curso seguido previo a la imposición de dicho régimen; y ubica la transición en los años Perspectivas - Revista do Programa de Pós-Graduação em Filosofia da UFT - n. 2 - 2018
} 


\section{Rutas inferenciales destacadas del MdF}

La figura 8 y listado de explicaciones que le siguen dota al esquema de una interpretación general que no necesariamente es privativa de la situación del sur del valle de Tehuacán, aunque Fitting haya privilegiado esta zona para realizar su trabajo de campo. Como ya se ha dicho, al abstraer el lugar del cual se versa a una región indeterminada X, el armazón interpretado abre la posibilidad de explorar si el modelo se puede aplicar a otras regiones y/o comunidades de México y el mundo. Sin embargo, dicha estructura, aun con las aclaraciones no plantea algo concreto acerca de las dinámicas atinentes a las entidades y relaciones que engarza. La concreción surge al destacar las rutas inferenciales que permite MdF, y ya se han dado algunos ejemplos al respecto. Sin embargo, los senderos más sustantivos comparan personas, unidades domésticas y otros ítems. Ponerlas de realce se facilita mediante la presentación de diagramas derivados del de la figura 8, gracias a la composición de morfismos y, muy especialmente, mediante el uso del singulete (ver figura 4, panel 4.1). Considérese el enunciado a continuación, que no es una cita textual de Fitting, pero expresa una idea que recorre el texto.

El cambio de estrategias de supervivencia de las unidades domésticas de una determinada región agraria está mediado por el desarrollo histórico de las comunidades en que están situadas, el cual, a su vez, está influido por dinámicas y transformaciones de la producción y distribución mundiales de alimentos.

ochenta del siglo pasado, pero no la fija en un año específico. La reconstrucción del modelo subyacente a esta obra bien podría incluir recursos que emborronan la temporalidad, como los conjuntos difusos, pero por el momento tal posibilidad rebasa las competencias matemáticas del reconstructor.

Perspectivas - Revista do Programa de Pós-Graduação em Filosofia da UFT - n. 2 - 2018 


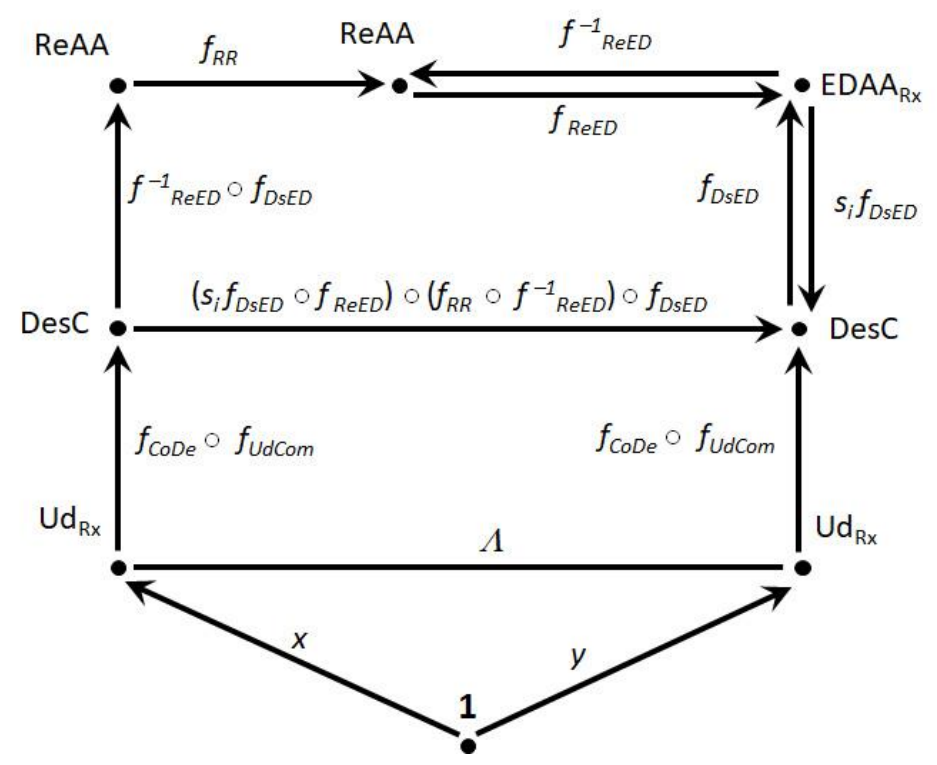

Figura 16. Las flechas $x$ y $y$ identifican respectivas unidades domésticas. $\Lambda$ (inciso 16, figura 11) relaciona unidades con unidades "descendientes" y $f_{U d C o m}$ (inciso 26, figura 12) sitúa grupos residenciales en comunidades. $f_{\text {CoDe }}$ (inciso 30, figura 13) mapea comunidades a desarrollos comunitarios. $f_{R R}$ (inciso 42, figura 14) mapea regímenes alimentarios a regímenes subse-cuentes. $f_{\text {ReED }}$ (inciso 44, figura 15) mapea regímenes a sus efectos económicos en la región $\mathrm{X}$; $f_{\text {ReED }}{ }^{-1}$ (inciso 44, figura 15) mapea los efectos económicos al régimen causante $\left(f_{R e E D}{ }^{-1}\right.$ es el inverso de $\left.f_{R e E D}\right) . f_{D s E D}$ (inciso 45 de la figura 15) envía desarrollos comunitarios a conjuntos de efectos económicos que tienen los

regímenes agroalimentarios en la región $\mathrm{X}$, y $s_{i} f_{D S E D}$ es una sección de $f_{D S E D}$ que identifica un determinado desarrollo comunitario vinculado al conjunto de efectos que un determinado régimen ha tenido sobre la región X. Elaboración propia.

La siguiente formulación, cotejada con la figura 16, muestra cómo el modelo de Fitting recupera esta noción.

A. Si $x, y$ son dos series correspondientes a unidades domésticas distintas, $x \wedge y$ y

$$
\left(f_{R R} \circ f_{R e E D}{ }^{-1}\right) \circ\left(f_{D s E D} \circ f_{C o D e}\right) \circ\left(f_{U d C o m} \circ x\right)=f_{R e E D}{ }^{-1} \circ\left(f_{D s E D} \circ f_{C o D e}\right) \circ\left(f_{U d C o m} \circ y\right),
$$

entonces existe una sección de $f_{D S E D}$ (llámese $s_{i} f_{D s E D}$ ) tal que

$$
\text { A.1. }\left(f_{C o D e} \circ\left(f_{U d C o m}\right) \circ y=\left(s_{i} f_{D s E D} \circ f_{R e E D}\right) \circ\left(f_{R R} \circ f_{R e E D}{ }^{-1}\right) \circ\left(f_{D s E D} \circ f_{C o D e}\right) \circ\left(f_{U d C o m} \circ x\right)\right.
$$

Cabría pensar lo expresado como el principio rector de MdF pues plantea que las transformaciones intracomunitarias resultan de los efectos locales que tienen las transiciones de los regímenes agroalimentarios -básicamente la idea principal de The Struggle for Maize. Si acaso las unidades domésticas representadas por las series $x$ y y están de alguna manera emparentadas (recuérdese que a esto se refiere $x \Lambda y$ ) y el tuplo $y$ se subordina al régimen agroalimentario subsecuente al que se sometía la unidad correspondiente a $x$, entonces están vinculados los desarrollos de las comunidades en las cuales se ubican dichas unidades, gracias al surgimiento de un nuevo régimen alimentario mundial, cuyos efectos locales en la 
región $\mathrm{X}$ dan lugar a reconfiguraciones de los espacios físico, socio-económico y cívicoorganizativo de los poblados que componen tal región.

The Struggle for Maíze también abunda sobre el impacto que tienen los regímenes agroalimentarios, particularmente el régimen neoliberal, en la vida de los habitantes del sur del valle de Tehuacán. Si se hace abstracción de esta comarca específica, el planteamiento podría generalizarse de la siguiente manera:

Si a dos personas distintas de la región X les corresponde el mismo estilo de vida, entonces es probable que ambas sean del mismo sexo y ambas han vivido sujetas al mismo régimen agroalimentario o a la misma transición de un régimen agroalimentario a otro.

En términos de morfismos y composiciones, las especificaciones que siguen, junto con la figura 17 , recuperan la idea recién presentada.

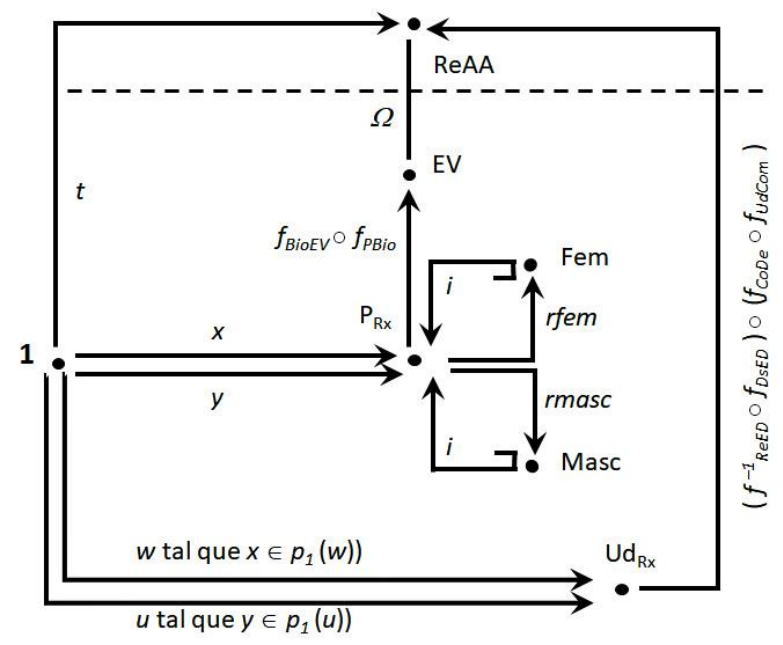

Figura 17. Los morfismos $x$ y $y$ identifican, respectivamente, a la persona $x$ y a la persona $y ; t$ identifica el régimen agroalimentario $t ; u$ y $w$ identifican respectivas unidades domésticas; $p_{l}(u)$ identifica el conjunto de personas que cohabita en la unidad representada por $u$ y $p_{l}(w)$ al conjunto correspondiente a la unidad representada por $\mathrm{w}$ (ver inciso 17, figura 11). rfem, rmasc y las inclusiones, $i$, de Fem en $\mathrm{P}_{\mathrm{Rx}}$ y Masc en $\mathrm{P}_{\mathrm{Rx}}$ se explican en los incisos 19 a 22 de la figura 11: estos morfismsos sirven para identifica el sexo de la persona en cuestión. La composición $f_{B i o E V} \circ f_{P B i o}$ mapea personas a estilos de vida: $f_{P B i o}(23$, figura 12) asigna personas a biografías, y $f_{B i o E V}(40$, figura 14) destina biografías a estilos de vida. $\Omega$ (inciso 41 , figura 14) relaciona estilos de vida con regímenes agroalimentarios. La concatenación $\left(f_{\text {ReED }}{ }^{-1} \circ f_{D S E D}\right) \circ\left(f_{C o D e} \circ f_{U d C o m}\right)$ vincula unidades domésticas con tales regímenes: $f_{U d C o m}$ (inciso 26, figura 12) mapea grupos familiares a comunidades; $f_{\text {CoDe }}$ (inciso 30 , figura 13) destina comunidades a desarrollos comunitarios; $f_{D S E D}$ (inciso 45 , figura 15) asigna estos desarrollos a conjuntos de efectos económicos de los regímenes alimentarios en la región $\mathrm{X}$; y $f_{R e E D}{ }^{-1}$ (inciso 44 , figura 15) mapea los efectos a los regímenes en cuestión. Elaboración propia.

A. Si $x$ y $y$ son dos personas de la región $\mathrm{X}\left(x, y \in \mathrm{P}_{\mathrm{Rx}}\right), x \neq y$ y $f_{\text {BioEV }} \circ f_{P B i o} \circ x=f_{\text {BioEV }} \circ$ $f_{P B i o} \circ y$ entonces es de esperarse que

A.1. $[(i \circ r f e m \circ x=x)$ y $(i \circ r f e m \circ y=y)]$ o $[(i \circ \operatorname{rmasc} \circ x=x) \mathrm{y}(i \circ \operatorname{rmasc} \circ y=y)]$,

A.1.1. para toda $w$ en $\operatorname{Ud}_{\mathrm{Rx}}$, donde $x \in p_{1}(w)$, existe alguna $u$ en $\operatorname{Ud}_{\mathrm{Rx}}$ donde $y \in$ $p_{l}(u)$, tal que:

Perspectivas - Revista do Programa de Pós-Graduação em Filosofia da UFT - n. 2 - 2018 


$$
\left(f_{R e E D}{ }^{-1} \circ f_{D S E D}\right) \circ\left(f_{C o D e} \circ f_{U d C o m}\right) \circ w=\left(f_{R e E D}{ }^{-1} \circ f_{D S E D}\right) \circ\left(f_{C o D e} \circ f_{U d C o m}\right) \circ u \text { o bien }
$$

A.1.2. para toda $u$ en $\operatorname{Ud}_{\mathrm{Rx}}$, donde $y \in p_{l}(u)$, existe alguna $w$ en $\operatorname{Ud}_{\mathrm{Rx}}$ donde $x \in$ $p_{l}(w)$, tal que:

$$
\left(f_{\text {ReED }}{ }^{-1} \circ f_{D S E D}\right) \circ\left(f_{C o D e} \circ f_{U d C o m}\right) \circ u=\left(f_{R e E D}{ }^{-1} \circ f_{D s E D}\right) \circ\left(f_{C o D e} \circ f_{U d C o m}\right) \circ w,
$$

A.2.existe una $t$ en $\operatorname{ReAA}$, una $w$ en $\mathrm{Ud}_{\mathrm{Rx}}$, donde $x \in p_{1}(w)$, y una $u$ en $\mathrm{Ud}_{\mathrm{Rx}}$ donde $y \in$ $p_{l}(u)$, tal que:

A.2.1. $\left(f_{\text {BioEV }} \circ f_{\text {PBio }} \circ x\right) \Omega t$ si y solo si $\left(f_{\text {BioEV }} \circ f_{P B i o} \circ y\right) \Omega t$

A.2.2. $t=\left(f_{R e E D}{ }^{-1} \circ f_{D s E D}\right) \circ\left(f_{C o D e} \circ f_{U d C o m}\right) \circ w=$

$$
\left(f_{R e E D}{ }^{-1} \circ f_{D S E D}\right) \circ\left(f_{C o D e} \circ f_{U d C o m}\right) \circ u
$$

El rubro A plantea el antecedente de que $x$ y y son dos personas distintas de la región X, pero tienen el mismo estilo de vida (la caracterización sociológica de sus vidas es la misma). Los incisos que siguen son consecuentes: A.1 indica que las personas en cuestión son del mismo sexo; A.1.1 y A.1.2 destacan que ambos sujetos han vivido en unidades domésticas sometidas al mismo régimen agroalimentario; incluso, tal como están expresados estos incisos, es posible que hayan vivido en unidades sometidas a la misma transición de un régimen a otro. Los puntos A.2, A.2.1 y A.2.2 plantean que el estilo de vida de ambas personas es congruente con algún régimen agroalimentario, el cual ha sometido alguna o algunas unidades domésticas a las que han pertenecido $x$ y $y$.

A lo largo de su texto, Fitting discute los efectos que el régimen agroalimentario corporativo (ella lo apela régimen de maíz neoliberal para aludir a su instanciación mexicana, así como aludir su aspecto concerniente al maíz) ha tenido en las estrategias de supervivencia de los pequeños agricultores del valle de Tehuacán y sus familias. En diversos pasajes contrasta estos comportamientos con aquellos de quienes vivieron el orden agroalimentario anterior (aunque Fitting no parece darle un nombre específico, pero si se sigue la terminología de McMichael, corresponde al llamado régimen intensivo norteamericano -el nombre que propone la presente reconstrucción para la instanciación mexicana del mismo, en el aspecto relativo al maíz, es el de "régimen de maíz posrevolucionario"-). La autora hace hincapié en las diferencias relativas al fenómeno migratorio, las cuales se plasman en la figura 18, diagrama elaborado a partir de morfismos que aparecen en la figura 8 y de las proyecciones de la figura 6.B. Sin ser cita textual, la oración siguiente expresa la idea contenida en algunos pasajes de The Struggle for Maíze: 
Por lo general, quienes migraban estacionalmente a Estados Unidos entre los años 30 a 80 del siglo pasado (régimen de maíz posrevolucionario) conseguían empleos en el sector agropecuario (sector 1), mientras que quienes emigran temporalmente a Estados Unidos, a partir de los años 80 hasta el presente, suelen conseguir empleo en el sector servicios (sector $3)$.

Otro aspecto de la transformación del fenómeno migratorio se resume en la aseveración:

Por lo general, los episodios migratorios de quienes emigraban estacionalmente a Estados Unidos entre los años 30 a 80 del siglo pasado (régimen de maíz posrevolucionario) duraban un año o menos, mientras que los episodios migratorios de quienes emigran temporalmente a Estados Unidos a partir de los años 80 hasta el presente suelen ser mayores a un año.

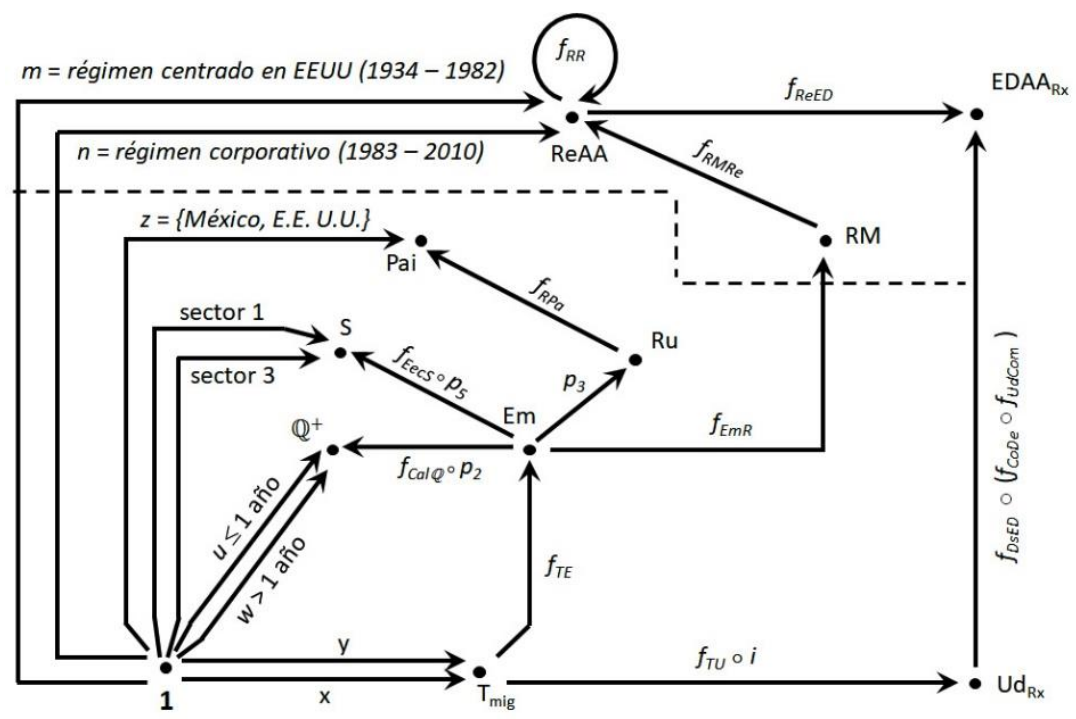

Figura 18. Los morfismos $x, y$, $w, u$, sector 3 , sector $1, z, n \mathrm{y}$ $m$ identifican, respectivamente: a la serie $x$ relativa a un migrante determinado; la serie $y$, representativa de otro migrante particular; el número $w$ (que es mayor a 1); el número $u$ (que es menor o igual a 1); el sector económico terciario (servicios); el sector económico primario (agropecuario); el conjunto de países \{México, EE. UU.\}; el régimen agroalimentario $n$ (régimen corporativo de McMichael); y el régimen agroalimentario $m$ (régimen intensivo centra-do en EE. UU. de McMichael). $f_{T E}$ (inciso 6, figura 9) mapea series representativas de migrantes $\left(\mathrm{T}_{\mathrm{mig}}\right)$ a experiencias migratoria (Em). La segunda, tercera y quinta proyección $\left(p_{2}, p_{3}\right.$ y $\left.p_{5}\right) \mathrm{de} \mathrm{Em}$ se explican en la figura 6.A. $f_{\text {Cal }}$ (inciso 25, figura 12) mapea intervalos calendáricos a números (la duración en años del intervalo que se trate). $f_{\text {EecS }}$ (inciso 1, figura 9) mapea puestos laborales a sectores económicos (S). $f_{R P a}$ (inciso 11, figura 10 ) mapea rutas migratorias $(\mathrm{Ru})$ a conjuntos de países (Pai). La inclusión $i$, en la fórmula $f_{T U} \circ i$, se explica en el inciso 9 , figura $10 ; f_{T U}$ (inciso 14 , figura 10) mapea personas productivas a unidades domésticas $\left(\mathrm{Ud}_{\mathrm{Rx}}\right)$ de la región $\mathrm{X}$. $f_{E m R}$ (inciso 37 , figura 14) mapea experiencias migratorias $($ Em) a redes migratorias (RM). $f_{R M R e}$ (inciso 39, figura 14) mapea redes migratorias a regímenes agroalimentarios (ReAA). $f_{R R}$ (inciso 42, figura 14) mapea regímenes agroalimentarios a regímenes agroalimentarios. $f_{R e E d}$ (inciso 44, figura 15) mapea regímenes agroalimentarios a conjuntos de dinámicas económicas que han repercutido en la producción y distribución de alimentos en la región $\mathrm{X}$, en los últimos 150 años $\left(\mathrm{EDAA}_{\mathrm{Rx}}\right)$. La composición $f_{D S E D} \circ\left(f_{C o D e} \circ f_{U d C o m}\right)$ mapea unidades domésticas de la región $\mathrm{X}$ a conjuntos de dinámicas económicas tocantes a la producción y distribución de alimentos a, en y desde esa región (ver inciso 26, figura 12 para $f_{U d C o m}$; inciso 30 , figura 13 para $f_{C o D e}$; inciso 45 , figura 15 para $f_{D S E D}$ ). Elaboración propia.

Perspectivas - Revista do Programa de Pós-Graduação em Filosofia da UFT - n. 2 - 2018 
Se puede dotar a la figura 18 de una interpretación que recoge los dos enunciados anteriores, como se muestra a continuación. Cabe aclarar que las inferencias siguientes son relevantes para sur del valle de Tehuacán; si acaso la región X es otra, quizá habría que modificar algunos apartados.

A. $m$ se corresponde con el régimen intensivo centrado en EE. UU. de McMichael, y $n$ se corresponde con el régimen corporativo de McMichael, por tanto:

A.1. $n=f_{R R} \circ m$;

A.2. $f_{\operatorname{ReED}}(n)$ se aproxima a lo que Fitting entiende por "régimen de maíz neoliberal";

A.3. $f_{R e E D}(m)$ se aproxima a lo que en esta reconstrucción se entiende por "régimen de maíz posrevolucionario"

B. Si A (A.1, A.2 y A.3) es el caso y $x, y$ son series alusivas a migrantes salidos de la región $\mathrm{X}$ у $m=\left(f_{R M R e} \circ f_{E m R}\right) \circ\left(f_{T E} \circ x\right)$ у $n=\left(f_{R M R e} \circ f_{E m R}\right) \circ\left(f_{T E} \circ y\right)$, entonces

B.1. $f_{R e E D}(m)=f_{D s E D} \circ\left(f_{C o D e} \circ f_{U d C o m}\right) \circ\left(f_{T U} \circ i\right) \circ x ; \mathrm{y}$

B.2. $f_{\text {ReED }}(n)=f_{D s E D} \circ\left(f_{C o D e} \circ f_{U d C o m}\right) \circ\left(f_{T U} \circ i\right) \circ y$;

C. Si A (A.1, A.2 y A.3) y B (B.1 y B.2) son el caso y $z=\{$ México, Estados Unidos $\}=$ $\left(f r_{R P a} \circ p_{3}\right) \circ\left(f_{T E} \circ x\right)=\left(f_{R P a} \circ p_{3}\right) \circ\left(f_{T E} \circ y\right)$, entonces es de esperarse que:

C.1. sector $1=\left(f_{E C S} \circ p_{5}\right) \circ\left(f_{T E} \circ x\right)$;

C.2. $\operatorname{sector} 3=\left(f_{E c S} \circ p_{5}\right) \circ\left(f_{T E} \circ y\right)$;

C.3. $u=\left(f_{C a l Q} \circ p_{2}\right) \circ\left(f_{T E} \circ x\right)$ y $u \leq 1$ año;

C.4. $w=\left(f_{\text {CalQ }} \circ p_{2}\right) \circ\left(f_{T E} \circ y\right)$ y $w>1$ año; $\mathrm{y}$

C.5. $f_{E m R} \circ\left(f_{T E} \circ x\right) \neq f_{E m R} \circ\left(f_{T E} \circ y\right)$.

El apartado A, mediante la fórmula $n=f_{R R} \circ m$, pone de realce que el régimen corporativo sigue históricamente al régimen intenso centrado en EE. UU.: $n$, con dominio en el sigulete, 1 (ver figura 4, panel 4.1), y codominio en ReAA, identifica el elemento $n$ de ReAA y dicho elemento se corresponde con el régimen corporativo; el morfismo $m$ señala al régimen de hegemonía estadounidense. A.1 y A.2 brindan una aproximación a lo que Fitting entiende por "régimen de maíz neoliberal" - la instanciación local del régimen corporativo- y lo que en esta reconstrucción se denomina “régimen de maíz posrevolucionario -la concreción local 
del régimen intensivo centrado en EE. UU.-- Los apartados B, B.1 y B.2 delatan que la serie representativa de un migrante en un determinado año se vincula con los efectos locales del régimen agroalimentario imperante por dos vías: una por el camino de la experiencia y red migratoria $-\left(f_{R e E D} \circ f_{R M R e}\right) \circ\left(f_{E m R} \circ f_{T E}\right)-$, la otra por la adscripción a la unidad doméstica, la comunidad y el desarrollo comunitario: $f_{D s E D} \circ\left(f_{C o D e} \circ f_{U d C o m}\right) \circ\left(f_{T U} \circ i\right)$. Dicho de otra manera, estos dos senderos conmutan: en el caso de la serie $x$, el régimen imperante es el de hegemonía estadounidense (maíz posrevolucionario en la instanciación local); tratándose de la serie $y$, destaca el régimen corporativo (de maíz neoliberal, en términos de la instanciación local). Los rubros C, C.1 a C.5 señalan que si las experiencias migratorias respectivas de $x$ y y los llevan por rutas que surcan a México y Estados Unidos, entonces es de esperarse que $x$ se corresponde a un episodio migratorio donde el sujeto en cuestión se ha desempeñado más en el sector agropecuario (tal es el significado de sector $1=\left(f_{E c S} \circ p_{5}\right) \circ\left(f_{T E} \circ x\right)$ en C.1); la experiencia migratoria del sujeto de la serie $y$ se ha destacado más en el sector de servicios (C.2); la duración de la experiencia migratoria correspondiente a $x$-el tuplo subordinado al régimen posrevolucionario- es menor o igual a un año (C.3), mientras que la duración correspondiente a la experiencia de $y$-serie subordinada al régimen neoliberal-es mayor a un año (C. 4); y C.5 destaca que seguramente son distintas las redes migratorias asociadas a $x$ y $y$-a eso se refiere la fórmula $f_{E m R} \circ\left(f_{T E} \circ x\right) \neq f_{E m R} \circ\left(f_{T E} \circ y\right)-$. En resumen, el régimen de maíz neoliberal presiona a que los migrantes se ausenten más tiempo de su hogar, cada vez que migran, y los orienta más hacia el sector servicios que al sector agropecuario.

The Struggle for Maize también discute la pérdida del conocimiento agrícola tradicional, tocante al cultivo del maíz, entre la juventud actual del sur del valle de Tehuacán. Desde la década de los ochenta del siglo Xx ha venido acentuándose la tendencia en la cual la vida económica de los jóvenes intercala periodos en que trabajan como migrantes lejos de su comunidad, con periodos en que regresan a su terruño y ocupan puestos asalariados temporales en industrias de la comarca hasta volver a reunir fondos para emigrar de nuevo; o bien regresan y simplemente pasan el tiempo hasta que se les acaba el dinero y vuelven a migrar. Tal dinámica ha socavado el saber agrícola tradicional entre este sector de la población. Las páginas del libro de Fitting ponen de realce la siguiente idea:

Tradicionalmente, aprender a cómo cultivar la milpa ha sido una parte importante de la educación de los varones. Sin embargo, bajo el régimen neoliberal se ha generado una 
división de saberes en lo que respecta al conocimiento agrícola tradicional: las personas mayores a los 35 años estiman el cultivo de maíz como un seguro familiar; de hecho, este es el único empleo disponible para quienes se encuentran en o cercanos a la tercera edad; por su parte, los jóvenes menores a 30 años están perdiendo -o de plano ya han perdidoeste conocimiento.

La figura 19, aunada a la interpretación que a continuación se desarrolla, recogen el contenido de lo plasmado en cursivas. Nuevamente, las siguientes inferencias son relevantes para sur del valle de Tehuacán; para otras regiones, será menester modificar algunos apartados.

A. $m$ se corresponde con el régimen intensivo centrado en EE. UU. de McMichael, y $n$ se corresponde con el régimen corporativo de McMichael, por tanto:

A.1. $n=f_{R R} \circ m$;

A.2. $f_{\text {ReED }}(n)$ se aproxima a lo que Fitting entiende por "régimen de maíz neoliberal";

A.3. $f_{R e E D}(m)$ se aproxima a lo que en esta reconstrucción se entiende por "régimen de maíz posrevolucionario".

B. Si A (A. 1 a A.3) es el caso y $x, y$ son series alusivas a personas productiva de la región $\mathrm{X}, x \neq y, \mathrm{y}$

$f_{R e E D}(m)=f_{D s E D} \circ\left(f_{C o D e} \circ f_{U d C o m}\right) \circ\left(f_{T U} \circ x\right), \mathrm{y}$

$f_{R e E D}(m)=f_{D S E D} \circ\left(f_{C o D e} \circ f_{U d C o m}\right) \circ\left(f_{T U} \circ y\right), \mathrm{y}$

$\left(p_{1} \circ x\right)=\left(i \circ r_{\text {masc }}\right) \circ\left(p_{1} \circ x\right), \mathrm{y}$

$\left(p_{1} \circ y\right)=\left(i \circ r_{\text {masc }}\right) \circ\left(p_{1} \circ y\right), \mathrm{y}$

$\left(p_{2} \circ x\right)=w(w>30$ años $), \mathrm{y}$

$\left(p_{2} \circ y\right)=u(15 \leq u<30$ años $)$, entonces es de esperarse que

B.1. "saber cultivar milpa" $\in\left(p_{6} \circ x\right)$ y "saber cultivar milpa" $\in\left(p_{6} \circ y\right)$

C. Si A (A. 1 a A.3) es el caso y $x, y$ son series alusivas a personas productiva de la región $\mathrm{X}, x \neq y, \mathrm{y}$

$f_{R e E D}(n)=f_{D S E D} \circ\left(f_{C o D e} \circ f_{U d C o m}\right) \circ\left(f_{T U} \circ x\right), \mathrm{y}$

$f_{R e E D}(n)=f_{D S E D} \circ\left(f_{C o D e} \circ f_{U d C o m}\right) \circ\left(f_{T U} \circ y\right), \mathrm{y}$

$\left(p_{1} \circ x\right)=\left(i \circ r_{\text {masc }}\right) \circ\left(p_{1} \circ x\right), \mathrm{y}$ 


$$
\begin{aligned}
& \left(p_{1} \circ y\right)=\left(i \circ r_{\text {masc }}\right) \circ\left(p_{1} \circ y\right), \mathrm{y} \\
& \left(p_{2} \circ x\right)=w(w>30 \text { años }), \mathrm{y} \\
& \left(p_{2} \circ y\right)=u(15 \leq u<30 \text { años }), \text { entonces es de esperarse que } \\
& \text { C.1. "saber cultivar milpa" } \in\left(p_{6} \circ x\right) \text { pero "saber cultivar milpa" } \notin\left(p_{6} \circ y\right)
\end{aligned}
$$

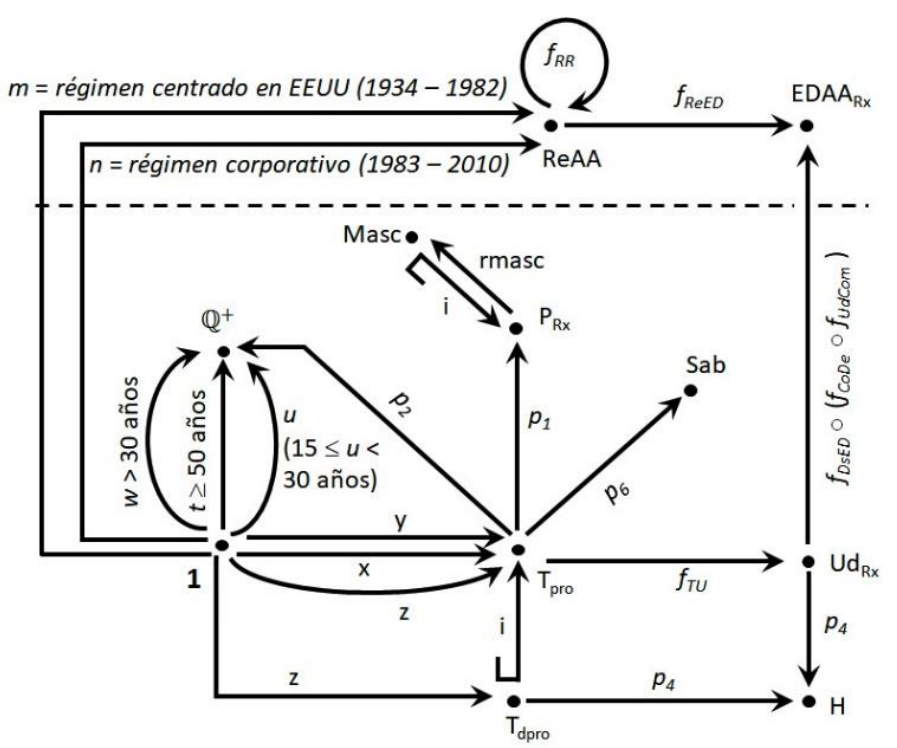

Figura 19. Los morfismos $x, y, z$ identifican respectivas series repre-sentativas de personas produc-tivas; $z$ identifica un determinado agricul-tor/artesano. Las flechas $u, t, w$ identifican números, tal que $u$ es mayor o igual que 15 y menor de $30 ; t$ es mayor o igual a 50; y $w$ es mayor a 30 . Los mapeos $n$ y $m$ señalan regímenes agroalimentarios específi-cos: $n$ el régimen corporativo y $m$ el intensivo, centrado en EE. UU. La inclusión del conjunto $T_{\text {dpro }}$ en el conjunto $T_{\text {pro }}$ se explica en el inciso 7 , figura 10. La primera, segunda y sexta proyección de $T_{\text {pro }}$ se ilustran en la figura 6.A ( $p_{1}$ mapea a personas, $p_{2}$ a números indicativos de la edad y $p_{6}$ a conjuntos de saberes (Sab)). rmasc mapea personas a varones (inciso 20, figura 11); la inclusión de Masc en $P_{R x}$ se explica en el inciso 19,

figura 11. La cuarta proyección de $\mathrm{T}_{\mathrm{dpro}}, p_{4}$ (mapea a conjuntos de medios de producción (H)), se ilustra en la figura 6.A. $f_{T U}$ (inciso 14, figura 10) mapea personas productivas a unidades domésticas $\left(\mathrm{Ud}_{\mathrm{Rx}}\right) . f_{R e E d}$ (inciso 44, figura 15) mapea regímenes agroalimentarios a conjuntos de dinámicas económicas que han repercutido en la producción y distribución de alimentos en la región $\mathrm{X}$, en los últimos 150 años $\left(\mathrm{EDAA}_{\mathrm{Rx}}\right)$. La cuarta proyección de $\mathrm{Ud}_{\mathrm{Rx}}, p_{4}$, mapea a conjuntos de medios de producción. La composición $f_{D s E D} \circ\left(f_{C o D e} \circ f_{U d C o m}\right)$ mapea unidades domésticas de la región $\mathrm{X}$ a conjuntos de dinámicas económicas tocantes a la producción y distribución de alimentos a, en y desde esa región (ver inciso 26, figura 12 para $f_{\text {UdCom }}$; inciso 30, figura 13 para $f_{C o D e}$; inciso 44 , figura 17 para $\left.f_{D S E D}\right)$. Elaboración propia.

D. Si A (A. 1 a A.3) es el caso y $z$ es una serie alusiva a una persona productiva de la región $\mathrm{X}, \mathrm{y}$

$f_{R e E D}(n)=f_{D s E D} \circ\left(f_{C o D e} \circ f_{U d C o m}\right) \circ\left(f_{T U} \circ z\right), \mathrm{y}$

$\left(p_{2} \circ z\right)=t(t \geq 50$ años $)$, es de esperarse que

D.1. $z \in \mathrm{T}_{\text {dpro }} \mathrm{y} p_{4} \circ z \subseteq\left(p_{4} \circ f_{T U}\right) \circ z$.

Igual que los puntos relativos a la figura 18, aquí A (A.1 a A.3) establece cuáles son los regímenes agroalimentarios correspondientes a $m$ y a $n$, así como la sucesión de uno a otro. B y B.1 proponen que si $x$ y $y$, son dos series distintas, ambas representativas de varones productivas de la región X, que se vinculan al régimen de maíz posrevolucionario, entonces seguramente entre los saberes tanto de $x$ como de $y$ figure el saber cómo cultivar milpa, a Perspectivas - Revista do Programa de Pós-Graduação em Filosofia da UFT - n. 2 - 2018 
pesar de que el sujeto correspondiente a $x$ tenga más de 30 años de edad mientras que el de $y$ se ubica en el rango etario de quince a treinta años. Los apartados C y C.1 fijan el escenario en que las dos series se vinculan con el régimen neoliberal: de nueva cuenta, las dos personas representadas son varones y una es mayor de 30 años mientras que la otra está entre los 15 y 30 años. Sin embargo, es probable que la de menor edad no sepa cómo cultivar milpa (a esto último se refiere la fórmula: "saber cultivar milpa" $\left.\notin\left(p_{6} \circ y\right)\right)$. En el escenario de los puntos D y D.1, $z$ es una serie representativa de un sujeto productivo con cincuenta años o más, en la época del régimen de maíz neoliberal; es de esperarse que $z$ se corresponde con un agricultor y/o artesano que labora en los terrenos y/o talleres de su unidad familar. Los medios de producción que emplea para realizar sus actividades son aquellos de los que dispone la unidad doméstica a la cual pertenece.

MdF también recupera la idea de pérdida de agrobiodiversidad que se comenta en Fitting (2011); al respecto, y con base en la figura 20, cabe plantear lo siguiente:

A. Igual que A (A.1 a A-3) para las figuras 18 y 19.

B. Si A (A.1 a A-3) es el caso, $x, y$ son series representativas de dos unidades domésticas distintas, $u$ y $w$ son conjuntos de semillas para sembrar,

$$
\begin{aligned}
& f_{R e E D}(m)=f_{D s E D} \circ\left(f_{C o D e} \circ f_{U d C o m}\right) \circ x, \\
& \left.f_{R e E D}(n)=f_{D s E D}\right) \circ\left(f_{C o D e} \circ f_{U d C o m}\right) \circ \mathrm{y}, \\
& p_{4} \circ x=f_{S H} \circ w, \\
& p_{4} \circ y=f_{S H} \circ u \text {, entonces } \\
& \text { B.1. } f_{U d Q} \circ x=\left(f_{V a r} * Q \circ f_{S^{*} V^{*}}\right) \circ w, \\
& \text { B.2. } f_{U d Q} \circ y=\left(f_{V a r} * Q \circ f_{S^{*} V^{*}}\right) \circ u, \text { y es de esperarse que } \\
& \text { B.3. } f_{U d Q} \circ x>f_{U d Q} \circ y .
\end{aligned}
$$

C. Si A (A.1 a A-3) es el caso, $z$ es una serie representativa de una unidad doméstica, $t$ es un conjunto de semillas para sembrar, $s$ es una semilla, maíz $G M_{\text {var } q}$ es una variedad genéticamente modificada de maíz, $t=f_{S S *} \circ s, G M_{v a r q}=f_{S V} \circ s$ y $p_{4} \circ z=f_{S H} \circ t$, entonces C. $1 . f_{R e E D}(n)=\left(f_{D s E D} \circ f_{C o D e}\right) \circ\left(f_{U d C o m} \circ z\right)$.

El punto A ya se ha discutido en lo tocante a las figuras 18 y 19, por lo cual no viene al caso reiterar su significado. En palabras llanas, el apartado B (B.1 a B.3) plantea que el banco de 
semillas (esto es, las semillas apartadas para la siembra) de una unidad doméstica sometida al régimen agroalimentario posrevolucionario seguramente es más diverso que el banco de semillas de una unidad subordinada al régimen agroalimentario neoliberal. El punto $\mathrm{C}$, por

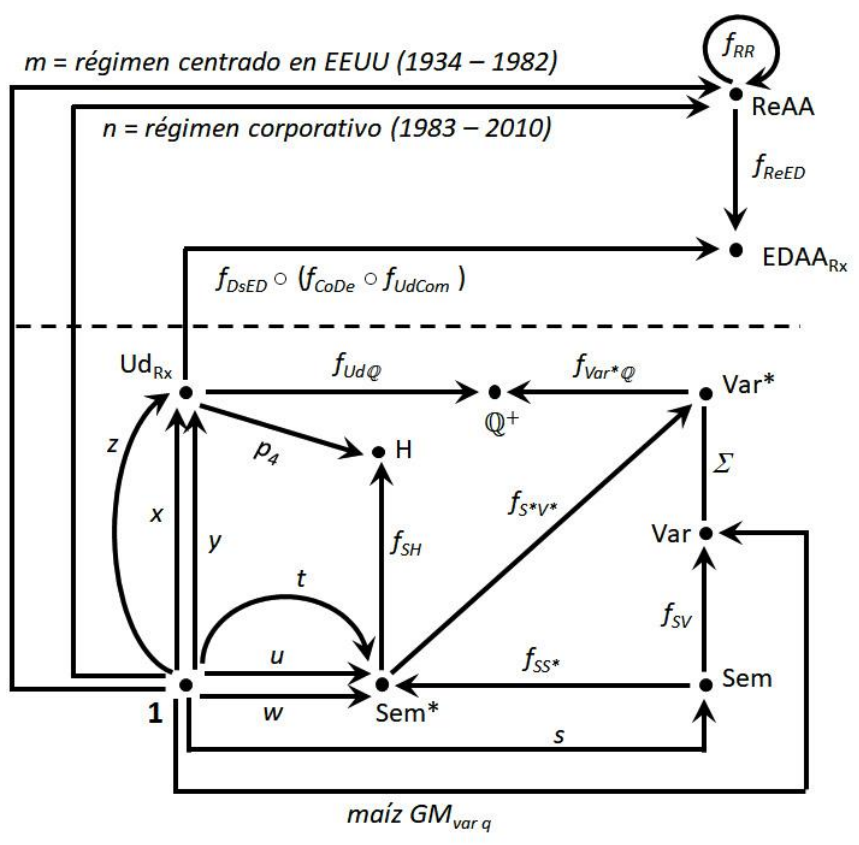

Figura 20. La función maízGM $M_{\text {varq }}$ identifica una determinada variedad de maíz transgénico; $s$ identifica una determinada semilla; $w, u, t$ apuntan a respectivos conjuntos de semillas. Los mapeos $x, y, z$ señalan unidades domésticas respectivas; $m$ identifica el régimen agroalimentario intensivo, centrado en EE. UU., y $n$ indica el régimen corporativo. La cuarta proyección de $\mathrm{Ud}_{\mathrm{Rx}}, p_{4}$, mapea unidades domésticas a conjuntos de medios de producción (figura 5.A). $f_{U d \mathrm{Q}}$ (inciso 29, figura 12) mapea tales unidades a números indicativos de agrobiodiversidad. $f_{S H}$ (inciso 28, figura 12) mapea conjuntos de semillas a conjuntos de medios de producción. Las flechas $f_{S^{*} V^{*}}, f_{S S^{*}}$, $f_{S V}, \Sigma$ y $f_{V a r * \mathrm{Q}}$ se describen en los incisos 31 a 35 de la figura $13\left(f_{S^{*} V^{*}}\right.$ mapea conjuntos de semillas a conjuntos de variedades; $f_{S S^{*}}$, semillas a conjuntos de semillas; $f_{S V}$, semillas a variedades; $\Sigma$ relaciona variedades con conjuntos de variedades; y $f_{\text {Var } * \bigcirc}$ mapea conjuntos de variedades a números, indicativos de agrobiodiversidad). La composición $f_{D s E D} \circ\left(f_{C o D e} \circ f_{U d C o m}\right)$ mapea unidades domésticas de la región $\mathrm{X}$ a conjuntos de dinámicas económicas tocantes a la producción y distribución de alimentos a, en y desde esa región (ver inciso 26, figura 12 para $f_{U d C o m}$; inciso 30, figura 13 para $f_{C o D e}$; inciso 45 , figura 15 para $\left.f_{D S E D}\right) . f_{R e E d}$ (inciso 44, figura 15 ) mapea regímenes agroalimentarios a conjuntos de dinámicas económicas que han repercutido en la producción y distribución de alimentos en la región X $\left(\mathrm{EDAA}_{\mathrm{Rx}}\right)$. Elaboración propia.

su parte, expresa algo sobre la relación entre variedades transgénicas de maíz y órdenes alimentarios: la existencia de una semilla, de una variedad genéticamente modificada (llámese maíz $G M_{\text {var } q}$ ), en el banco de semillas de alguna unidad doméstica $z$ solo es posible si esa unidad está subordinada al régimen de maíz neoliberal. Esto es obvio, pues antes de dicho régimen no existían las variedades transgénicas comerciales de la gramínea: se trae a colación aquí simplemente para mostrar la expresividad que se puede operar con el diagrama.

\section{Conclusiones}

MdF se deriva de la situación que describe Fitting tocante al sur del valle de Tehuacán, pero se dota a la estructura una interpretación más general al plantear que las unidades domésticas, comunidades, etc. se ubican en una región hipotética X. Hay muchas otras localidades en México y Centroamérica que sufren procesos semejantes a los pormenorizados en The 
Struggle for Maize, de modo que MdF podría ser aplicable a ellas, con los debidos ajustes en cuanto a la especificación del lugar y otras cuestiones de contexto. Sin embargo, es menester establecer las condiciones generales que hacen similares a estas comarcas. Deben ser regiones donde la mayoría de las unidades domésticas son o "descienden" de unidades (existentes en los últimos 150 años) que se dedican a la agricultura y/o la producción artesanal, poseen o de alguna manera pueden hacerse de los medios de producción para realizar estas actividades y destinan el fruto de su trabajo principalmente a la satisfacción de las necesidades familiares. Otro requisito importante es que la zona sea, en efecto, susceptible a las influencias de los regímenes agroalimentarios: valga la exageración, pero seguramente es pobre la aplicabilidad de $\mathrm{MdF}$ a una comunidad agraria de Corea del Norte, salvo que el estudio privilegiara la primera mitad del siglo XX y enfocara los efectos locales del llamado régimen británico.

El aparato reconstructor empleado es básicamente conjuntista y no hubo necesidad de utilizar functores, adjuntos, transformaciones naturales y otros recursos de la teoría de categorías. Entonces, ¿por qué se anuncia al principio del tex to que el instrumental adoptado está inspirado en dicha teoría? En términos estrictos, está inspirado en el modo en que se presenta la categoría de los conjuntos en libros introductorios a la teoría de categorías, como el de Lawvere y Schanuel (2002). La composición de mapeos y el estipular la inclusión y la pertenencia como morfismos dotan a la presentación diagramática de recursos para simplificarla, y en ese sentido le brindan mucha flexibilidad. La figura 8 muestra el armazón conceptual de MdF, y demarca los conceptos y relaciones de lo que podría considerarse la base de datos histórico/etnográficos, de aquellos que conforman la superestructura concerniente a los regímenes agroalimentarios. Las figuras 9 a 15 interpretan el armazón y a partir de la 16 se ponen de relieve rutas conmutativas que vinculan superestructura con base de datos para así captar los contenidos de The Struggle for Maize respecto de la migración, los estilos de vida y el conocimiento agroecológico.

MdF está constituido por un número considerable de términos primitivos y de términos que se derivan de estos primeros, como son $\mathrm{Ud}_{\mathrm{Rx}}$, Com $\mathrm{T}_{\text {pro }} \mathrm{y}$ los demás que se reseñan en las figuras 5 a 7; además, MdF está surcado por una cantidad elevada de funciones. Si se compara con los productos de corrientes filosóficas que utilizan herramientas conjuntoteoréticas para reconstruir teorías científicas, como el Programa Estructuralista, tales productos suelen ser más austeros. A pesar del peso que pudieran tener las excentricidades del reconstructor de MdF en la diferencia señalada, buena parte de la discrepancia reside en 
reconstruir a partir de monografías académicas "no canónicas" versus reconstruir teorías científicas fosilizadas en libros de texto canónicos. Pero no es que la segunda opción es más correcta que la primera, depende de lo que se persigue con la reconstrucción. Es el mejor camino para seguir si lo que se pretende es contribuir a una taxonomía de teorías consagradas en los ámbitos donde se entrenan nuevos científicos, una taxonomía con base en las estructuras conceptuales de sus especímenes, sus aplicaciones paradigmáticas y sus relaciones inter-teóricas. Pero si el interés estriba en la emergencia y transformación conceptual en campos de investigación que abordan fenómenos nuevos, derivados del actual desarrollo socioeconómico-ambiental, entonces las monografías académicas y los papers serán fuentes importantes. Y puesto que, en muchos casos, son incipientes las concepciones generadas en estos espacios de frontera, las reconstrucciones de ellas son menos elegantes.

Ahora bien, el Programa Estructuralista (BALZER; MOULINE \& SNEED, 1987) ha desarrollado una metateoría sumamente sofisticada, cuyas distinciones aquí no se han traído a colación, pero bien valdría la pena hacer uso de ellas. Convendría a futuro reconstruir la teoría de los regímenes agroalimentarios en atención a los lineamientos del Programa relativos a núcleo teórico (y sus componentes), aplicaciones intencionales y red teórica (las reconstrucciones de los estructuralistas privilegian el llamado predicado conjuntista en lugar de la presentación diagramática que se hace aquí, pero la preferencia por un recurso u otro es un punto de segunda importancia). Desde los años ochenta hay tinta invertida respecto de tales regímenes (FREIDMAN, 1987), por tanto, la teoría en cuestión ya tiene cierto grado de madurez y ya cuenta con sus textos "canónicos" (se antoja pensar que el de McMichael (2014) es uno de ellos). Luego de haber realizado esta tarea se podría reevaluar MdF y ver dónde y de qué modo encaja en este entramado teórico.

\section{REFERENCIAS}

BADIOU, A. Mathematics of the Transcendental. London: Bloomsbury, 2014.

BALZER, W.; MOULINES, C. U. \& J. D. SNEED. An architectonic for science. The structuralist program. Dordrecht: Reidel, 1987.

EHRESMANN, A. C. \& J. P. VANBREMEERSCH. Memory Evolutive Systems: Hierarchy, Emergence and Cognition. Amsterdam: Elsevier, 2007.

FITTING, E. The Struggle for Maize. Campesinos, Workers, and Transgenic Corn in the Mexican Countryside. Durham: Duke University Press, 2011. 
FREIDMAN, H. The Family Farm and the International Food Regimes. En SHANIN, T. (ed.). Peasants and Peasant Societies. Oxford: Blackwell, 1987, pp. 247-258.

GOLDBlatT, R. Topoi. The Categorical Analysis of Logic. Mineola: Dover Publications, 2006.

GÓMEZ-RAMIREZ, J. A New Foundation for Representation in Cognitive and Brain Science. Category Theory and the Hippocampus. Dorderecht: Springer, 2014.

IBARRA, A \& T. MORMANN. Scientific Theories as Intervening Representations. Theoria, v. 21, n. 1, p. 21-38, 2006.

LANDRY, E. (ed.) Categories for the Working Philosopher. Oxford: Oxford University Press, 2017.

LAWVERE, F. W. \& S. H. SCHANUEL. Matemáticas conceptuales: una primera introducción a categorías. México: Siglo XXI, 2002.

MCLARTY, C. Elementary Categories, Elementary Toposes. Oxford: Oxford University Press, 1992.

MCMICHAEL, P. Food Regimes and Agrarian Questions. Rugby: Practical Action Publishing, 2014.

MORMANN, T. Structural Universals as Structural Parts: Toward a General Theory of Parthood and Composition. Axiomathes, v. 20, n. 2-3, p. 209-227, 2010.

PERUZZI, A. The meaning of category theory for $21^{\text {st }}$ philosophy. Axiomathes, v. 16, n. 4 , p. 425-460, 2006.

ROSEN, R. The representation of biological systems from the standpoint of the theory of categories. Bulletin of Mathematical Biophysics, v. 20, n. 4, p. 317-341, 1958.

SALLACH, D. L. Topos Modeling of Social Conflict: Theory and Methods. En NAKAI, Y.; KOYAMA, Y. \& T. Terano (eds.). Agent-Based Approaches in Economic and Social Complex Systems VIII. Post-Proceedings of The AESCS International Workshop 2013. Tokyo: Springer Japan, 2015, pp. 39-51.

Fe de erratas

1. Página 246, figura 13, inciso 31, tercera línea del inciso debe leerse “...(ver inciso 28, figura 12$) \ldots$.. en lugar de “...(ver inciso 28 , figura 13$) \ldots$...

2. Página 247 , figura 14 , inciso 38 , segunda línea del inciso debe leerse “...(ver inciso 11 , figura 10$) \ldots$.. en lugar de “...(ver inciso 11 , figura 12$)$..." 